F 487

A9

;opy 1

Far

A9) //HADD-BOOKS

0

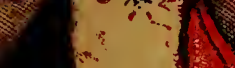

C

20

10

2

1
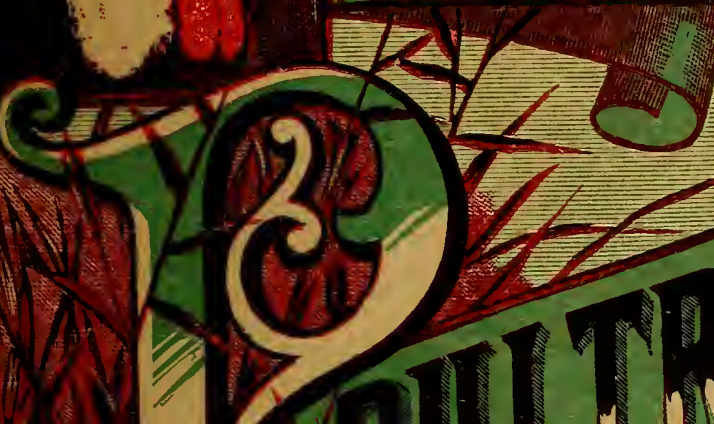

$$
\therefore \text { - }
$$
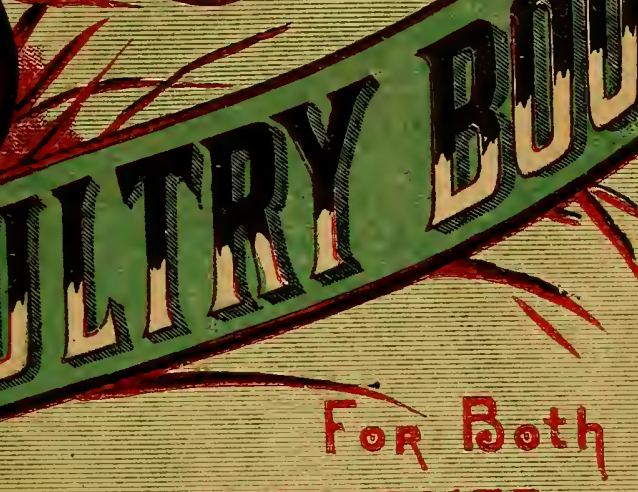
THE FARMER

10. - J FAחCIER

$$
\begin{aligned}
& \text { sociated Fanciers } \\
& \text { PHILADA. }
\end{aligned}
$$





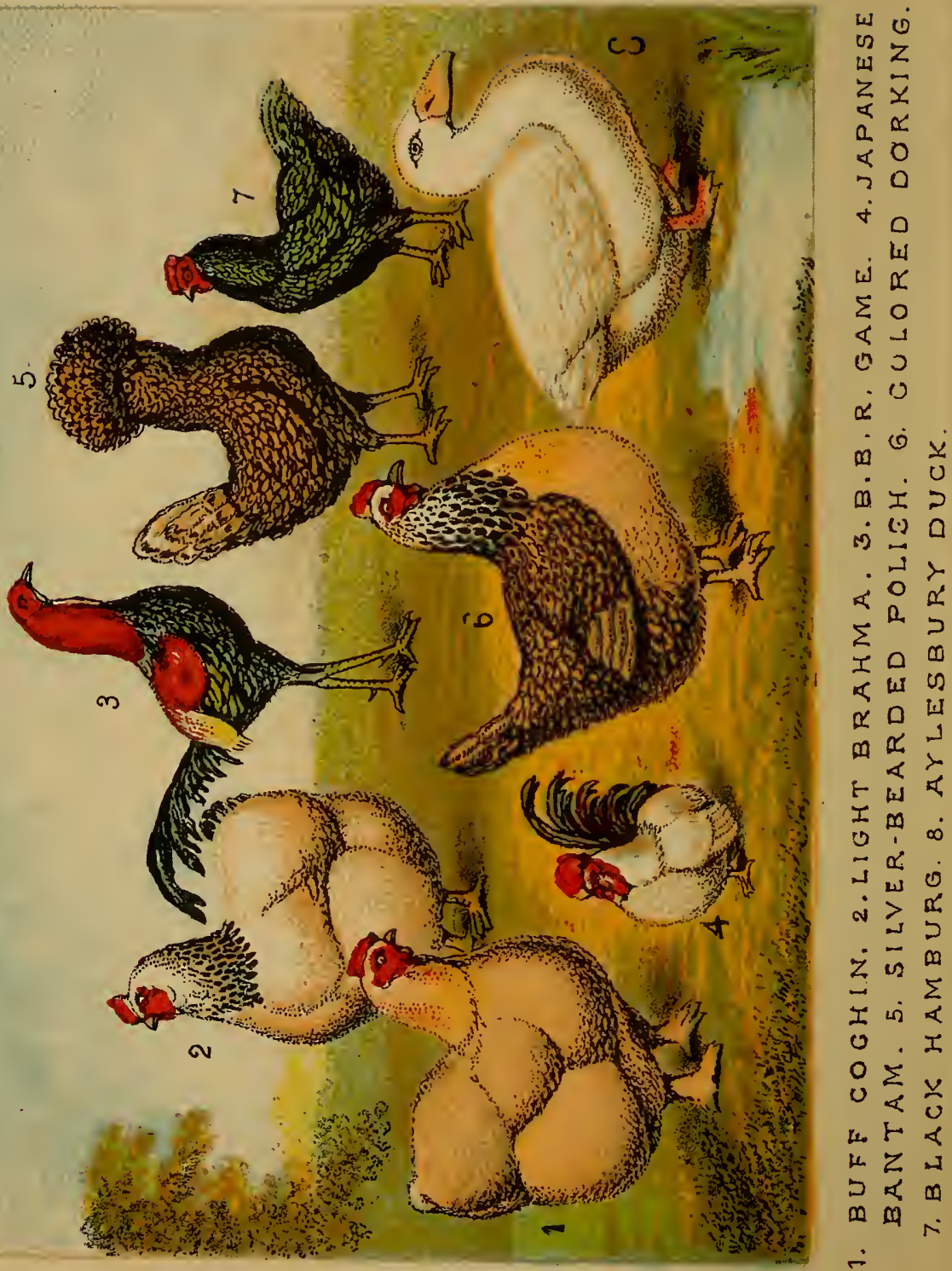




\title{
FANCIERS' HAND-BOOKS.
} (No. 3.)

\section{THE PEAOTICAI}

\section{POULTRY BOOK,}

FOR BOTH

\section{THE FARMER AND FANCIER.}

\author{
REVISED BY
}

\section{JOHN E. DIEHL,}

American Poultry Association Judge.

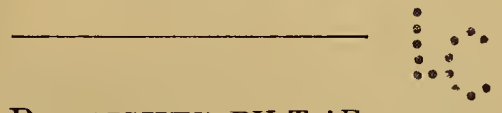

PUblishen By Thie

ASSOCIATED FANCIERS, CITY OFFICE : 400 NORTH THIRD STREET, 


\title{
SF487 \\ - A9
}

Entered according to Act of Congress, in the year $\times 884$, by the ASSOCIATED FANCIERS,

In the Cfice of the LIBRARIAN OF CONGRESS, at Washington, D. C.

\author{
Gitt \\ Publisher \\ 1. Ja:OB
}




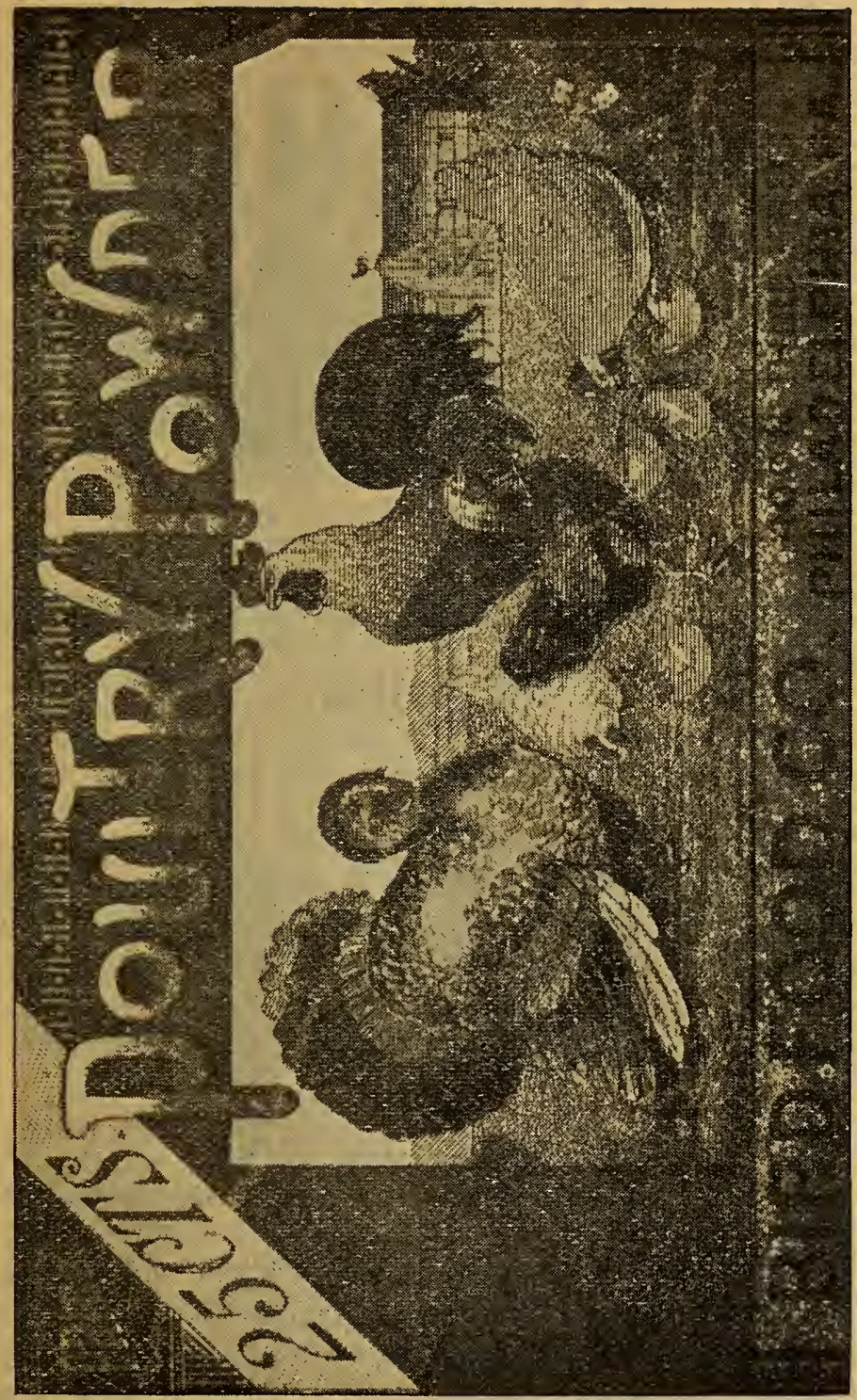




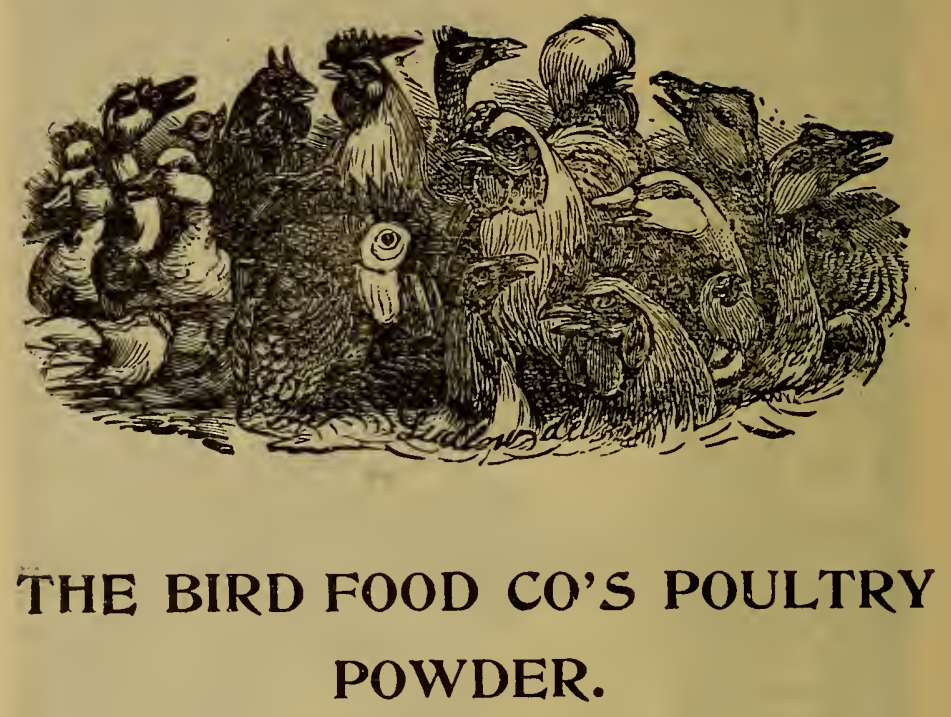

This Poultry Powder is the practical result of the long continued experiments of the Associated Fanciers, for the improvement of Poultry. It is the most energetic and stimulating Powder in the market, for improving the health and physical condition of poultry.

It is guaranteed

to promote rapid growth in young chicks;

to increase the laying qualities of hens;

to keep fowls of all kiuds in constant health and perfect condition;

to prevent chicken cholera and all kindred diseases.

Price 25 cents per package. As the boxes are very large and heavy the Postage on each of them is 30 cents extra, so that when sent by mail, the price will be 55 cents. 


\section{MANAGEMENT OF POULTRY.}

There is no family, rich or poor, living in the country $\mathrm{Cr}$ town suburb, that may not with advantage keep poultry. It must with ordinary care prove highly remunerative, ancl be a means of consuming quantities of kitchen and table refuse, which in suburban houses and cottages is often thrown away. A setting of eggs, a single pair or a trio, will, with economical management, be sufficient to give one a fine stock of fowls to begin with the second season; and enough may be made by selling the surplus stock to pay the original cost. Neighbors can always be found who will be ready to pay at least twice as much for the surplus stock as for ord1nary fowls.

Of course it is essential for the successful breeding of Fancy Poultry that they have a warm, sunny, comfortable,

FIG.1.

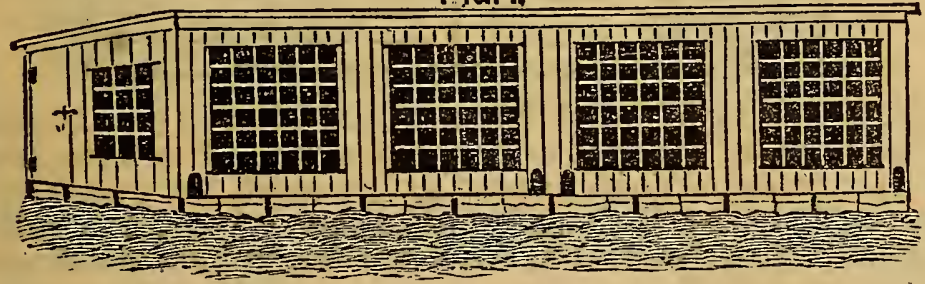

and well ventilated house. This can be built for a tew dollars. If one more extended is needed the annexed plans will be found useful; and it can be built on any scale desired, to suit the space at command.

Figure I, shows the front elevation. Figure 2, the plan of floor. The house should face the south or south-east.e A passage three and one-half feet wide runs along the back, the entire length of the house, separated from the rest of the space by a partition of three boards high, and lath above that to the ceiling. - The entrance to the house is by means 
of a door at each end of the passaye-way. Four doors, $\mathrm{D}$, open from the passage into as many rooms, each partitioned like the passage. The nests, $N$, are placed in tiers, two high; the lower tier resting on the floor, and facing the passage partition, the middle board of which is hinged, and raises up, thus allowing the eggs to be gathered from the passage. The perches, $\mathrm{P}$. are frames as shown, being about 20 inches high; the cross-bars being 18 inches apart. These are movable, and can be lifted out of the way when cleaning. The windows in front are 8 feet high and 5 feet wide, being made in two large sashes, the upper hinged at the middle and opening inward. :Along the back are a row of ventilators, V, placed close under the eaves, which, when the windows are dropped back about $\mathrm{r} 2$ to I 8 inches, give perfect ventilation, and yet no draft on the fowls.

The end windows are single sashes, and immovable. The holes for egress and ingress of the fowls are shown in Fig. I. The height of the building is $61 / 4$ feet on the back, and ro feet in front. Rafters are ordinary 13 -foot joist, placed 2 feet

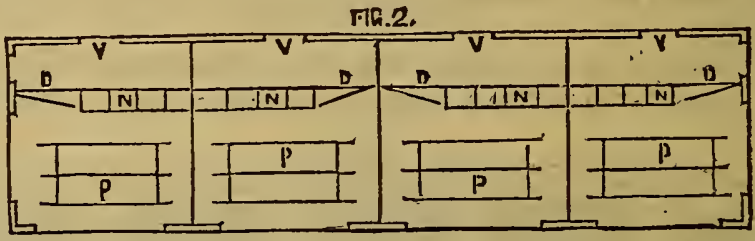

apart. Siding of ordinary tongue and grooved pine boards. These can be battened or not, as desired. The foundation proper is locust posts, placed Io feet apart, set 3 feet deep, and well rammed; the sills, which are 4 by 6 , are spiked fast to these posts, and the spaces between are either boarded up or stoned.

The number of rooms may be two, three, four; or more, according to the number of varieties kept. . One' great advantage in this style of house is, that it can be enlarged at pleasure. All that is necessary is to build on to one end as many additional feet as are required.

The division of the yards will have to be governed by the lay of the land. The yards should contain as much ground as possible, well grassed over, and dotted here and there with trees. Plum trees almost always thrive and bear fruit abundantly when planted in chicken yards. 
Another good plan for an inexpensive poultry house is shown in Figure 3 . It is meant for two breeds of fowis. The dimensions are, 24 feet wide, 6 feet deep, 6 feet from ground to eaves, and 8 feet to ridge of roof inside at each end of the building; and under the same roof, there is an open shed, 5 feet $\varsigma$ inches square, inside measurement; the remaining 12 feet are the two fowl-houses divided in the centre. The door of each house is approached through the open shed, and has a hole in it for the chickens to pass through. 'The perches are so arranged as not to annoy the' hens while in the nests on the floor. Four inches of broken stone and sifted cinder ashes, mixed, rolled; beaten down, and well watered. make a firm floor. Each shed has a dust bath in it. The outer walls of the house are built with feather edged 9 -inch boards, over-lapping each other one inch; also, the two ends of each house up to the door.

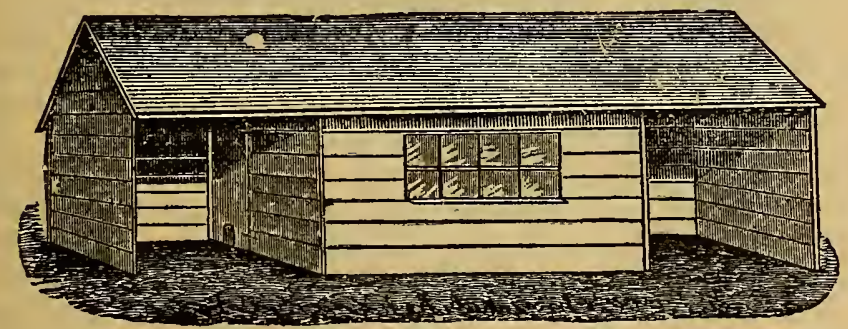

FIG. 3 .

Inside the house is lined with three-quarter inch white 9inch boards. The doors are 2 feet 3 inches wide, and 5 feet 9 inches high. The window is glazed, and fixed so as to give light to both houses. The house, painting included, will cost less than $\$ 50$

Poultry houses should be whitewashed inside and out. For the inside, add two tablespoonfuls of carbolic acid or a pound of sulphur to a pailful of wash, to lill vermin. Do not be afraid of putting on too much, but apply the wash to every corner and crevice in the building. If you have plank floors, clean them off nicely and put on three or four inches of fresh earth. Dirt floors should be dug up the depth of one foot. Wash your windows (if you have any in your louse, and if not you ought to have them), so that the fowls 
can sec daylight, and in bad weather they will enjoy the confinement of the poultry houses much better. Wash off the roosts with kerosene at least once a week. Take every nest box and wash inside and out, and put in clean straw, sprinkling upon it some sulphur or loose tobacco. Observe these rules, and your fowls will do better and keep healthier.

When the poultry house is completed the next thing, on course, is to decide what breeds of fowls shall be its tenants. This is to a great degree a matter of individual taste. The smaller breeds will lay more eggs during the whole year, and are very profitable to keep $\mathrm{i}^{-}$eggs are the only desire. They are also good for table use, snly they are small. If a person is intending to rear chickens for all there is in them, and make a business of it, we woulc advise some one of the Asiatic or large native breed. Hatch the chicks very early, and feed well from the time they are out of the shell until they are ready for market. When the weather begins to get cool and has the appearance of winter, the fowls should have a good, comfortable house with plenty of sunlight and well ventilated, but not kept too cool. Feed cooked vegetables in the morning, wheat or screenings at noon, and corn at night. Have plenty of chaff or dry leaves in the hen house and throw the corn in it. The chickens will scratch and get warmed up, and get the house warm, and it will remain so during the night. Give them plenty of gravel and ground bone or oyster shells. Feed regularly and keep plenty of fresh water for them all the time. This had best be given in a fountain, as shown in the cut. (For sizes and prices, see the latter part of this book).

During the winter when eggs are scarce at any price, you will find the Asiatics shelling out the eggs in surprising quantities. The fowls must be kept in good condition. If any get sick remove them from the flock at once. Do not keep too many chickens in one flock. In the spring, just as soon as eggs begin to get cheap, fatten the chicks and sell all except enough to breed from during the next season. In the 1atter part of February and March chickens will bring better prices than at any other time of the year. Be sure that every chick is as fat as you can get it, when you have them ready for the market. The large breeds, like Partridge Cochins or Plymouth Rocks, are the best for eggs during cold weather, and bring a big price when sold by the nound. 
All poultry intended for market should be well fattened, especially that sent for the holidays. The best manner of killing fowls is by bleeding in the neck; never wring the neck. Poultry intended for market should be dry picked, and if the feathers are plucked before the bodies are cold, this can be easily done. If poultry is scalded in the oldfashioned way, it lessens the value fully one-third. After the fowl is dry-picked, plunge it in a kettle of very hot water, holding it there only long enough to cause the bird to plump; then hang it up, turkeys and chickens by the feet, and ducks and geese by the head, until thoroughly cooled. This scalding makes the fat look bright and clear, and the fowl ap-

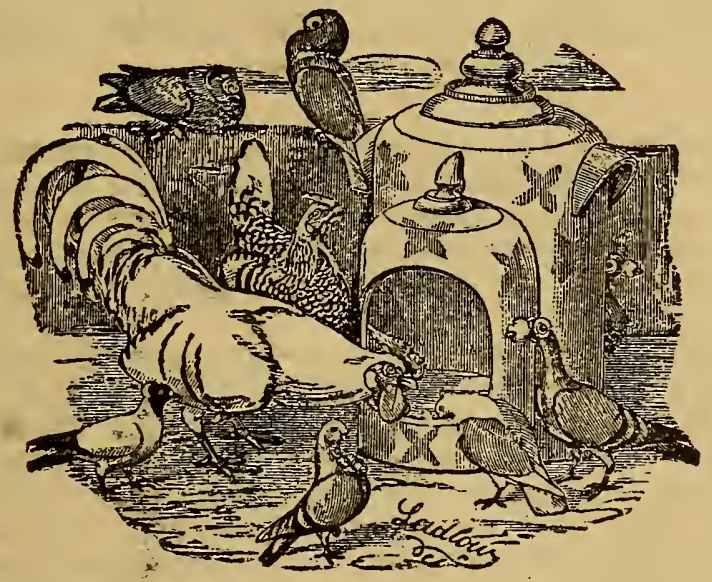

STONE DRINKING FUUNTAIN.

\section{et:}

pears nice and plump. In packing, use clean packages, lining the sides and ends with paper, and cover over, between the layers, with clean rye straw. Pack as closely as possible, so there will be no chance for the poultry to move about and become bruised. Good noultry will always sell for a full price, while common and inferior grades invariably sell low, and in most cases at a loss to the shippers.

For breeding purposes, where the lighthest grade of fowls are kept and the best results are aimed at, but a fuw hens should be allowed to one male bird; in the large breeds like Cochins or Brahmas about six hens to a cock; and in 
th: smaller varieties, as Leghorns and Hamburgs, ten hens to a cock, is the correct number.

Farmers do not seem to realize how important it is to save and properly apply the poultry droppings. When carefully saved, twenty-tive pounds will furnish sufficient to manure ail acre of corn; producing an effect equal to that of the b ist commercial fertilizer. Poultry manure is identical in atiun with guano, both being very rich in ammonia, and therefore, powerful plant stimulants. For this reason it is not safe to use the droppings without first mixing them with other substances, such as pulverized clay, dry loam, or land plaster.

\section{HATCHING AND CARING FOR YOUNG CHICKENS.}

Always have your sitting hens ready and accustomed to their nests by the time the eggs arrive. If it is necessary to remove a lien from one nest to another, do so at night rather than in the daytime, as she will be more likely to stick to her new nest. In warm weather make the nest on the ground.

Sprinkle flour of sulphur over ana around your sitting hens to keep them free from vermin. Ruffle their feathers and their bac!ss, and dust them thoroughly. Never grease a hen while she is sitting; if you do, not a chick will you get. If convenient, provide a small yard for your hens to dust and exercise themselves in ; keep corn and water constantly by them; watch them closely for the first seven days : and see that they do not remain off too long. A hen should not stay off her eggs longer than fifteen or twenty minutes in cold weather; but, in the summer, an hour or two will not injure them.

After your hen has been sitting eight or ten aays, go to her at night with a strong light and examine the eggs, and remove the unfertile ones. These you can easily discern by holding them up before the light, in the following manner: hold the egg in the right hand, small end dow 11 , between I': thumb and forefinger; now place the little finirer of the $1 \mathrm{ft}$ hand across the top or middle of the large ind of the egg, a little below rather than on a level with the flame of the lamp." Those eggs having chicks in them will appear 
quite dark, except a small portion near the top. Those that are unfertile will be quite clear, like new-laid eggs, and should be removed at once, as they generate gases whirk often cause them to burst and smear the good eggs, some. times spoiling a whole nest. A little practice will enable the novice to detect the fertile from the unfertile ones by the tenth day. With Leghorn and Spanish eggs, the difference can be seen much sooner than with the eggs of Brahmas or Cochins, as the shells of the latter two are thicker and darker. An expert can detect the unfertile eggs as early as the fifth or sixth day.

Breaking of an egg by the hatching hen or by others attempting to lay in the same nest, may occur and thus smear the other eggs. When this happens it need not cause failure, and will not if attended to in time. But failure will be the result if the remaining eggs are not cleansed. : As soon as it is discovered that the egg has been broken and its contents been smeared over the others, they should at once be immersed in a basin of luke-warm water, and every one of them carefully cleansed. If the nest has been befouled in the same manner, the surface had better be removed anil replaced by clean hay or straw. The albumen of a brolen egg acts substantially as a varnish, and when smeared on the outside of a shell will close the pores in such a manner that the embryo chick is deprived of air and thus destroyed.

When the chicks begin to come out of the shell they need considerable care. Often after the eggs are pipped they will become partially crushed by the uneasiness of the hen; unless the chicks have help they will become pasted fast to the shell, and will perish. A small portion of the broken shell and the thick skin under it should be removed near the bill of the chick, and if any sign of blood appears the egg should be replaced under the hen, and allowed to remain several hours, when it must again be examined. Whenever indication of blood appears all efforts to free the chick should cease for the time, but, if there is no appearance of blood, enough of the shell and thick skin niay be removed to enable the chicken to free itself. It is frequently convenient to give the hatch of two hens to one mother, and reset the other one, and a hen is seldom the worse for sitting six weeks; indeed, a hen which has been hatching six weeks will remain longer with her birds than one that has been on the nest but three weeks. 
For the first twenty-tour hours young chicks require no food. After that, for about two or three weeks, feed hardboiled eggs, boiled cracked rice, mixed dry with corn meal, and a little red pepper, occasionally added. Give our Poultry Powder as per direction, with above, every other day; and feed the chicks five or six times a day, not more at a time than they will eat. Very young zhicks cannot consume enough food at a single feeding to last them for several hours, as their crops are small, and their growth rapid, and the demand for material proportionately active, and to compel them to wait from morn to eve as is done in a great many cases, is not only cruel, but works greatly to the disadvantage and loss of the breeder.

After the chicks have become three weeks old they can be fed different varieties of food; but for morning feed it will pay well to feed cracked rice boiled and mixed with corn meal or wheat shorts; rice being cheap, and there not being much required, it goes a great way. For interval feeds during the day, feed wheat screenings; bread crumbs, dry or soaked in milk; boiled potatoes; cabbăge chopped fine; meat, raw or cooked; and table scraps; and occasionally cracked corn, but do n't forget a good range and clean quarters.

To prevent gaps in young chicks have your hen house raised two or three inches above the ground on a platform, so as to let pure air circulate under the house at night, and don't let the little chicks out until the morning dew has dried off.

\section{CAPONS AND CAPONIZING.}

The object of caponizing is to improve the quality and increase the quantity of the flesh of fowls. A capon will outgrow a cock of the same age, just as an ox will exceed a bull in weight, and for the same reasons, which are: that castration makes an animal less restless and quarrelsome, and less of the nutriment it digests is diverted from beefforming. The operation is not very difficult, and is quickly performed after a little practice. There need be no more than 6 or 8 per cent. of the birds killed, even by an indifferent operator; and as these die by bleeding to death, they may be eaten as if they had been butchered in the regiliar 
way. A capon is a cockerel which has been thoroughly castrated. A "slip" is one on which the operation has been attempted but not thoroughly performed. "Slips" are easily distinguished from capons without dissecting them. A cockerei's comb ceases to grow after he is caponized, and there is no more color in what little comb he does have than in that of a sick hen. He is quiet in his manner, neither fights nor crows (because he has nothing to crow about), nor pays any attention to hens. A "slip" is more of a nuisance in this latter respect than if he had not been operated on. The testicles, which were only partially removed, grow again, and are frequently found much larger in slips when castrated the second time than in ordinary cockerels of the same size. They fatten well, and are nearly as good eating as capons, br nging only two or three cents less per pound. A capon can be easily told by his unusual appearance, while a slip cannot readily be distinguished from an ordinary cockerel, except by the scar, which can of course be seen when the bird is dressed. Bright yellow meat is required; and the pure, unalloyed Plymouth Rock or American Dominques makes the best capons known.

A good capon has smooth, yellow meat, and a competent judge can tell one when dressed and his head cut off. Capons are no more difficult $t$ ) winter than other fowls are, if the operation has bec $n$ performed early enough to allow them to recover before cold weather commences. A capon can be induced to brood a flock of chickens and care for them like a hen. To dress capons for market, leave the head on, also the feathers of the neck, wings, and tail.

Caponizing instruments, embracing the latest improvements, accompanied by full directions for operating, will be sent on receipt of $\$ 4.00$.

\section{POULTRY DISEASES.}

To keep fowls in constant health and to increase their lying qualities, we recommend our Poultry PowDER, which is sold at 25 cents per large package. It is too heavy to be sent by mail, but we will forward one dozen packages free of charge anywhere not over 800 miles from Philadelphia. on receipt of $\$ 3.00$. 
Fros.ED Comb.-Mix two parts of glycerine and one part turpentine; rub the afflicted parts every morning with the mixture. At noon apply a compound of three parts sweet oil and one part rose water, and at night apply the first mixture again as before. A few days of this treatment will be pretty sure to restore the parts to their normal condition.

BUMBLE Foot.-This is an unsightly excrescence, which is very apt to appear on the Asiatics and other heavy breeds. It seems to act very much as does a stone bruise upon a boy's fuot. An application of lunar caustic or iodine to the surface may sometimes reduce the swelling. Should suppuration set in, open the wound, and if possible keep out the dirt and wet long enough to give it an opportunity to heal.

LEG WEAKNESS is nothing but the result of high feeding, rapid growth, and forcing. It is not necessarily fatal. Mix a little bone meal with the food, put a teaspoonful of copperas in the drinking water; and with a variety of food the chicks will get over the difficulty without trouble.

Feather Pulling.-This comes from a lack of animal foud. The small breeds, being active in habit, are subject to it when in confinement The best preventive is to supply the fowls with a variety of food, and if meat cannot be procured, use lesscorn and more bran, wheat, buckwheat, and oats. The vice is not inherent, but acquired. Should one hen in the flock become addicted to it, she will teach the others.

EgG EAting.-Sometimes hens eat their eggs, but this bad habit may be cured by making the nests dark, leaving only a faint light in them. Hens prefer a secluded, dark:ened nest, but they will always return to the light as soon as they can, and they will leave the egg untouched in preference to eating it in the dark. It is this aversion to darkness that prompts them to prefer the open air in winter, rather than remaining inside.

CROP-BOUND. - Should a fowl became crop-bound, work the crop well with the hand, and endeavor to force away the obstruction in the passage-way to the gizzard. Should this fail, draw the skin to one side and cut the crop suffi- 
ciently to relieve it of the contents. Sew up the wound with silk, and the fowl will not be seriously damaged. After cutting, be sure that the obstruction in the passage is remuver as well as the contents.

SUFT-SHELLED EGGS.-If the fowls lay soft (shell-less) eggrs it betukens a lack of shell-forming material, and the deficiency can be suppiied by pounding oyster shells to pieces and giving them to the fowls. Oyster shells are composed of carbonate of lime, and so are the shells of eggs. They are therefore identical in substance.

Roup in some forms is contagious, while in other shapes it may exist in:flocks without affecting any but those of weak constitutions. Roup, when malignant, makes known its presence by a peculiar, disagreeable odor. The sick fowl looks droopy, and a slight pressure on the nostrils causes a discharge, which is very offensive to smell. Make a solution of copperas water, and with a small syringe inject some of it into the $n$ sstrils, and also down the throat. If the bird is no better in a few hours, try a severer remedy, which is the injection of a mixture of coal-oil and carbolic acid. Add ten drops of carbolic acid to a tablespoonful of coal oil, and force a small qnantity into each nostril. This will cure when all other remedies fail. Night and morning give our Roup PILls, either in the food or by forcing it down the throat. Add $s$ me, also, to the food of those that are well.

A box of these pills, which are an infallible cure for both Roup and Cholera, will be mailed on receipt of 25 cents.

Cholera.-This disease, which is the most terrible that chicken flesh is heir to, may be brought into the yards, or may arise from filth. The first thing to do when the disease makes its appearance is to disinfect the premises. This may be done by adding an ounce of sulphuric acid (oil of vitriol) to a gallon of water, and sprinkling it freely over the yards, roosts, nests, and the floors. Chloride of lime is also excellent and may be used freely. It will affect the fowi: slightly, but will be more beneficial than otherwise. A solution of chlo ide of lime in water may be used in place of the acicl, if $1 \mathrm{r}$-ferred The sic's fowls should be at once removed from the others. They may be known by evincing a nervous, anxious look, with drooping spirits, great thirst, and greenish droppings.

Lice.- To be rid of them, provide a dust bath, rub ti:e fowls with Persian insect powder, the best quality of which 
we wil furnish, postage paid, for 50 cents per pound Clean out th: p.ultry houses and coops, rub the roosts with coal oil and whitewash the buildings inside and out with hot whitewash, to which carbolic acid has been added.

GAPES is a disease caused by the lodgment of small rink worms in the wind-pipe, generally from one to a dozen, and which naturally obstruct the air to and from the lungs, causing suffocation and often death, unless removed. When a chick is suffering with the disease, place it in a close box and burn carbolic acid dry in the box, but be careful that the chick does not become suffocated; still, as he is near death's portals by the disease, it is safe to take a big r.sk. The fumes from the acid cause the worms to loosen their hold, and become powerless, and the patient will cough them out.

Scaly Legs. - This disease can be easily cured. The scales are occasioned by myriads of small insects, invisible to the naked eye, but clearly made out by the microscopc. They huddle in whitish-gray blotches, at first upon the shanks of the fowls, and if not removed or destroyed early, will increase very rapidly. To cure scaly legs, saturate a cloth with coal oil and rub the legs to the shank.

\section{NCUBATORS.}

The increasing interest manifested during the last few years in the subject of artificial incubation has naturally led to the invention of numerous machines for that purpose. Many of these have been simply experimental, while others, more pretentious, have been widely advertised as absolutely perfect.

We have no interest in any particular make of incubator, but sell all good makes. If you will write to us, giving the capacity of machine wanted and other particulars, we will give you the benefit of our experience and quote prices for suitable machines. 


\section{HOW TO MANAGE AN INCUBATOR.}

Having received the machine, unpack it carefully, read and study the directions, and if in doubt about any point, write to the manufacturers. Do not be in too much haste ab ut putting the eggs in. Wait till you learn the working of the machine fully. If you have a good, dry cellar, that is the p'ace to put the machine ; if not, put it where the sun or wind will not strike it. The best results will be had by not buriaing a fire in the room. Having fixed the regulator, fill and trim your lamp. Now, fill the machine with water, till wi hin one inch of the top; this gives room for expansion. Now lay the thermometer on the egg-tray, about the fourth row from the back of the machine, and let me say right here, study the thermometer, so that at a glance you can tell what degree it is. Then fill the moisture pan or pans with warm water, and set them in their places.

The egg must have moisture, remember that ; and if the machice does not supply it, you must. The reason so many fully matured chicks die in the shell is for want of sufficient moisture; the membrane intervening between the chick and the shell will become so tough that the little orphan cannot break through it, and so dies. In putting the eggs in the drawer, put the large end-up. After putting the eggs in the machine, do not change them for three or four days.

Attend carefully to the lamp. The wick does not need trimming every night; rub off the burnt wick with a stick or with a knife. The wick w 11 last three times as long by doing this. Keep the burner clean ; an incubator lamp is so near the floor that it catches a great deal of dust.

A hen, after sitting a week or ten days, loses much of her natural heat, from causes not necessary to mention here; but, at the same time, changes are taking.place in the egg. Circulation of the blood has commenced, so there is generated in the egg a vital heat that balances the loss of temperature sustained by the hen. So. taking this as a guide, we must reduce the temperat ure of the egg-chamber as the heat in the egg increases. The nearer the time for hatching, the more moisture the egg needs. When the chicks begin to pick the shell, ktep the machine closed, and do not disturb them at this time. Nearly every one warts to pull out the drawer and watch the little fellows work out; but don't do it, or you will chill them so thev will never get out. 


\section{PRICES OF FOWLS.}

We are often asked by correspondents, "why the same variety of fowls will range so much in price. Hor iustauce, Minorcas are quoted from $\$ 10$ co $\$ 30$ per trio. Why is it one trio is worth $\$ 10$, and another trio of same breed $\$ 30$ ?"

Prices rauge according to the number of "points" the fowls will record, that is, the nearer perfection as show fowls they are, the more they are worth, although the lowest and highest priced fowls inay be own brothers and sisters; a feather out of place, a stinted comb, a rye tail, will disqualify a bird in the eyes of a fancier, while, for all practical purposes, it is just as good as one that will score away up in fancy points. F $;$ ' urther information send postage stamp for reply.

\section{THE DIFFERENT BREEDS AND VARIETIES OF FOWLS.}

\section{PLYMOUTH ROCKS.}

The great popularity that the Plymouth Rock fowl has attained is without a parallel, and no other breed is so highly esteemed in America to day. It has attained this popularity entirely on its own intrinsic merits. As table fowls they are juicy, fine-grained, and tender. As spring chickens, they feather very early and mature with remarkable rapidity. As market fowls they are unsurpassed; having large plump bodies, with full breasts, clean, bright yellow legs and yellow skin, they always command the highest market price. At maturity they weigh: cocks, $9 \frac{1}{2}$ to 12 lbs.; hens, 7 to 9 lbs. As egg producers they are not excelled, and can $h^{-}$repended 
upon for eggs all the year round. In hardiness, both as chicks and mature fowls, they are unequalled, and being an American breed, they adapt themselves to all climates and situations, better thin any other breed. As mothers, they are excellent, being kind, and gentle, and good foragers. They bear confinement well, and are easily kept in an enclosure. This fine breed is preeminently the farmer's fowl, and the best for all who desire a general purpose breed.

\section{Barred Plymouth Rocks.}

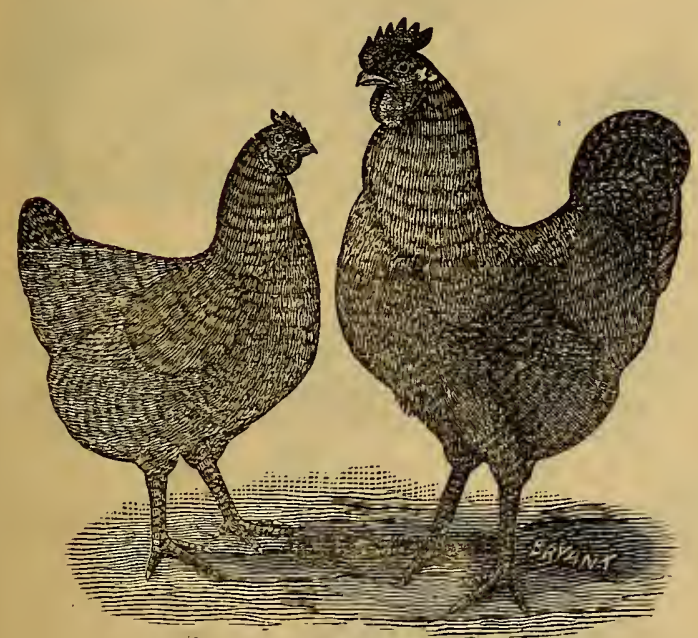

BARRED PLYMOUTH ROCKS.

In mating this variety, select light - colored cockerels and pullets of clear, dark plumage. If the cockerel is as dark as the pullets, the females of the offspring will frequently be very dark. If the hen is too light, the males of the offspring will possess white tails, and bevery undesirable as show hirds. Plymouth Rocks are worth per trio, $\$ 6.00$ to $\$ 20.00$.

\section{Buff Plymouth Rocks.}

This is a new variety which is much admired, they have the same characteristics of the others but are of a 
deep buff plumage, clean and uniform in shade, except the tail which should be a richer buff; or copperish bronze, the under color of a little lighter shade than the surface color, and should extend to the skin. The are valued at $\$ 10.00$ to $\$ 20.00$ per trio.

\section{White Plymouth Rocks.}

These fowls have become very popular. They are rather larger than the ordinary $\mathrm{Ply}$ mouth $\mathrm{R}$ ock, which they resemble ill all other respects except color of plumage which as the name in dicates, is snow white. 'T h ey lay a very large egg, of a rich brown color.

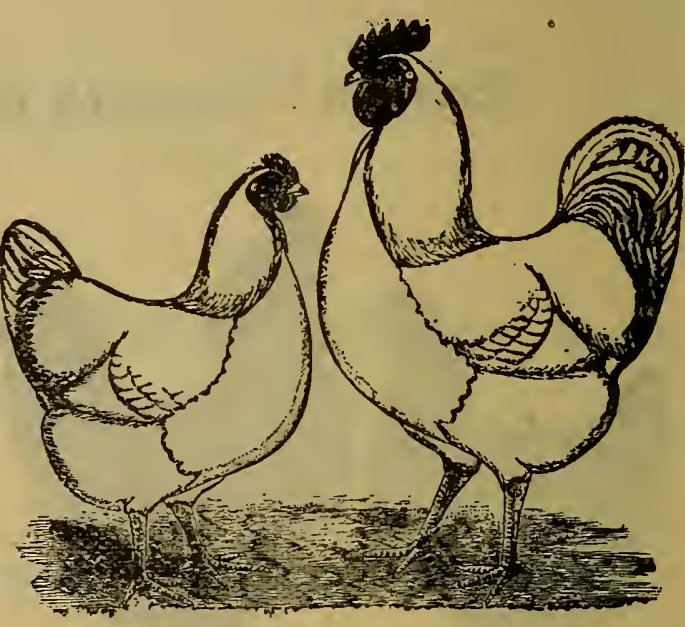

WHITE PLYMOUTH ROCKS.

White Plymouth Rocks are worth from $\$ 10$ to $\$ 30$ per trio.

\section{WYANDOTTES.}

This breed originated in this country in recent years. The standard weight for cocks is eight los., and for hens $6 \frac{1}{2} \mathrm{lbs}$. Their flesh is very sweet, juicy, fine-grained, tender, and delicate. For spring chickens this is one of the best varieties, as they mature early and have, plump bodies, and full breasts, clean yellow legs, and bright yellow skia. As layers they are only excelled by the 


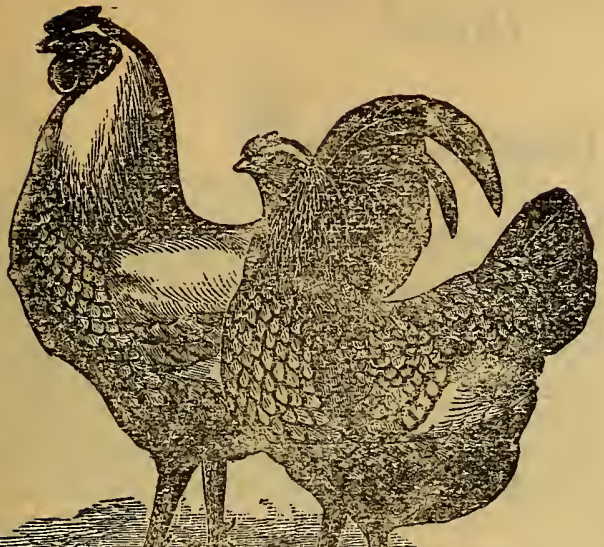

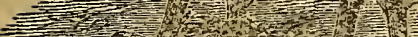
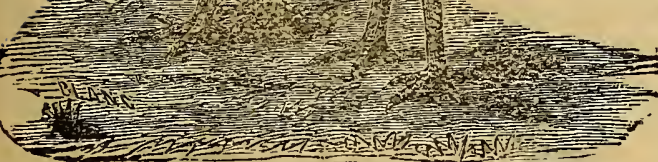

ITYANDOTTES.

The varieties of this breed are silver laced, marked as in above illustra. tion, golden laced, Partridge laced, pure white buff and black. In shape, carriage, comb, and all other points, they resemble the ordinary breed of Wyandottes ; they are about the same size,

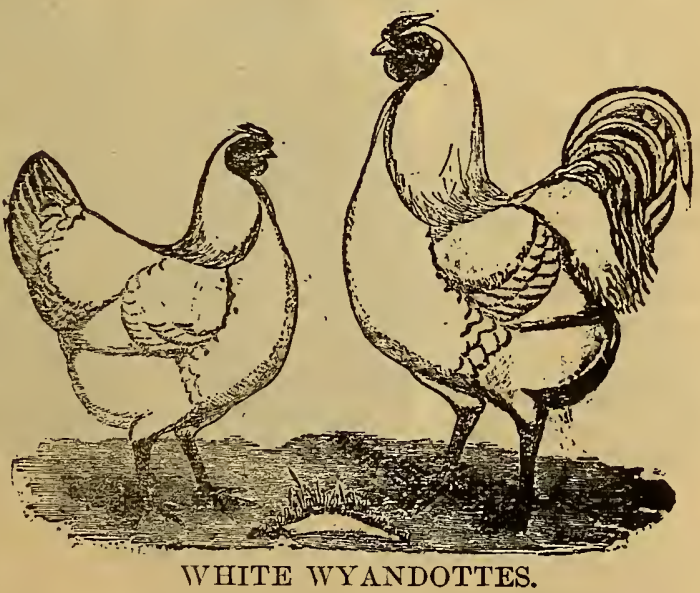
just as good layers, and quite as hardy. Wyandottes are worth from $\$ 10.00$ to $\$ 30.00$ per trio. in winter they are more prolific layers than the latter. They are exceedingly hardy and tree from disease; and while not nonsetters, they will not, sit persistently like some of the A siatic breeds. In fact, this breed is one of the best for the farmer or the market poultryman or the private family. 'The breed was made originally by a crosa of several different fowls. 


\section{JAVAS.}

\section{Black Javas.}

The Black Java is a black fowl, with purplish azure reflections; and the cock is glossy and velvety black; plump and square; back broad and body deep; comb single and deeply serrated, standing erect in both sex's; with well-proportioned wattles. Their disposition is vury quiet. They are excellent sitters and good mothers, although not very broody. Their eggs are medium size and white, but not so pure a white as the Spanish or Hamburgs. The chicks are of a bluish black, with whitish down about the breast and under parts; they are sprightly, and grow well with ordinary attention; feather soon; when six months old the pullets are unsurpassed in beauty, and are very attractive Like all black feathered fowls the dressed bird is white, but as a table fowl it is excellent, inclining to be always fat with ordinary feeding.

Black Javas are worth, per trio, $\$ 6$. to $\$ 20$.

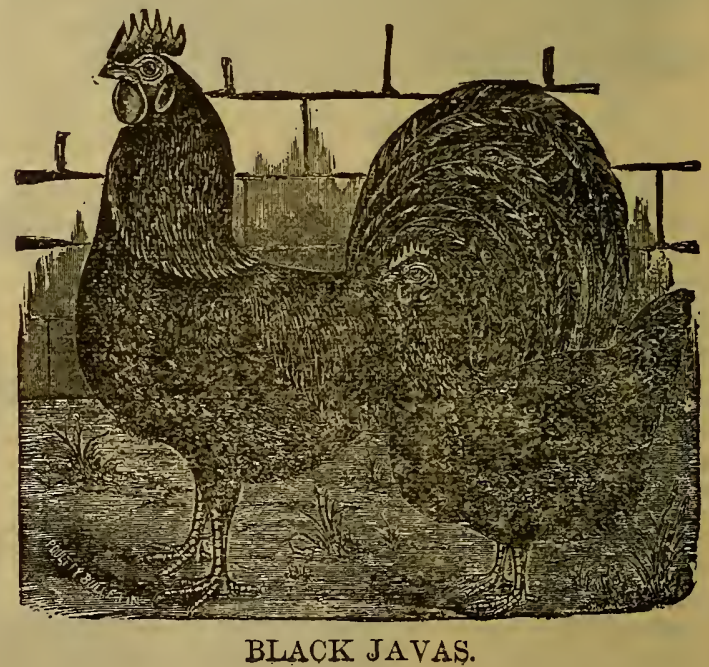




\section{Mottled Javas.}

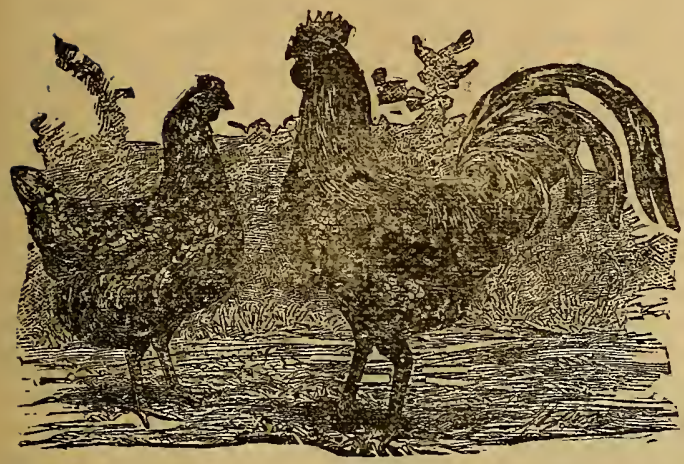

MOTTLED JAVAS.

In plumage the Mottled Javas so $\mathrm{mewh}$ at resemble the IIoudans. Thesize is auost the same as tiat of the Plymouth Rock, and, like them, the flesh is as good for table use as that of any other fowl, and superior to some. They are very hardy, and excellent layers. T'here are also pure White, and spangled varieties, with same characteristics.

Mottled Javas are worth from $\$ 6.00$ to $\$ 20.00$ per trio.

\section{THE AMERICAN DOMINIQUE.}

These good - sized fowls are very hardy, active, and will thrive on almost any soil. They have a rose comb, hence are not liable to suffer in the winter; they are good sitters and mothers, and reasonably good for the table. They should be more largely raised by farmers. 'i'he American Dominique is a fowl that is sure to give good satis faction anywhere and especially

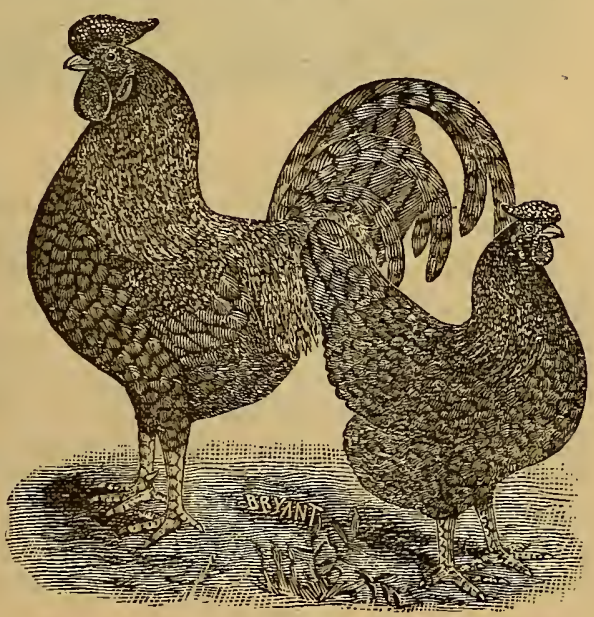

AMERICAN DOMINIQUE. 
so on a firm. 'They are very hardy, good winter layers, not easily frost bitten, of good size, plump, fine Heshed and dress well. They will lay in the coldest months, and this too without extra care or food; although a warm house and stimulating food are necessilly with them as with all other fowls to secure the best results. 'Their vellow legs and skin mike them favorites for marketing. 'Their sober plumage does not make them conspicuous objects for the hawks to pounce upon, and this is no small qualification where fowls are allowed a large range.

One of the best crosses for producing market chicks is that of the Dominique and Brahma. 'The Dominique is small and the cross does not lesult in an over-grown pot fowl, as is the case with the Plymouth Rock and Brahma, which sometimes prevents them from being good layers. Fowls that fatten very readily are not always good ego producers.

Price of the American Dominique per trio, is $\$ 8$ to $\$ 15$.

\section{AMERICAN WONDERS.}

American Wonders are a new breed, which originated in our Middle States. They resemble the American Dominiques in size and shape, with red rose comb, red faces, wattles, and ear lobes, and round plump bodies. 'They are bred in $t w o$ different colors. The plumage of one variety being pure white, while the other is a pure buff, the male of the latter is of a darker and richer shade than the female. They are excellent layers, and fine table fowls, their meat being fine-grained and delicate for eating.

They are valued at from $\$ 10.00$ to $\$ 15.00$ per trio. 


\section{JERSEY BLUES.}

Thirty or thirty-if ve yedis ayo these fowls, which originated in the stale whose nawe they vear, were dermed a very valuable nieed.

In color they are light blue, sometimes approaching a dun, and in the best specinens the prumage closely resembles that of the Allualusian bretd. 'I He lail and wings are somewhat short; the legs are generaliy black, though occasionally of a dark blue. They are perfectly hardy, good layers of large eggs, and when desired for the table, their meat is fine and white, similar to a Turkey.

Jersey Blues are worth from $\$ 15.00$ to $\$ 30.00$ per trio.

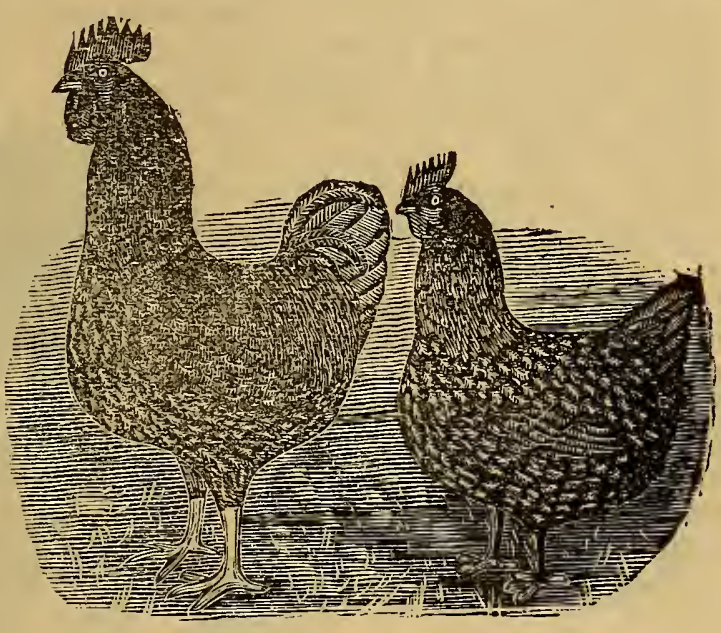

JERSEY BLUES

\section{ERMINETTES.}

Erminettes are an American breed of fowls that have been known for the past few years, but have not taken very well with the fancy, although they are a good sized healthy bird, and make a good marketable variety. In shape and size they resemble the Javas, while in plumage they are of a white groind color, spotted with black. Some have single, and some have rose combs, some have feathered shanks, and others have their shanks free from feathers. 'They are good layers of large eggs, and, make good table fowl.

Erminettes are worth from $\$ 10.00$ to $\$ 20.00$ per trio, 


\section{SCOTCH CREEPERS.}

Scotch Creepers are one of the oldest known breeds of fowls, and as their surname implies, they are supposed to have originated in scotland. in former years they were plentifui, but of late they have become almost obsolete in this country, which is a great pity, as they certainly are a valuable breed of domestic fowl. They have a large plump body with very short legs, and their movements somewhat resembles a creep rather than a walk. They are not in. clined to scratch the ground with their feet as much as other breeds, as they can not balance their bodies well on one foot, hence, they will not disturb a garden much, and their bodies being heavy they can not fly very high

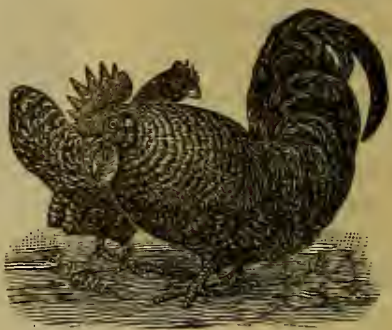

SCOTCH CREEPERS. and can be kept in a low enclosure. They mature well, and are good layers of a large egg. In plumage they are found in all colors, the gray ones predominate and are sometimes called Scotch Grays.

They are valued at from $\$ 10.00$ to $\$ 20.00$ per trio.

\section{SHERWOODS:}

Sherwoods are a comparative new American breed. They look to be a cross between the White Cochin and the White Leghorn. They have good sized single combs of a bright red color as are also their faces, wattles and ear-lobes, eyes red, beaks yellow, shanks yellow, and feathered to toes. Plumage pure white, entirely free from other colored feathers. They are good layers and table fowls.

o Sherwoods are valued at $\$ 10.00$ to $\$ 15.00$ per trio. 


\section{ASIATIC BREEDS. \\ Brahmas.}

The Brahmas possess all the qualities that are usually wanted by the beginner in Fancy Fowl breeding. 'They are large, fine layers of good sized eggs; very tame, do not stray far away from their home, and are very healthy. They stand cold weather admirably; if it is desired to keep them enclosed in a yard, a fence two feet high will answer as they are very poor flyers. As sitters they cannot be beaten, although it may be objected that their weight is more likely to break the eggs or trample the chicks to death than some of the smaller breeds. A flock of Brahmas can be kept anywhere, and will thrive, providing their quarters are dry and the sun shines upon it at least a portion of the day.

\section{Light Brahmas.}

Every white fowl, with feathered legs, is not a Light Brahma, although the term is applied indiscriminately

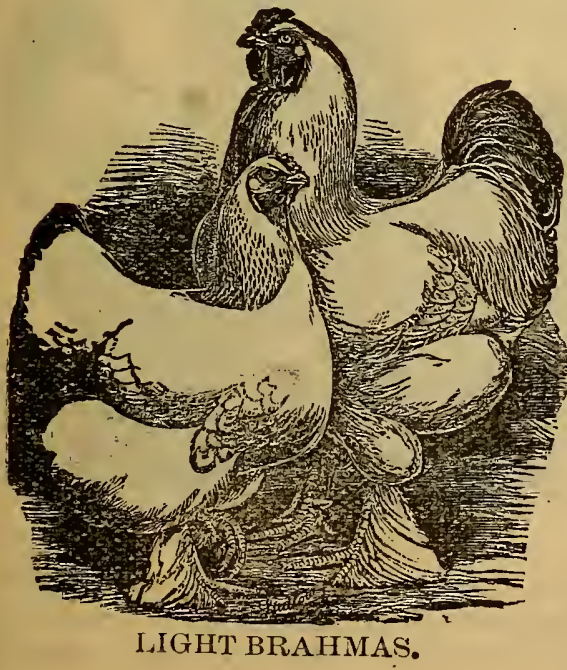
to all classes of light hens. The ${ }_{-}$ight Brahma usually weighsabout 12 pounds for cocks, and 8 pounds for hens; but they are now being bred smaller. They are noted for possessing the pes or triple comb, which is low and close to the head. The beak is yellow, with a dark stripe down the upper mandible; the ear lobes and wattles red; with a full breast and deep body. The hackles are full and abundant, the upper part being white, but 
while the lower two-thirds is white, the lower part has a distinct glossy black stripe down the centre of each feather. The wings are white, with some black; while the tail should be black. The fluff; or short feathers, should be abundant. The legs should be feathered, even the middle toes being corered. The color of the legs and skin should be yellow. Any fov:l with a single or rose comb, no matter how well feathered it may be on the legs, is not a Brahma. With this discription of a Brahma, it is not a liard matter to select them when with other flocks.

Light Brahmas are worth from $\$ 6.00$ to $\$ 20.00$ per trio.

\section{Dark Brahmas.}

For purposes of beauty and utility, Dark Brahmas are well worth the attelltion of fanciers. 'The soot and dust do not soil and discolor their plumage, as they will lighter colors. This breed has this advantage, then, for town fanciers, as no breed is more liardy from the time the chicks pick the shell, to old age. This variety has not been known sr long, nor disseminated so widely as his cousin the Liglit Brahma, out in no respect is it the inferior. that we know of. Some per

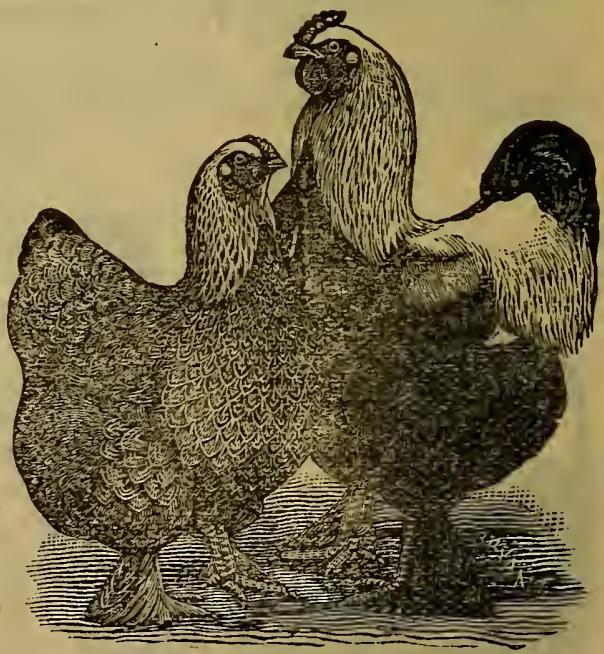

DARI BRAHMAS.

sons think Dark Brahmas sunerioi for fattening and for capons. It is said they plurk nicer, fatten more evenly, and their skin shows a brighter yellow collor, when 
dressed. In egg production, they are second to none of their Asiatic relations. With their great vigor of constitution, when young they feather rapidly, and are early ready for market as "spring chickens" or "roasters." At maturity, cocks weigh 10 to 12 pounds, hens 7 to 9 pounds. In size the Dark Brahmas surpass every other breed yet known. They lay nearly every day; even in the depth of winter; and if pure bred, scarcely ever sit until they have laid thirty or forty eggs. As winter layers no breed equals them. They are very hardy, and grow uncommonly fast, being therefore ready early for the table, in which particular they are profitable fowls, having plenty of breastmeat. They bear confinement as well as the Cochins; being, however very much more sprightly; and scarcely ever, like them, get out of condition from over feeding. They make a valuable cross with a Crevecœur or Dorking cock.

Dark Brahmas, per trio, bring from $\$ 10.00$ to $\$ 25.00$.

\section{White Brahmas.}

This is a comparative new variety; they resemble the Light Brahma in every respect except in plumage, which is pure white in every part. 


\section{COCHINS.}

The Cochin family possesses the valuable quality of being winter layers; and if they are properly managed, and are of right age they will lay eggs and raise chickens at mid-winter, if desired. There are many points about the Cochins that corrmand them to the notice of villagers and city people, one of which is the fact that they are not restless if given but little space.

The eggs are never of the whiteness of those laid by the European varieties of fowls, but are chocolate or cream color.

\section{Buff Cochins.}

The Buff are the oldest of the different varieties of the Cochins. The greatest difficulty in breeding them originally, was the constant appearance of dark feathers, which were particularly prevalent in the neckhackles of hens. The beauty of these fowls consists largely in the uniformity of the buff coloring without markings. Patient and careful effort, however, has been rewarded by fowls that are beautiful in plum. age and desirable in form.

The exception to the rale thatBuffCochins

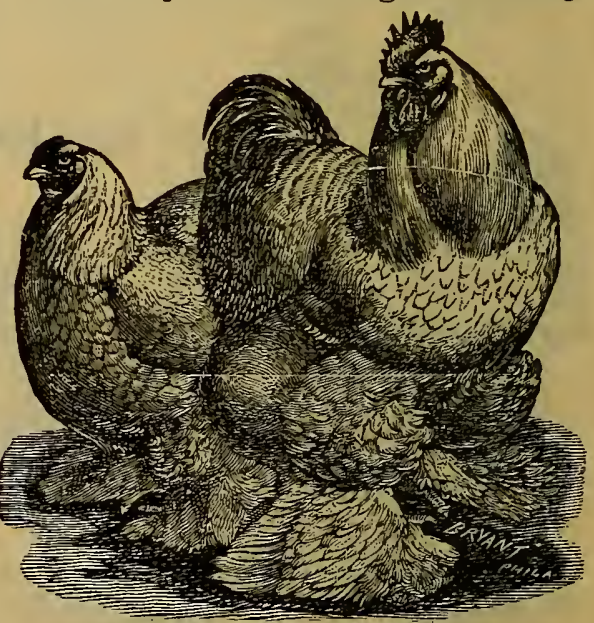

BUFF COCHINS. must be wholly buff, is that in the tail of the cock, black feathers are allowed to intermingle. It is preferable, however, that these should be dark chestnut instead of black. The tendency of the plumage, which may be of 
a brilliant buff on young stock, to turn "mealy" in tint before they have reached a year, is an important feature to be met.

The standard weight for cocks is $10 \mathrm{lbs}$., and of hens 8 lbs. Buff Cochins are worth from $\$ 8$ to $\$ 25$ per trio.

\section{Partridge Cochins.}

This breed of fowls is one of the oldest and best. They are not only large, but very compactly built and heavily feathered; possessing fine carriage and elegant shape. The cocks have black breasts, and iull flowing hackles of a brilliantrcd color. Portions of the $\mathrm{w}$ ing a $\mathrm{re}$ colored mahogany bay with greenish bl.ack edges to each feather. The tail and $f l u f s$ are black, and thelegs ycllow. When theyy are in full plumagethc blending of colors make a handsome

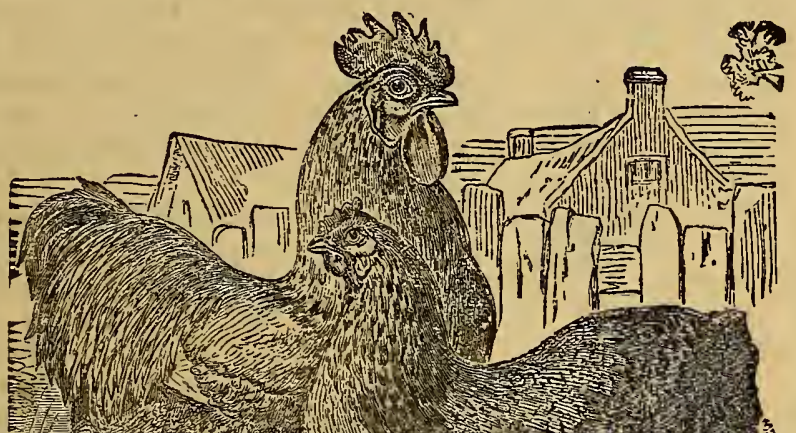

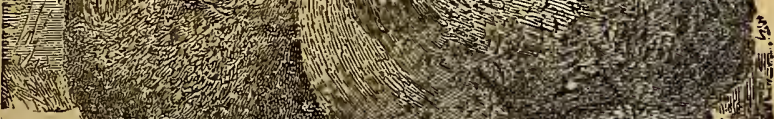
$11^{\prime \prime} \rightarrow$, appearance, which is not easily surpassed. The hens are handsome, with reddish gold tinge on the neck, with broad black stripes down the middle of the feathers; while breast and body are of a rich brown color, dis- 
tinctly and handsomely penciled with a darker brown; and although the plumage of the cocks and hens is apparently very dissimilar, their uniformity in all other respects is easily noticeable.

The Partridge Cochins are exceedingly hardy, being able tostiud nut only severe winters but tlie hot summers also. They lay well, and are good sitters, remaining close to the nest during incubation; and although they are accused of crushing the eggs and chicks, much of the difficulty arises from their being compelled to jump on the nests from above instead of passing on from the front. They are the best and most careful of mothers, and tenderly nestle and scratch for their broods until the chicks are quite adranced in age. When cocks of this breed are crossed on oldinary common hens, the produce is almost entirely like the sire. This is due to the breed being an old established one; and the fact that the chicks are always uniform in color and shape, shows the value of the Partridge Cochins as one of the best pure breeds for intoroving common flocks.

They are valued at from $\$ 8.00$ to $\$ 25.00$ per trio.
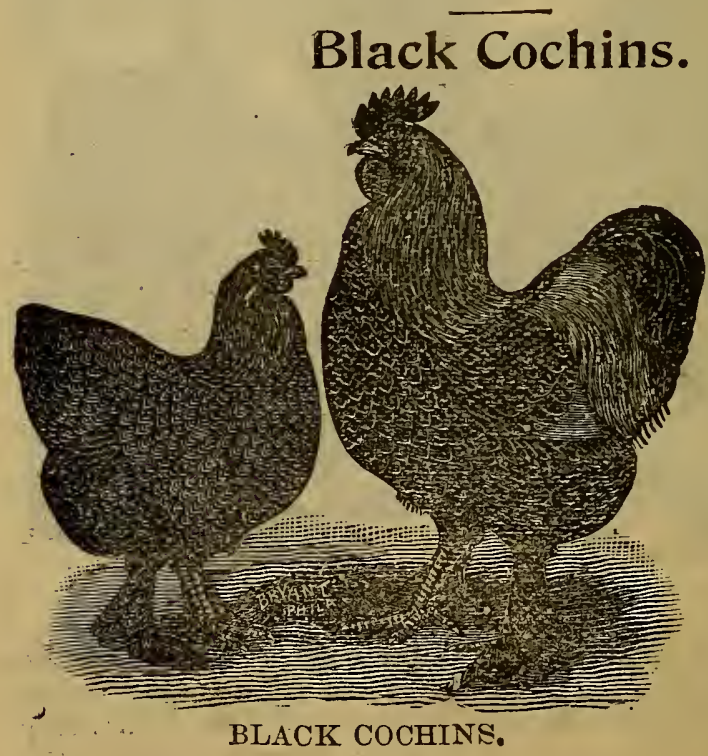

Black Cochins have many excellent qualities that commend them to all who are admirers of the Asiatic breed of fowls. Being of a solid color, they are more easily bred true to feather than otherCochins, excepting the white. They are very hardy, and are considdered by some to be better win. 
ter layers than any other kind of Cochins. 'They usually are not so large as the Partridge or Buff Cochins; but they are generally of good size and are remarkably free from "cullings" or under sized specimens. In consideration of early hatching, power to resist cold, winter laying qualities, general average size, and juicy, delicious flesh, the Black Cochins deserve to have a high place among fancy poultry. They are valued at $\$ 6$ to $\$ 20$ per trio.

\section{White Cochins.}

White Cochins, when well bred and properly cared for, make a very fine appearance, particularly on a nice lawn or grass plot. No one who has an eye for beauty of plumage can pass them by without admiring their color and grand proportions. They should be placed in vell-shaded runs, or given proper shelter of some kind, as exposure to the glare of a summer suil, day after day, will give to their handsome white plumage a yellowish appearance.

White Cochins are equal to other varieties of Cochins in all essential qualities. They are magnificent fowls and

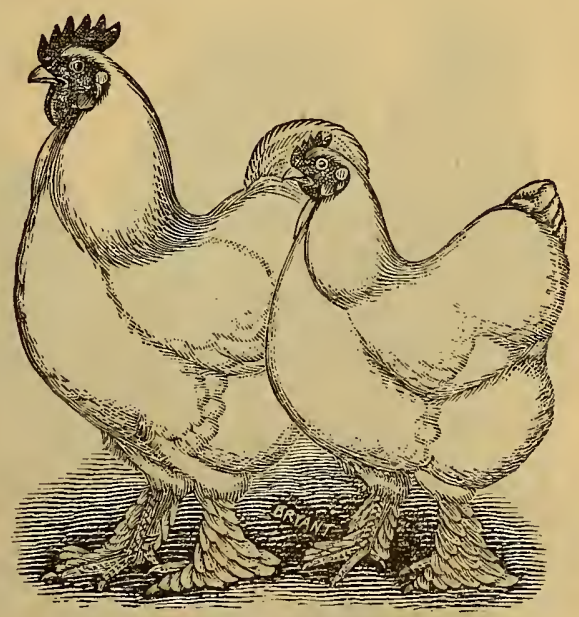

WHITE COCHINS. worthy of a more general cultivation among American fanciers. The little white chicks are very beautiful and much admired. They are easier to breed true to color. than a parti colored variety.

The standard weights of cocks are from 8 to $12 \mathrm{lbs}$; and of hens, from 6 to 8 los. White Cochins are worth from $\$ 8.00$ tu $\$ 25.00$ per trio. 


\section{LANGSHANS.}

Within the last few years the Langshans have come to the front as desirable fowls. Being almost as large as Brahmas, they make good market fowls. 'Thi llesh dresses white, and is fine in grain. One of the greatest advantages of the Langshans is that they begin to lay when but tive months old, thus rivaling solne of the smaller breeds. 'They sit, but are not persistent; and are, therefore, considered intermediate between the sitters and non-sitters. Very few know the difference between the Black Langshans and Black Cochins, both being black and feather legged. The Langshan haś sickle feathers, which flow over the tail and stream in the

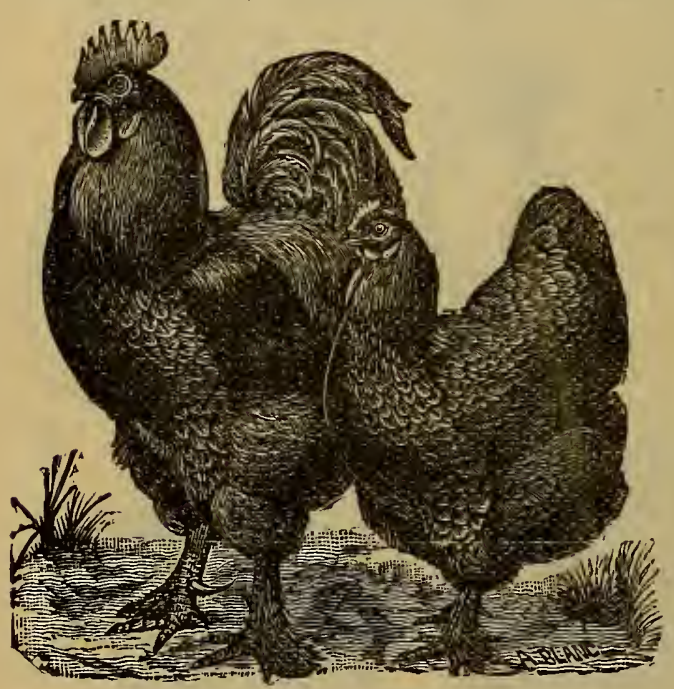

BLACK LANGSHANS. breeze; while the tail of the cochin turns abraptly over, having no sickles. The skin and legs of Langshans closely resemble the turkevs', while the cochin is yellow under the bottems of the feet, on the skin, and between the toes. 'The Cochin is low and compact, wh ile the Langshan is mo resymmetrical, active, and can fly over a low fence. The Langshan matures early, while the Cochin is slower in reaching its full size. WWen the young Langshans are first hatched they have a large proportion of white on the body which sometimes confuses those who are not familiar with them. A great many people wonder why black fowls should produce chicks partly white. Fortunately, 
however, as they grow the white disappears, and after a time they assume their natural black color.

There are also pure white and pure blue Langshans of the same size, quality and characteristics as the black ones. Langshans are worth from $\$ 9$ to $\$ 20$ per trio.

\section{FRENCH BREEDS:}

\section{The Houdan.}

The Houdan is one of the most valuable acquisitions to our breeds of poultry. 'These fowls are non-sitters, lay well, and are fine table-birds. As the breed is an old one, they are very uniform in every respect. They are above the medium size, being the largest of the nonsitters, and possess the fifth toe,like the Dorkin g, which they resemble very $\mathrm{much}$ in shape. They unfor tu n ately have dark legs, however, which makes them ob-

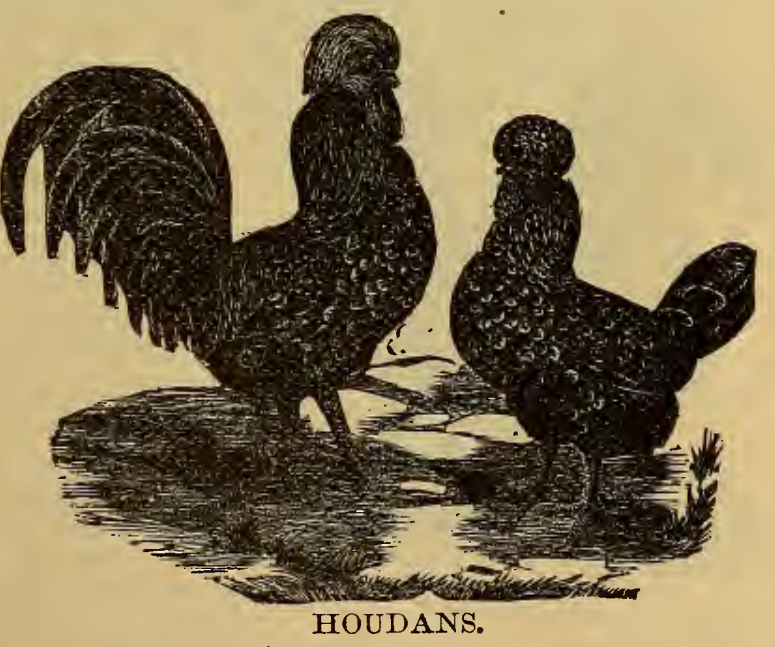
jectionable to some, but their good qualities easily overcome such disqualification in the market.

As regards economic and useful qualities, the Houdan has but few peers. It lays nearly as many eggs as the Leghorn and far larger. In meaty qualities, the Creve- 
coeur and the La Fleche only equal it, and any other variety excels it. They are hearty, vigorous, of exceedingly rapid growth as chicks, and not at all subject to disease. Used as a cross on large fowl, the Houdan cock has no superior, and we forsee the day when it will be one of the most popular fowls for home and market consumption in all America. The French prefer them to all other varieties, and they are the masters of breeding poultry for market. The price is $\$ 6.00$ to $\$ 15.00$ per trio.

\section{LA FLECHE.}

This is a French breed of fowls which have never attained much popularity on this side of the Atlantic. In appearance they somewhat resemble the Black Spanish. Both sexes have large, long bodies, standing on

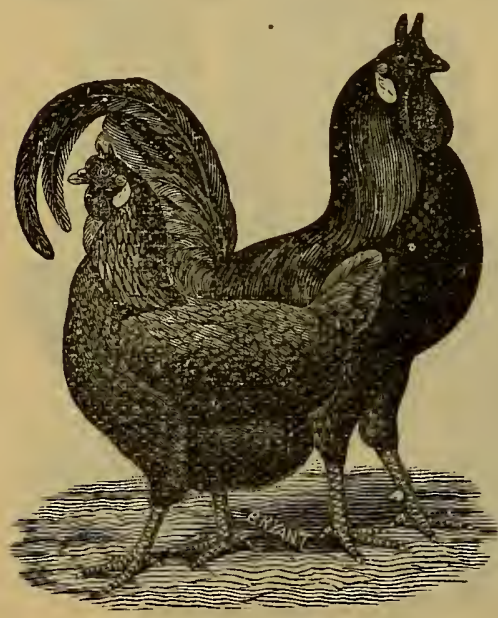

LA FLECHE. powerful and long legs, and weigh heavier than one would judge from their looks on account of their plumage lying very close to the skin. Their feathers are dense black with green reflections, and their legs are slate color. The look of the head is peculiar, the comb being not only two horned, much like the Crevecour, near the top of the head, but also appearing in the form of two little studs or points just in front. The wattles are very long and pendulous, of a bright red like the comb.

The appearance of the La Fleche is very bold and intelligent, and their habits active and lively; at the same time they do not appear to thrive well in the climate of our Northern States, but no doubt are admirably adapted for localities below Mason and Dixson's line. 
The hen is an excellent layer of very large white eggs, and is a non-sitter. The flesh is excellent, and the fine white transparent skin makes a favorable appearance on the table, and in juiciness and flavor it is only excelled by the Game fowl.

La Fleche are worth, per trio, $\$ 12.00$ to $\$ 25.00$.

\section{CREVECOEURS.}

This breed is of French origin, and is the favorite fowl of that country. In form the fowl is very full and compact, and the legs are exceedingly short, especially in the hens, which appear almost as if they were creeping. Their motions are quiet and deliberate, and they appear the inost contented in confinement of any fowl we know of. They rarely sit, and are tolerable layers of very large white eggs. The comb is in the form of two well-developed horns, surmounted by a large black crest; the wattles are full, and like the comb, a very dark red. The throat is furnished with ample whiskers and beard. The plumage is black.

The merits of this breed

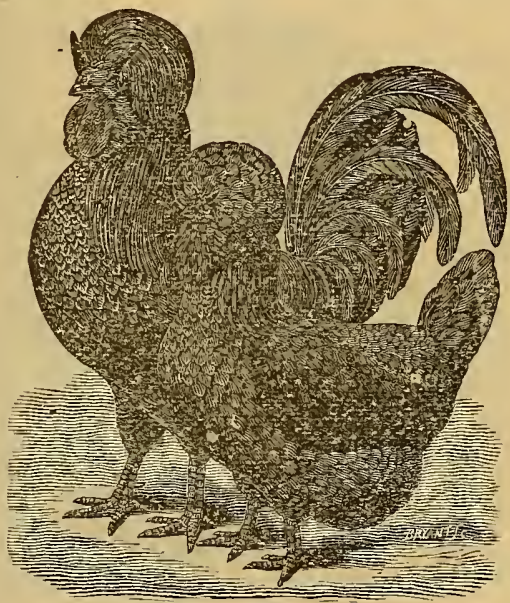

CREVECEURS. consist in its edible qualities, early maturity, the facility with which it can both be kept and reared in confinement, and the large size of the eggs.

In our Northern States the Crevecour has met with poor success, owing to the fact that it is too delicate to stand the cold climate. We should suppose it to be well ariapted to States where the weather is never colder than it is in the south of France.

A Crevecour cockerel is crossed with Langshan hens, 
and the pullets make excellent table-fowls. The shape is magnificent for a market fowl, especially at six months, or over. The bodies are very long and deep, producing that parallelogram shape so admired in the Dorking. The chicks also mature early, and make fine broilers. Both cockrels and pullets are black, with small crests, medium muffs, black legs, clean or almost featherless, and small coral combs. They grow to a large size, especially the females, which seem to be better proportioned than the males. For eggs, this cross is not a success.

Crevecœurs are worth from $\$ 12.00$ to $\$ 25.00$ per trio.

\section{ENGLISH BREEDS. \\ Dorkings.}

To any one who has a moderate grass run and a dry locality, the Dorkings will give perfect satisfaction; but they are not suitable for confined spaces and damp yards. They are fair layers of large eggs; and for the table they are voted by epicures to be the best fowl in existence, excepting perhaps the Games. In size they are quite large, with full. plump breasts.

\section{Colored Dorkings.}

This is one of the largest and best varieties of the Dorking family. While they are rot over hardy or extra layers, their excellence for table use more than counterbalances these faults. The breed has lately fallen into disrepute from ignorance of its merits. On a dry gravely soil, with plenty of exercise on clean grass runs, no breed of fowls will give better satisfaction. They lay large eggs of pinkish color, and are almost non-sitters, unles they are allowed to steal their nests among the briars or in a field, as for some unaccountable reason they dislite to sit in a poultry house. When full grown, the cocks will 
weigh 8 to 10 lbs., each, and hens 5 to 7 lbs.; and for juicy flesh they are the fowl par excellence.

Colored Dorkings are worth from $\$ 8$ to $\$ 25$ per trio.

\section{Silver Gray Dorkings.}

This is undoubtedly but an offshoot from the colured variety and a fixed t $y, p e$ of plumage made by careful selections.

Colored Dorkings will occa sionallyproduce silver gray chickens, such are sometimes exhibited a nd bred with Silver Grays; but

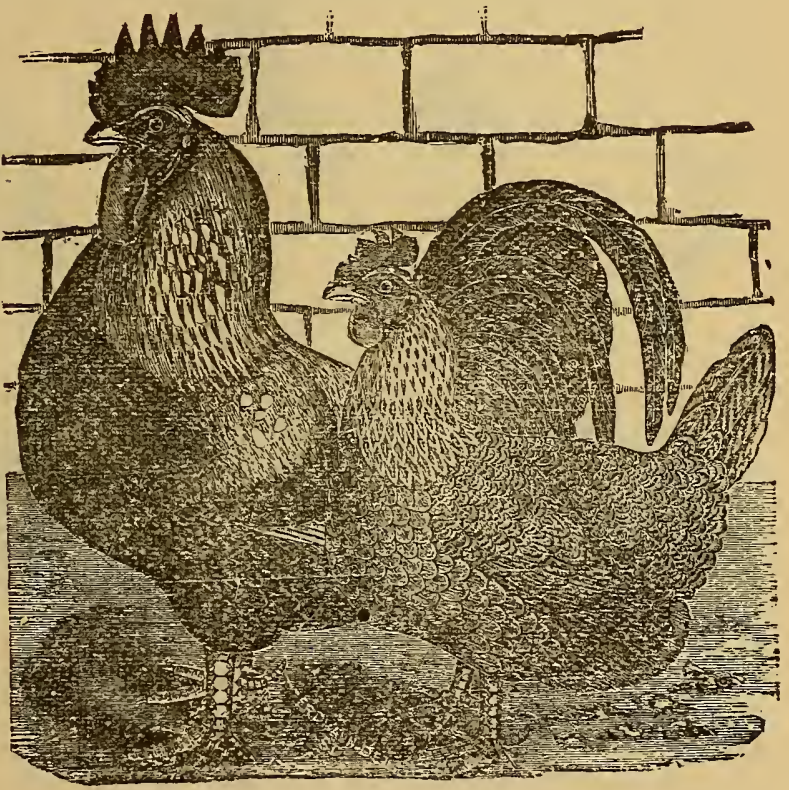
it is need.

SILVER GRAI DORKINGS.

less to say that disappointment is sure to ensue unless the strain has been kept pure for generations. They are as large as the Colned Dorkings, and similar in all respects, except in the plumage.

It should be remembered that Silver Gray and the other valieties of Dorkings degenerate more than almost any other fow is from interbreeding; and if fresh blood be not introduced they will rapidly decrease in size. They do not bear close confinement well, and they prove satis- 
factory only when allowed full liberty and where the soil and climate is dry.

They are worth from $\$ 10.00$ to $\$ 15.00$ per trio.

\section{White Dorkings.}

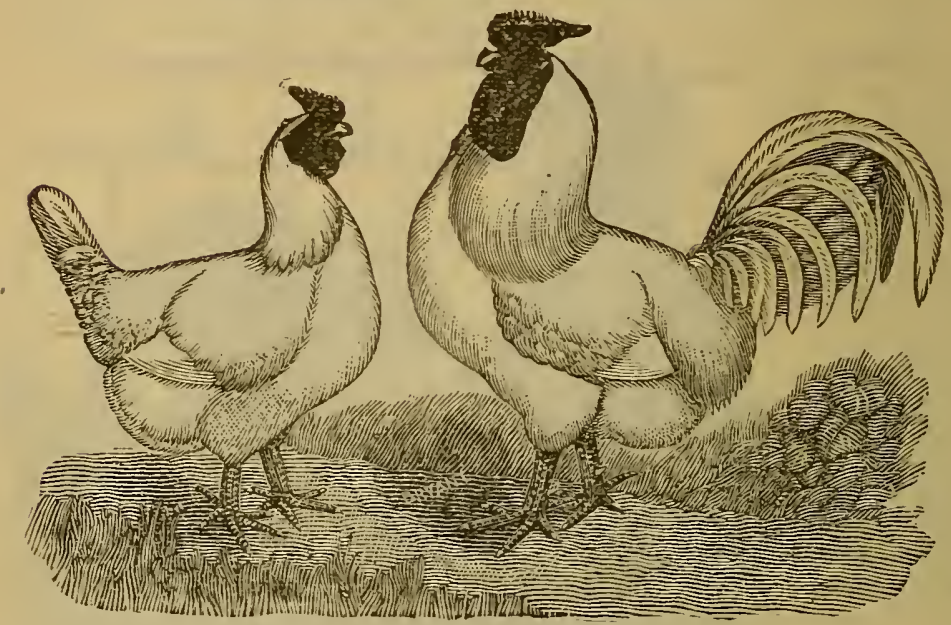

WHITE DORKINGS.

White Dorkings are an exceptionally brautiful rariety, provided they have a clear grass range. The breed has of late rears fallen into disrepute, from the fact that those who have bred them claim that they are delicate and not good layers. Still, they have niany admirers who deny these faults They lay a pinkish egg, are almost non-sitters, of medium size, and as table fow ls are unsurpassed. They have a rose comb, and are sonewhat smaller than the other varieties.

White Dorkings are worth from $\& 7$ to $\$ 20$ per trio,

There are two varieties of the White ones, rose and single combs, otherwise they are alike, 


\section{POLISH FOWLS.}

There are no breeds of fowls which, if viewed carefully and critically, will excite more interest, as showing great evidence oflong-continued and careful breeding for fancy, than the Polish. There are many crested birds in the world, many of them belonging to wild species, and by natural influence certain beautiful markings appear that are permanent; but it is reasonable to suppose that the crest and plumage of the Polish fowls are the effects of man's selection, and that the crest particularly was obtained by careful selection to gratify $h$ is love for the unique. The skull presents a globular appearance, which is neczssary to furnish sufficient surface for the growth of a large crest, this being the nain characteristic which distinguishes the Polish fowls.

Polish fowls are non-sitters. They have blue legs and small co nbs, which are nearly hidden under the crest of feathers. As chicis they are a little delicate, and are not as e: sily raised as some other breeds, if hatched early in the season, before warm weather has really come. May and June and even later, are the months to have the young chicks to come out. Then, with the mild dry weather they thrive as well as could be wished for.

Polish are easily restrained; and are well suited to small places where only a few fowls can be kept. They are most excellent layers, laying a large egg; and are very ormamental for the grounds of a country residence. While not large, they are very plump with full breast, and their flesh is very tempting and toothsome.

\section{White Crested Black Polish.}

The white crested Black Polish is a very odd looking fowl with a large white topknot which contrasts beantifully with the glossy black plumage. They are nonsitters, excellent layers, and are great favorites with those who keep them and know them best. This variety is the most popular of all the Polish breed. 
While the handsome and attractive plumage and peculiar markings of the White Crested Black Polish make

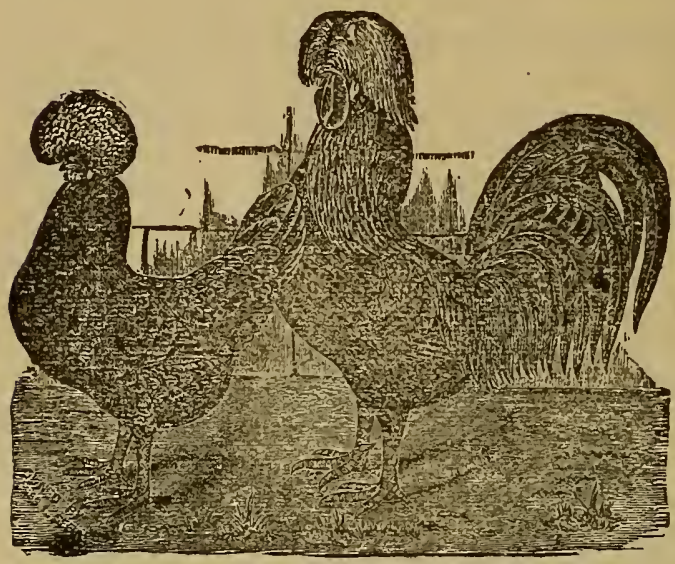

WHITE CRESTED BLACK POLISH.

them objects of interest to breeders and fanciers alike, they have qualities, practicall and profitable, which commend them" to all who breed poultry, as they ale most excellent layers of good-sized eggs, and under proper management will lay as well as almost any other breed we know of. Like the Leghorns and Ham-

burgs in some respects, they need warmth, care, and attention, during the prevalence of cold weather, and if they do not have this accorded, they cannot and will not lay eggs during the winter and early spring-in fact not till the weather becomes warm and pleasant. In one respect, however, they are different from the Leghorns, for not having those large combs which the Leghorns have in such an eminent degree, they do not suffer so badly during severely cold weather, if accidently or carelessly exposed to its influence. 'The large topknots afford a considerable protection to the birds about the head, though this is where liawks abound, sometimes objectionable.

One feature, and a desirable one in breeding this variety of Polish, is that almost as soon as the chicks are dry from the shell the fancier can tell whether the birds will have the proper proportion of white in the crests or not.

White Crested Black Polish, price per trio, $\$ 6$ to $\$ 25$. 


\section{White Crested White Polish.}

The White Crested White Polis h are unquestionably one of the most ornamental fowls bred in this country at the present time. 'Iheir $\mathrm{p} u \mathrm{re}$ white plumage, their large and ornamental crests, and their graceful forms put them in the front rank for all lovers of beautiful birds. They are peculiarly domestic, in which they are unlike many other fowls, fond of being petted, and manifest pleasure at being noticed and

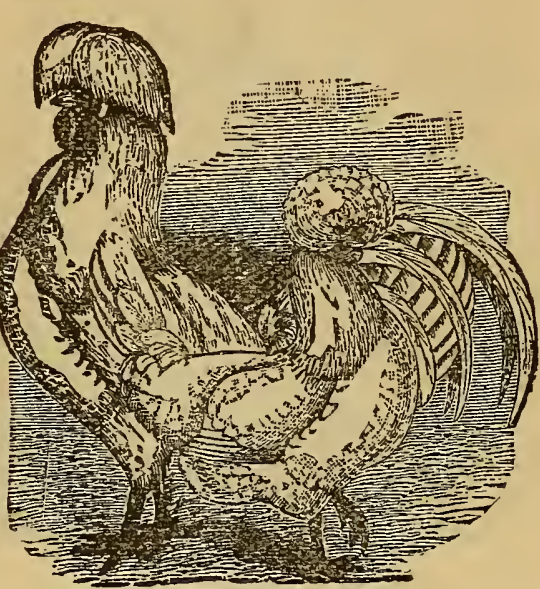

WHITE CRESTED WHITE POLISH. caressed. In addition to the above qualifications they are hardy and healthy, and free from diseases that are so rrevalent in most poultry yards. They are prolific layers, non-sitters, and adapted to a small yard; in fact, just the breed for the village and city. The quality of the meat these fowls furnish for the table is unsurpassed. White Crested White Polish, per trio, $\$ 10$. C0 to $\$ 25.00$.

\section{Silver and Golden Polish.}

These varieties of the Polish family are quite as striking: in appearance and as ornamental as either the White or White Crested Black, and possess all the other desirable qualities. They are bred both with beards as shown in the engraving, and plain. The crest feathers on good specimens should be set thickly making a large bunch; and all the plumage is laced or spangled with black; the ground color in the silver variety being white, and in the golden breed is a deep brownish-yellow, 'The comb 
is so small as to be hardly perceptible beneath the high crest of feathers. The Silver Polish has for ground color

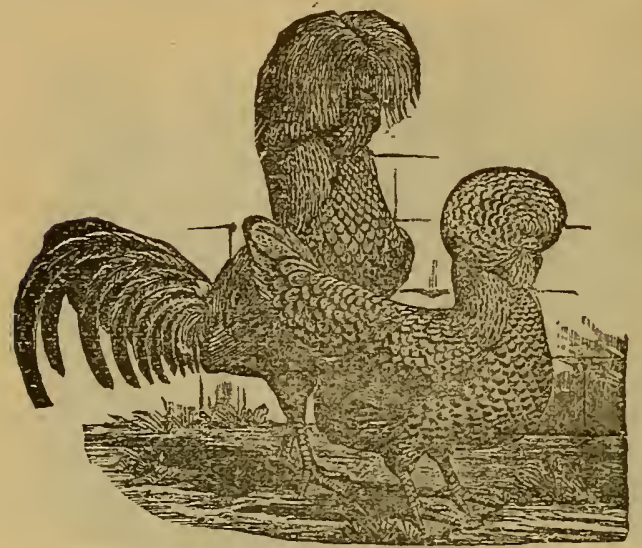

SILVER BEARDED POLISH. silver white. The crest feathers on good specimens should be set thickly making a large bunch, each featlier. laced with black, and all the plumage either laced or spangled with blacki. Of coul'se the beauty of each bird depends on the regularity and uniformity of the prescribed marking; also the value for exhibition purposes.

The comb is small, haldy to be noticed in its retreat in the crest, were it not for its $T^{T}$ sluape. There is scope for skillful practice in breeding the Silver Polish, and indeed, all the Polish varieties.

The price per trio, for either Silver or Golden Polish, is $\$ 8.00$ to $\$ 20.00$.

'There is also a Buff laced variety, similar to the above in other respects.

\section{HAMBURGS.}

The Hamburgs are very uniform in size, and are quite small, being a little smaller than the Leghorns, but rivaling them in egg production. They are persistent layers; never offer to sit; have rose combs that are not easily frosted; and are good foragers, hunting and seeking their own food when given the range of the farm, but not at all partial to confinement, as their repeated attempts to get orer the tallest fences mivestrong eridence of their love for freedon. In order to hatch them, the eggs must be placed under common hens, owing to the disinclination of the Hamburgs to sit, and if not fed regularly and 
systematically they will not thrive, because of their great laying powers which entails a heavy drain on the fowl. In order to succeed with them they must not only be well fed but on a variety of food, which must include meat and ground bone. The reason is, that such fowls as Leghorns and Hamburgs, are compelled to perform greater service than most other breeds, and if not supplied with meat, bone, and lime in some form, soon become addicted tu

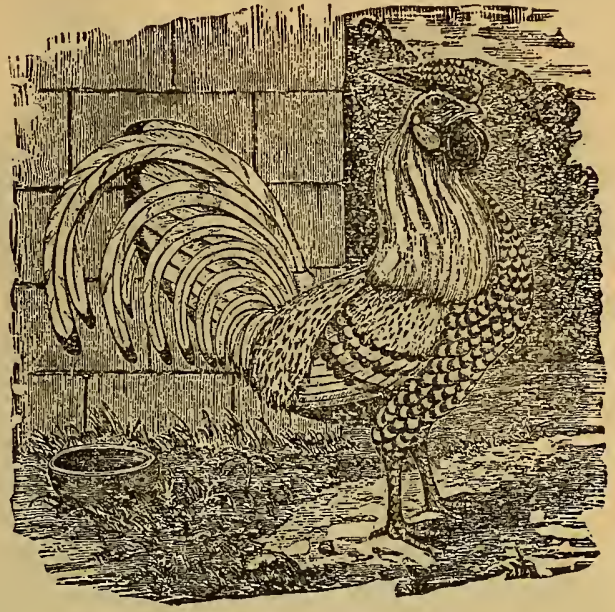

SILVER SPANGLED HAMBURGS. the vice of feather pulling, which is the worst evil that could befall a flock of fowls.

\section{Spangled and Penciled Hamburgs.}

Of these varieties the Golden Spangled and Silver Spangled are the favorites, and next the Silver Penciled. The Black Hamburgs are perhaps the hardiest of the varieties of this breed, and though beautiful in plumage, cannot compete with the spangled varieties where fowls are valued for beaucy alone. They are not as rapid in growth as might be desired or expected in a breed of small size; but when fully matured they will lay as many eggs in a year as can be realized from any other breed. In some cases hens are said to have reached 200 to 220 eggs in one year. As a rule, with good range, they are healthy, and chicks are usually reared. In the Penciled varieties the pullets lay at about four months; in the Spangled, at about six months: The eggs from the Hamburgs are the whitest. in color of any other, are of 
fair size, and the young chicks are active and full of life. The object of breeders of this fowl is to bring them to

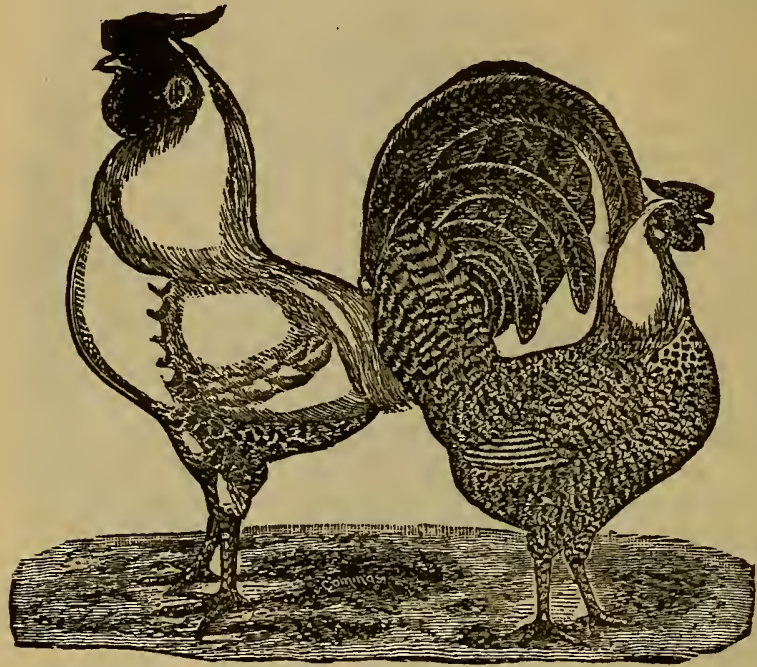

SILVER PENCILED HAMBURGS.

maturity with com plete markings. In very damp, cold weatherthey aresubject to rou $1 ;$ b ut, w he n compared with otlier fowls, largely owing to their gleat laying qualit jes, they return as handsome profitsas any othel breeds that are now known.

The different markings and characteristics of the Spangled and Penciled Hamburgs are as follows:

Sillver Penciled.-The size of this exquisite breed is small, but the shape of bcth cock and ben peculiarly graceful and sprightly. Carriage of the cock very conceited, the tail being borne high, and carried in a graceful arch. The comb in this as in all the otler varieties, to be rather square in front and well peaked behind, full of spikes, and free from hollow in the centre. Ear lobe pure white, free from red edging. Legs small and blue. The head, hackle, back, saddle, breast, and thighs of the cock should be white as snow. Tail Black, glossed with green, the sickle and side feathers liaving a narrow white edging the whole length, the more even and sharply defined the better. Wings principally white, but the lower wing converts marked with black spot on the end of each feather. Hens should have a pure white backle. The rest of the body should have each feather distinctly marked or "penciled" across with bars of black. The tail feathers should be penciled the same as the body, 
Golden Panciled.-The form of the variety is the same as the preceeding, and the black markings are generally similar, only grounded on a rich golden hay instead of white.

The coch's tail should be black, the sickle and sidefeathers edged with bronze; but the tails bronzed all over are often seen. The bar on the wing is not imperative. The color of the cock is always much clarker than thatof the hen, generally approach. ing a richer chestnut

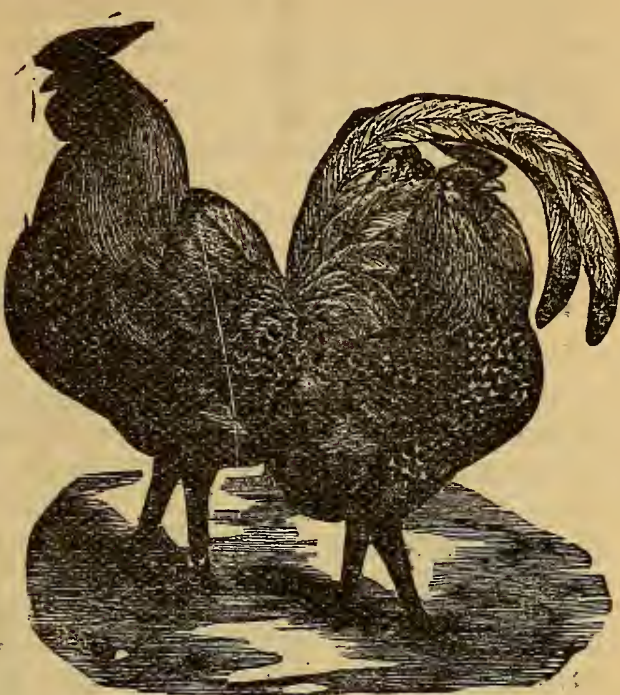

SILVER SPANGLED HAMBURGS. GOLDEN SPANGLED.This variety is of a golden bay color, each feather having only o ll e b l ack mark at end of it, which for ms the spangle. The hackle.is streaked with greenish-blacli, the tail black. All spangुles should be regular in shape.

GOLDEN SPANGLED HAMBURGS. 
Silver Spangled.-The ground color is silvery white, with round spangles resembling those on the golden variety. The tail is white in both cock and hen, ending in black spangles.

Any of these varieties are worth from $\$ 6$ to $\$ 25$ per trio.

\section{White Hamburgs.}

This variety is rather more rare than the other kinds of Hamburgs. In all points, excepting of course color of plumage, they closely resemble the Black They also are very excellent layers, and non-sitters. If hatched late the chicks are quite hardy and mature rapidly.

This variety is hardly suitably for the city breeders of fowls, as the white plumage is too easily soiled by dirt and smoke; but on a green lawn in the country nothing can exceed in beauty of contrast the White Hamburgs. Being one color, they can be bred more satisfactorily than either the spangled or Penciled varieties.

Those who intend to keep Ham-

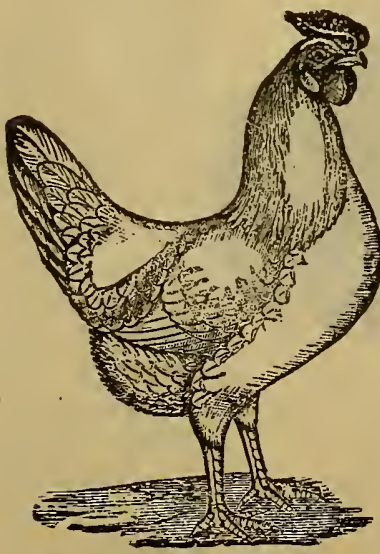

IV HITE HAMBURG. burgs must make up their minds to one of three things: to give them unlimited range or construct high fences; if these two methods are not satisfactory, then cut their wings; for they will fly.

Those who wish to raise fowls for their eggs, and are not particular about breeding pure-bred birds for the purpose, should try a cross of a White Hamburg and good light Brahma hens, the re sult being a cross-bred fowl which will make an unusually good layer, especially during the winter, when eggs are worth far more to sell than they are to keep for

hatching.

White Hamburgs are worth from $\$ 10$ to $\$ 25$ per trio. 


\section{Black Hamburgs.}

The Black Hamburgs are non-sitters, lay medium-sized white eggs, and are the rivals of the Leghorns. Their brilliant black plumage; elegant, broad, rose combs; and handsome carriage place them high on the list as ornamental fowls they are active and industrious where they have free range, and cost very little to keep.

To breed them properly, as regards plumage, great care must be exercised in the selection of both the cocks and the hens. It must not only be black, but a brilliant, lustrous black. A prominent feature is the tail, which should be broad and full, for it adds much to the carriage and general appearance of the bird. The comb, which is denominated a "rose," should be broad, and the points nice and regular; the spike at the rear, which inclines slightly upward, being one of the most important points. The color of the plumage may be considerably brightened by the

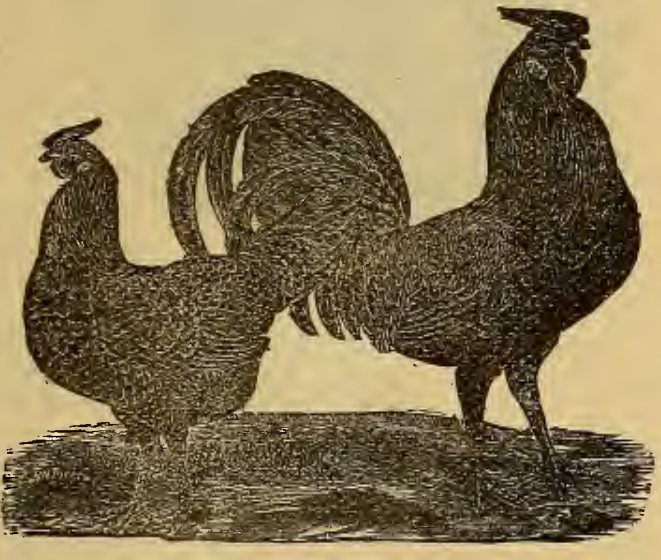

BLACK HAMBURGS. feeding of sunflower seed, or by the use of small quanti ties of linseed meal occasionally. They are sometimes used for crossing with Black Java, Black Cochin, Black Spanish, or Langshan hens. For beauty, eggs, and profit in proportion to cost, the Hamburgs are not inferior to any of our breeds.

July is not too late for hatching Hamburgs, as they mature very early. Like the Leghorn, they lay when four or five months of age, but should be somewhat forced in growth when hatched as late as July.

Black Hamburgs are worth from $\$ 6$ to $\$ 25$ per trio. 


\section{RED CAPS.}

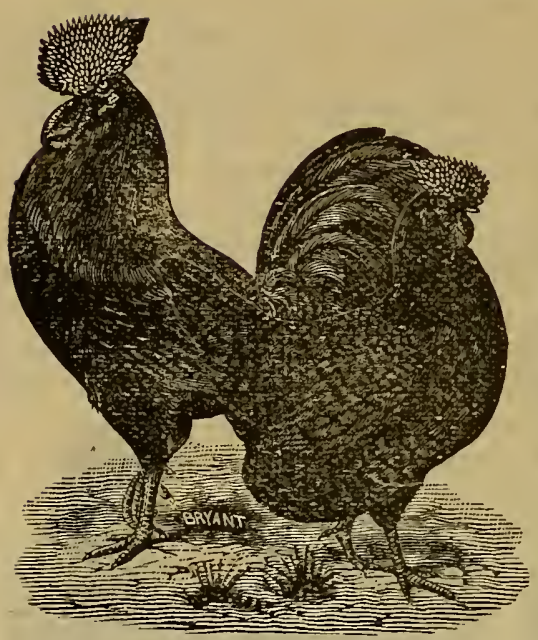

RED CAPS.

Red Caps somewhat resemble the Golden Spangled Hamburgs only they are a much larger bird, with a broaler comb. Plumage as follows: necks blue black, each feather edged with red; breasts and body black; back of a rich dark red, intermixed with black; tail full and well extended, of a rich greenish black color; thighs black, and of med. ium length; legs and toes of a leaden blue shade. They are good layers of a fair sized egg. They are worth from $\$ 15.00$ to $\$ 25.00$ per trio.

\section{SPANISH BREEDS.}

\section{Black Spanish.}

The Spanish are among the old established varieties, and are entitled to all the honors which so characteristically distinguish them. The effect of long and careful breeding is especially observeable in the white face which is most strikingly peculiar to this breed alone. The laying qualities of these non sitters are excellent, averaging about ten to twelve dozen eggs each per annum, when properly managed; though high breeding has perceptibly diminished these qualities in many strains. The egg is proportionately large, with a white, smooth shell, and of delicate flavor, which make it a most desirnble market variety. The pullets usually lay at six 
months old, and will continue through the wiuter; buc the heus rarely begin laying before January, aftel which, however, they seldom stop more than a day or two.

As table fowls they do not present so fine an appearance as their forms when covered with plumage would indicate; and are not as juicy and highly flavored as are those of many other breeds.

Black Spanish are worth from $\$ 600$ to $\$ 20.00$ per trio.

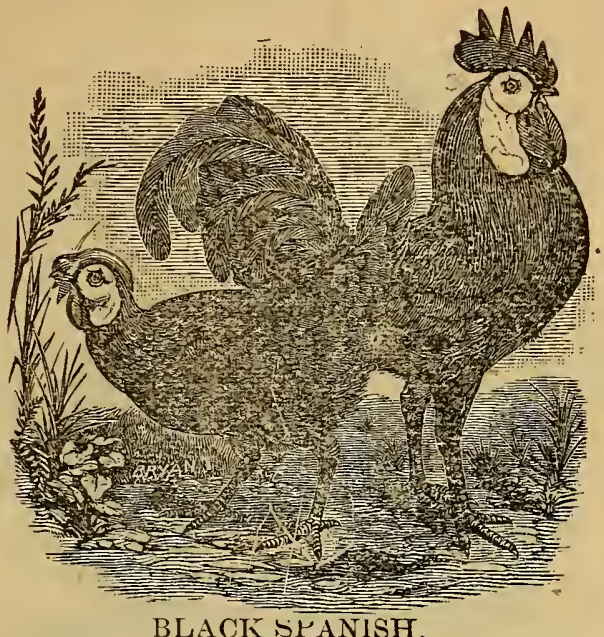

BLACK SPANISH.

\section{THE LEGHORNS.}

We know of no breed of fowls which can be better denominated as "egg machines" than the Leghorns; and farmers who live within a reasonable distance of our large cities are gradually finding out the fact that it pays to breed them for their eggs. As foragers they are unrival. ed; and if they have their full liberty on a farm, they will secure nearly all their living during the summer months. In confinement they may do comparatively well, but it is only when they are un restricted that they return that satisfactory measure of profit of which they are capable. 


\section{White Leghorns.}

White Leghorns are the oldest of the Ceghorn family, and are very beautiful fowls. They have pure white plumage, blood red combs, yellow beak, white ear lobes, and orange yellow legs. They are medium size, beautiful in symmetry; and the carriage of the cock is very stately.

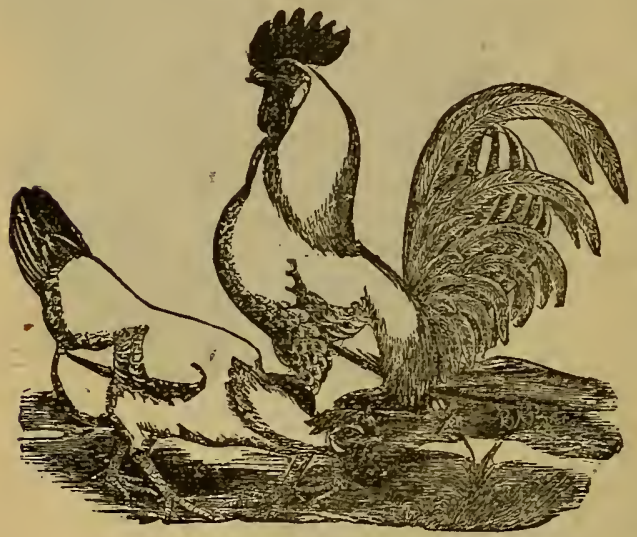

WHITE LEGHORNS. While in disposition they are timid and suspicious, they can be easily tamed so as to be handled. They mature very early; the you ng cockerels often begin crowing when six weeks old, and the pullets sometimes lay before they reach the age of five months. They are good foragers and consume very little food. They are, like the rest of the Leghorn family, the best layers in existence. They are bred with both single and rose combs.

White Leghorns are worth, per trio, $\$ 6.00$ to $\$ 15.00$.

\section{Brown Leghorns.}

Brown Leghorns are the most beautiful of the Leghorn class. They are acknowledged to be the best layer's in existence, laying, if properly bred, a large egg. 'They are of medium size and non-sitters. Every feature commected with them is attractive and pleasing; and in this variety we must recognize one of the leading class of fowi, whether for pleasure or profit. They are great foragers, and in summer if given their liberty need but little 
feeding. They mature early. Cockerels crow at six weeks; and pullets commence laying at three and four montlis, continuing to lay during the entire seasoll. For the table they are muexcelled, the meat being deli. cate and sweeter than that of larger fowls; and the extra cockerels may be arielsly disposed of uthigh príces, where they are appreciated. The chicks are undoubtedly one of the most

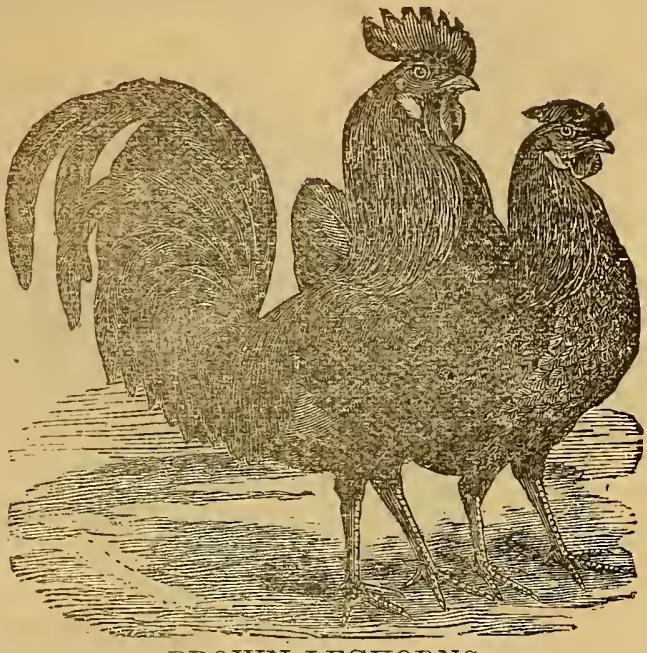

BROTVN LEGHORNS. handsome of all breeds from the shell to maturity. They get their tail and wings when a few weeks old, and are very hardy and easily raised.

Where the winters are serere the Rose-

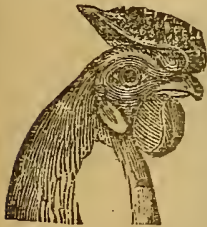
Comb variety of the Leghorn family is the best, as the combs are not so likely to get frost-bitten. Being very active they require an enclosure with a high fence or their wings must be cut to prevent them from fiying. ROSE COMB. Cut the long feathers of one wing only. If as before.

both wings are cut they fly almost as well

Brown Leghorns are worth, per trio, $\$ 5 . \mathrm{c} 0$ to $\$ 15.00$. 


\section{Black Leghorns.}

This is a variety of the Leghorn family that is of com. paratively recent origin, and one which is not often met with. In all respects, except color, they are identical with the Brown and IVhite Leghorns, but are not bred with rose combs, as these varieties sometimes are.

Their admirers say that they are even better layers than any other variety of the family; but the remarlis wi enthusiasts should be taken cautiously, as it seems neerless for any fowls to be more constant layers than Brown or White Leghorns. They are iather larger than the other varieties of Leghorns.

Black Leghorns, per trio, are worth from $\$ 3$ to $\$ 25$.

\section{Buff Leghorns.}

Buff Leghorns are a comparatively new variety, which has gained considerable notoriety; they are similar in all respects to the other varieties of Leghorns except in plumage, which should be of a deep clear Buff color, uniform in shade, except the tail, which should be of a richer deep Buff, or a copperish bronze; the under color of the body feathers may be of a little lighter shade than the surface, and should extend to the skin.

They are valued at from $\$ 10.00$ to $\$ 25.00$ per trio.

\section{Duckwing Leghorns.}

Duckwing Leghorns are quite a new rariety, they are of the same shape, size and style as the other Leghorns, with a plumage and markings like the Game Fowls of that variety; there are two kinds, the Silvers and Golden.

They are valued at from $\$ 10.00$ to $\$ 20.00$ per trio. 


\section{MINORCAS.}

While this breed has been popular in England for some time, it has only been within a few years that it was introduced into the United States. It closely resembles the Leghorn, but has a larger comb; has red ear-lobes, and is said to be eren a better layer. They are both white and black.

Either variety are worth from $\$ i 0$ to

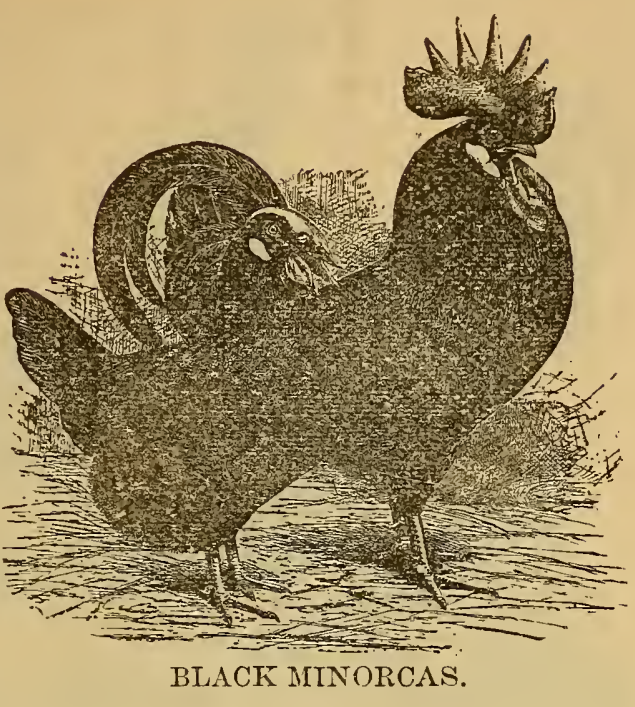
$\$ 30$ per trio.

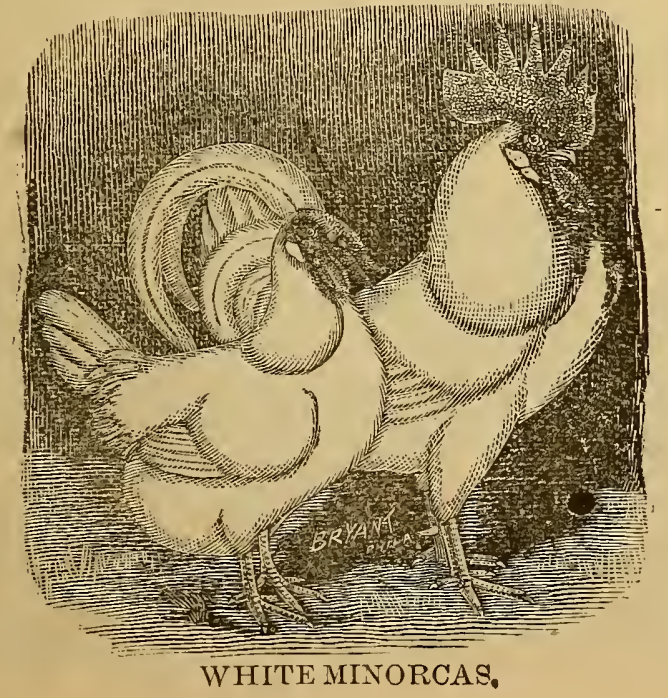




\section{ANDALUSIANS.}

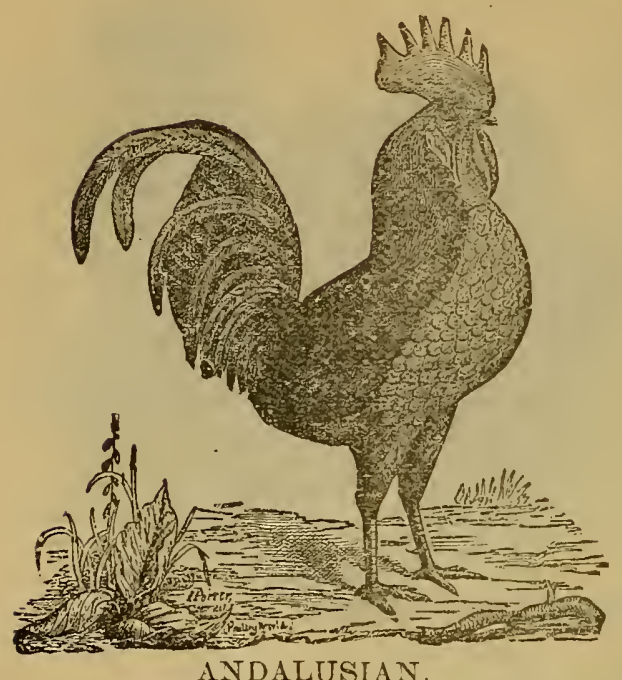

These fowls are of Spanish origin, and have curious slate. blue plumage. They are of fair size, and are said to be most excellent layers of large eggs which are of an exquisitely delicate flavor. The young chiclis feather fist, and are quite hardy. Coming from a warm climate, this breed is not adapted to localities where the winters are long and severe.

This breed has not hecome very popular, although for no apparent reason as they possess some very valuable qualities.

The Audalusian must be considered a truly useful and handsome fowl; being, according to general testimony, the hardiest of all the Spanish breeds. This breed appears each year to inclease the number of its admirers, and may very probably attain in time to a distinct class of its owll.

Andalusians are worth from $\$ 8.00$ to 25.00 per trio.

\section{CAMPIONS.}

The Campions are comparatively a new breed of a mediteranian origin; they are about the size and shape of the Leghoin, with a nedium sized single comb, evenly serrated, which with the wattles and eal'-lobe is of a liglit red. Color of plumage: hackles silvery white, back and breast silvery white, spotted with black; wings black, 
barred with white; tail sickle feathers large and full, d e e p black edged, with white or grey; shanks of medium length, of a blue slate color. There is also a golden variety sinilar to the silver, ex cept i n plumage, which is of a golden bay

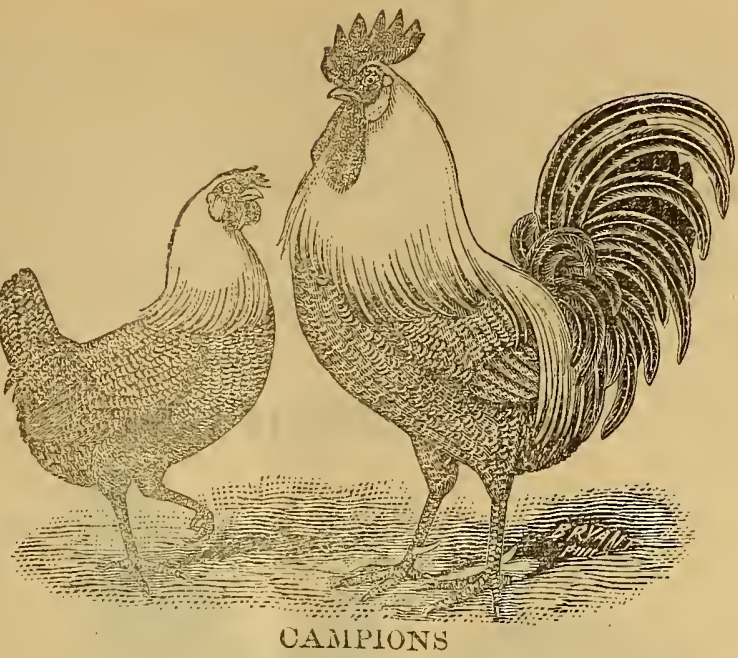
with black markings. They are good layers of medium sized eggs. They are valued at from $\$ 10$ to $\$ 25$, per trio.

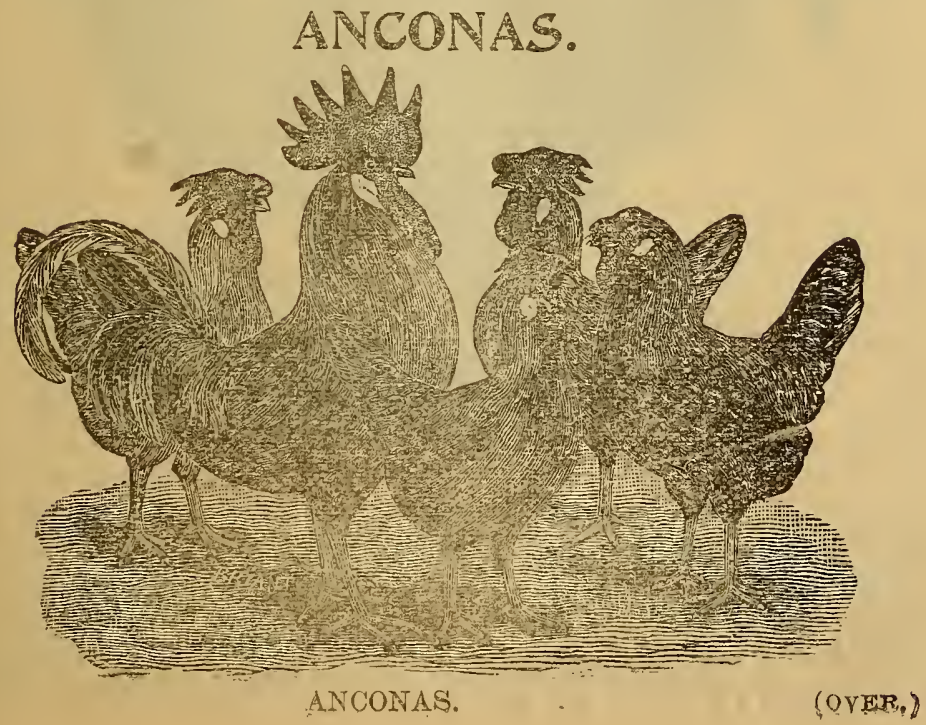


Anconas are a comparative new breed for this country, and are of a mediteranean origin. In style and shape they are similar to the Minorcas; they have large red single combs; the male birds being straight and upright, while the females droop on one side; the face and wattles are bright red, while the ear-lobes are pure white; the plumage is a white ground, with each feather spotted with black. They are as hardy as the Minorcas and equally as good layers. They are worth from $\$ 15$ to $\$ 25$, per trio.

\section{SICILIAN.}

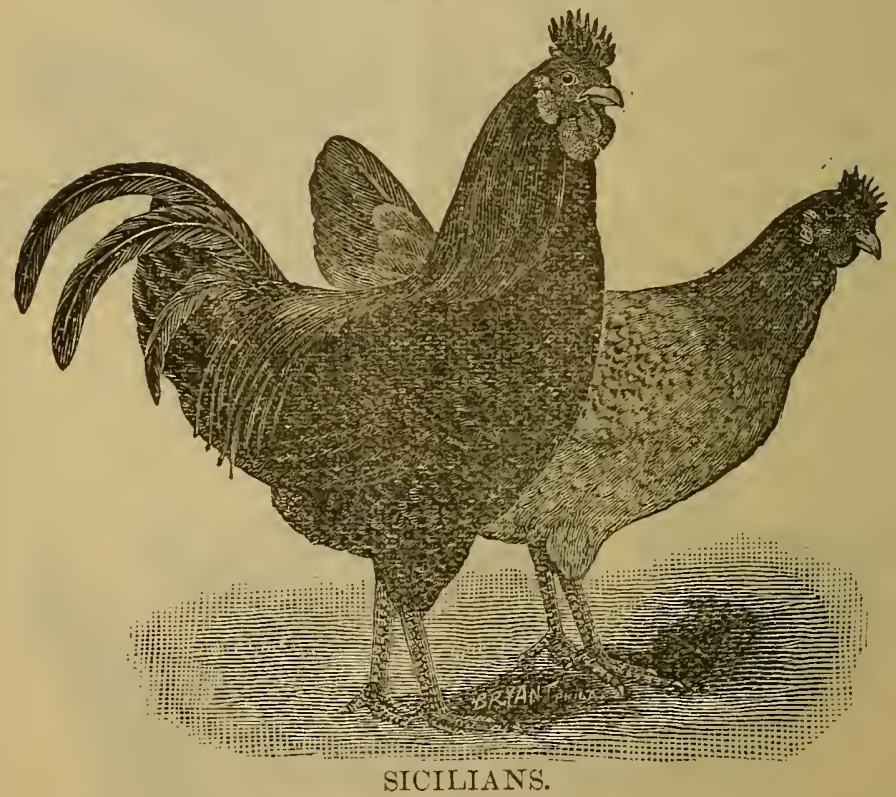

Sicilians are a breed of fowls supposed to have originated in the Island of Sicily, they are quite scarce in this country, and are seldom met with at our poultry shows. They are about the size and shape of the Hamburgs; they have cup shaped combs, evenly scrrated around the edges, red in color as are also their faces and wattles, 
while the $\epsilon$ ar-lobes are a biuish white. The plumage of male bird is a bright red, with the centre of each feather marked with black; the plumage of the hen is of a lighter shade, approaching buff; with each feather marked with black; the tail is full and drooping of a dull black color, each feather edged with brownish grey; shanks of medium length and of a slatish blue color. They are good layers, but their eggs are small, their meat is fine grained, white and delicate.

Sicilians are valued at from $\$ 10.00$ to $\$ 25.00$, per trio.

\section{THE GAIIE FOWIS.}

The modern English Game Fowl occupies the same position among the gallaniceous order that the English thoroughbred horse does among the equine, or the greyhound among the canine races.

With his clean head, bright eye, strong beak, lanky neck, broad shoulders, powerful thighs, and long strongboned legs, symmetrical taper of body, smooth and brilliant feather, he is the very beau-ideal of a Game bird, and a triumph to the oreeder.

There is not much wonder that the pure bred Game fowls are so much admired, even by those who do not care to breed them; for they are typical of strength, courage, and endurance; and their handsome plumage is still another item in their favor. From time immenorial the Games have had great attention paid to their breeding, care, and management; and there is no other variety of fow is which can boast of a longer line of pure bred ancestry tnan can the Games. There are several different varieties of the Game fowl, though they are very much alike in the general characteristics of form, courage and endurance. The Black Breasted Reds shown in the following illustration, are more largely hren. than any other variety. This variety, therefore, is now rather easier to breed than the others. 


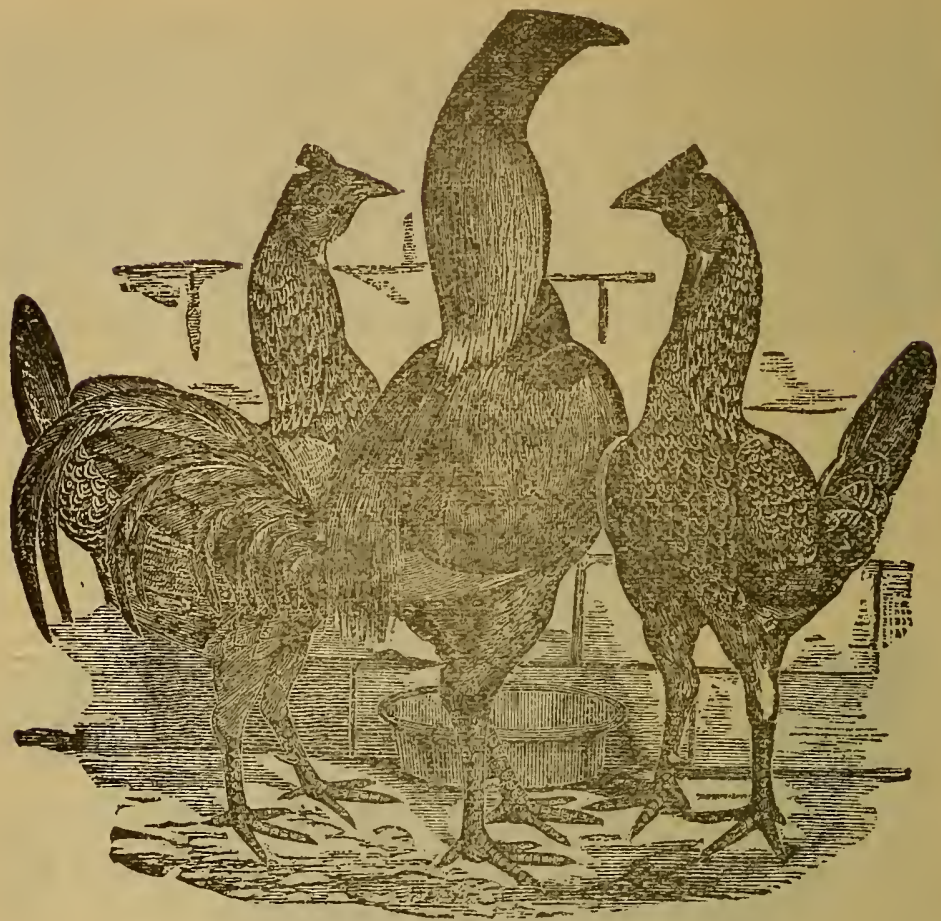

BLACK BREASTED RED GA.ME FOWLS.

Breeding Pit Games - tho e for the pit exclusively -- is a very fascinating occupation, to many breeders; and the "champions" rearlily bring good prices. Pit Gamss are not, necessarily, of any particnlar breed, but are generally made-up from the staunchest, gamiest of other game breeds. Some breerlers now have strains of pit games that cannot be excelled, and are well known and eagerly sought after by the sporting fraternity in all parts of the country. We like the Games for their gamy qualities and for their ability to produce a valuable and profitable cross with the larger breeds of fowls, such as the Brahmas and Cochins. The best winter layers we ever saw-and we have seen and had some fine ones-were made up of a cross between a Game cock 
and a Light Brahma hen They are good layers, the best of mothers, quite hardy, and for the table, their flesh is said by epicures to far excel that of any other fow 1 . There are almost innumera. ble varieties of this breed, all of which have their good points.

The combs and wattles of Game cocks are always "dubbed." The trimming should

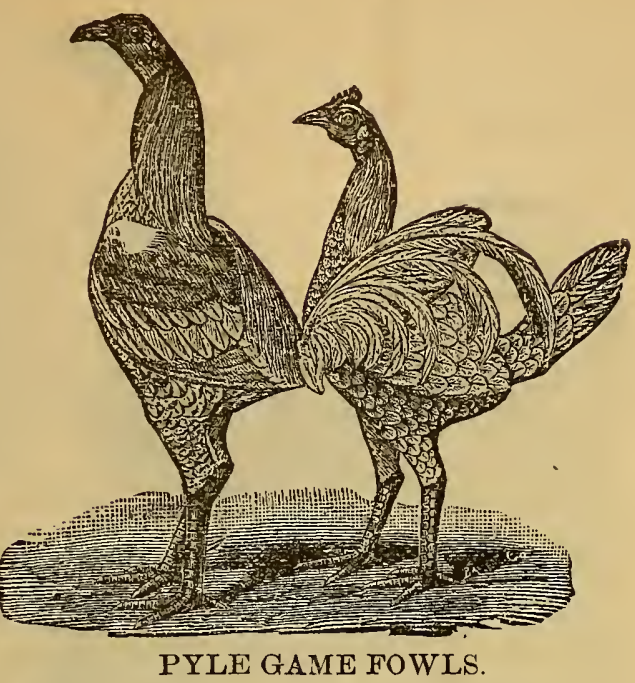
not be too close, and should be done with a pair of sharp shears, as the work done with a knife will produce too much bleeding, which must be avoided. Undoubtedly the suffering is severe during the operation of cutting,

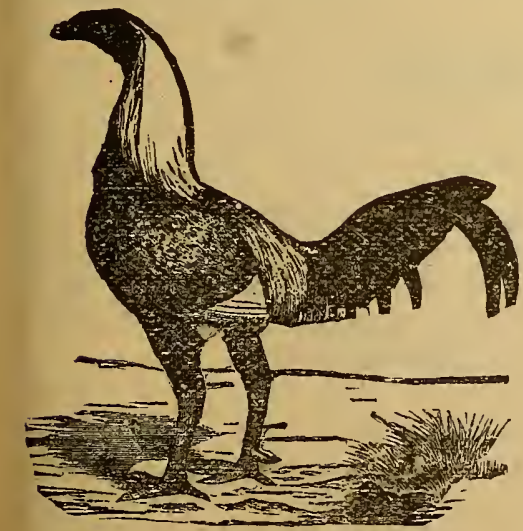

DUCKWING GAME. but it is quickly through with. So unconcerned does the fowl appear when placed on the ground after the operation, that instances are found where the bird turns about and falls to eat its own comb and wattles. The recognized varieties of exhibition Game fowls are Black, Black breastedRed,Blue, Brown-red, Silver and Golden Duckwing, Ginger Red, and Irish Gray, Red and White Pyle, 


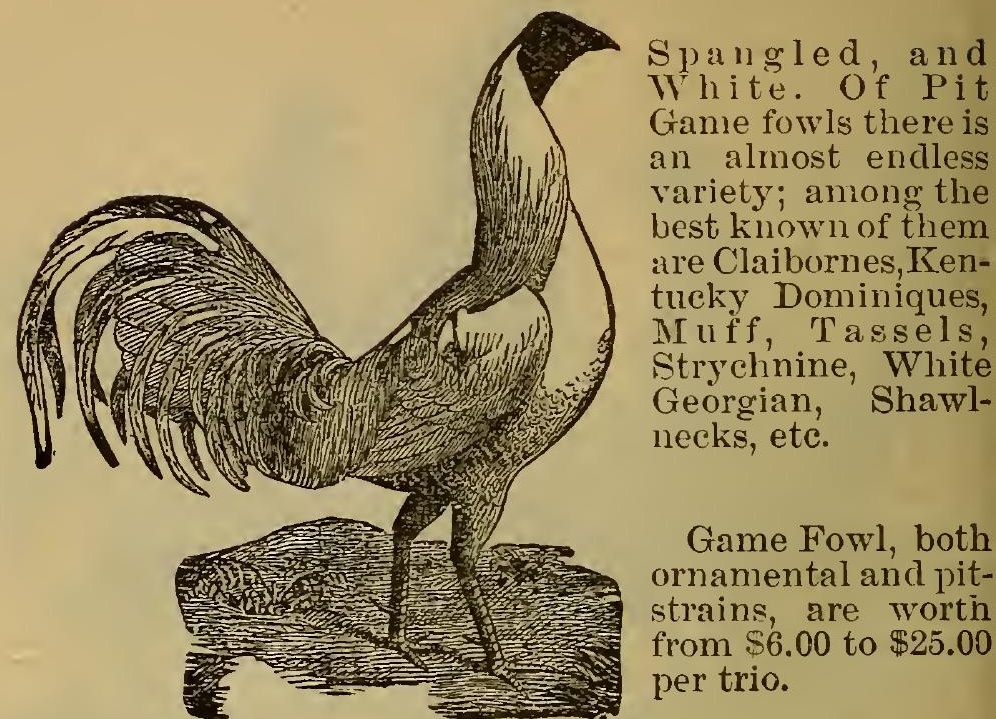

WHITE GEORGIAN.

\section{BIRCHEN.}

The Birchen Games are a new variety similar to all other Games except in color, which is as follows: beak black or dark brown, eyes black or dark brown; face, comb, wattles and ear lobes dark purple or black; hackle silvery white with a narrow black stripe through the middle of tne feather, as also is the back of the male bird, while the breast is of a black ground erenly laced with silvery white; wing covers and tail a glossy black; shanks and feet a dark willow, or nearly black. The hen is black except in neck hackle, which is similar to the cock.

They are valued at from $\$ 10.00$ to $\$ 25.00$, per trio. 


\section{MALAYS.}

The Malays are a variety of games that will fight with their natural spurs, indeed they are very quarrelsome, but will cow when they feel the steel.

Their prineipal merit is their strange appearance and value as a cross upon other breeds. Mated with the Dorking they are said to produce splendid fowls for table use and which also lay well; and with the Black Spanish, while both parents are long legged, the result is usually a short legged fowl of peculiar beauty in plumage and

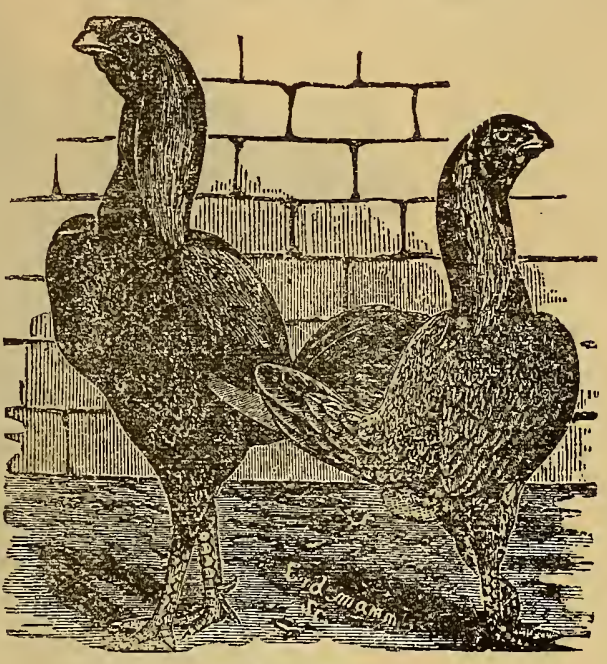
extraordianary good sitters and mothers.

The shicks are rather delicate, but the adult birds are hardy enough. The hens are inferior layers. The most objectionable fault of this breed, however, is their abominable quarrelsone disposition, which becomes worse the more they are confined. There are blacks, reds and whites. Malays are worth from $\$ 10.00$ to $\$ 20.00$ per trio.

\section{CORNISH INDIAN.}

The Cornish Indian Game are a cross-breed between English Game and the Malay, they very much resemble the latter except they are a little darker in plumage, have a pea comb, and are somewhat larger in the legs; they have a fierce bold expression, but are not very cour. ageous when pitted against a thorowghbred Game; they 
are fille layers of a good sized eg $\mathrm{g}$; and their table quality is excellent, their meat being fincgrain ed, white and delicate.

They are valued at from $\$ 10.00$ to $\$ 20.00$, per trio.

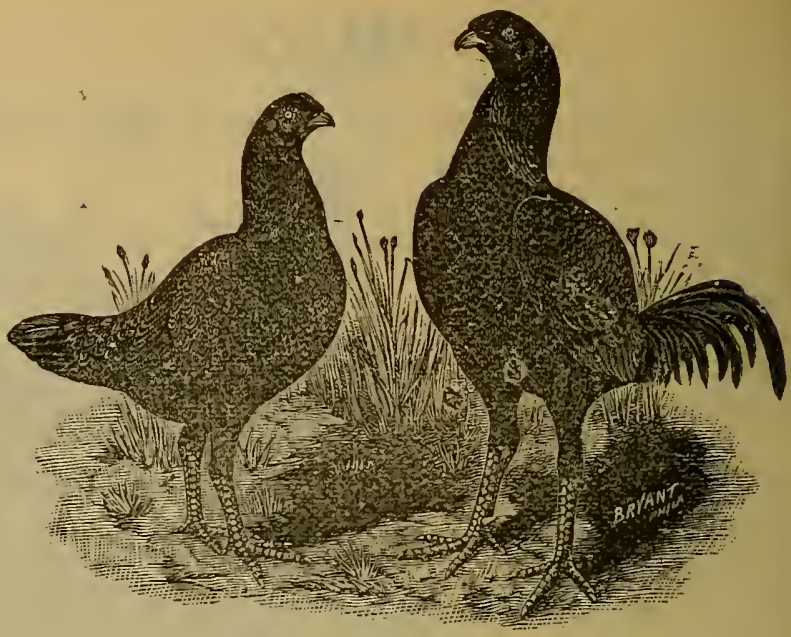

CORNISH INUIANS. 
Sumatras are a specie of the Game family, they are a handsome fowl of medium size, with characteristics somewhat similar to Games; they have a very rich lustrous black plumage throughout; wattles short; beak of medium length; eyes very bright, of a dark brown

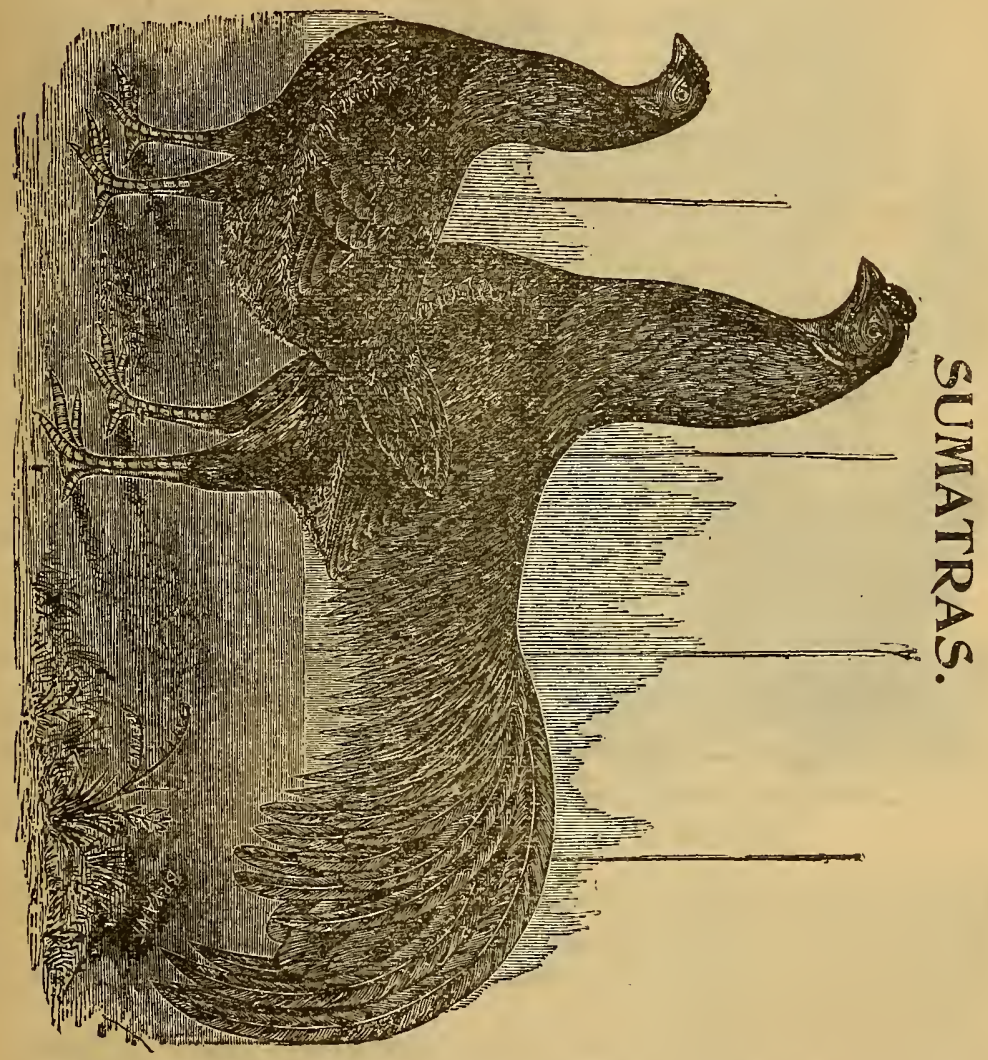

or black color; comb pea shaped, small and dark red in color as are also the wattles and ear-lobes; body firm and muscular; tail long and drooping; shanks of medium length, of a dark olive or leaden black color. They are fair layers, but not a very hardy breed for this climate. They are worth from $\$ 10.00$ to $\$ 20.00$ per trio. 


\section{MISCELLANEOUS BREEDS.}

\section{Black Russians.}

These fowls were introduced into the United States with considerable flourish of trumpets some years ago, but they failed to sustain the reputation given them by

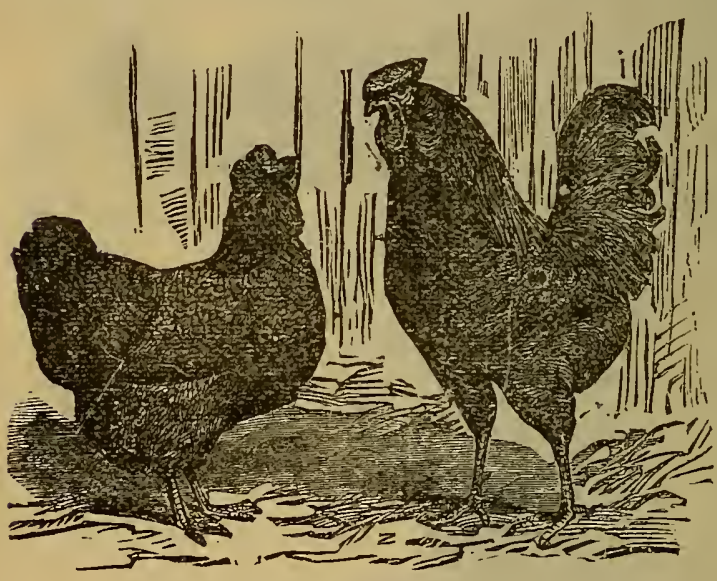

BLACIK RUSSIANS.

those who in1ported them. 'They are decidedly rough looking fowis, orna me nted with tufts of feathers on each jaw and a $n$ abundant beard of feath ers under the jaw. In Europe they are bred in white, buffi, and mixed colors, as well as black. They are fairly hardy, small eaters, but poor layers. In size they are about as large as the comnon barn-yard fowl. On the whole, we should not recommend the breed as one that will give satisfaction.

We do not breed them, but can generaliy procure them for those who would like to give them a trial, after the any-thing-but-flattering statement given above concerning the merits of the bird.

. Black Russians, per trio, are worth from $\$ 10$ to $\$ 20$. 


\section{FRIZZLED FOWLS.}

This is one of the most curious of fow ls. 'The fathers all turn the wrong way, as if in rebellion against the laws of nature. This is most noticeable with the hackle feathers, but the entire plumage is more or less arranged this way. They are of no practi cal use, and are only bred as a curicsity. They are of all colors and parti colors.

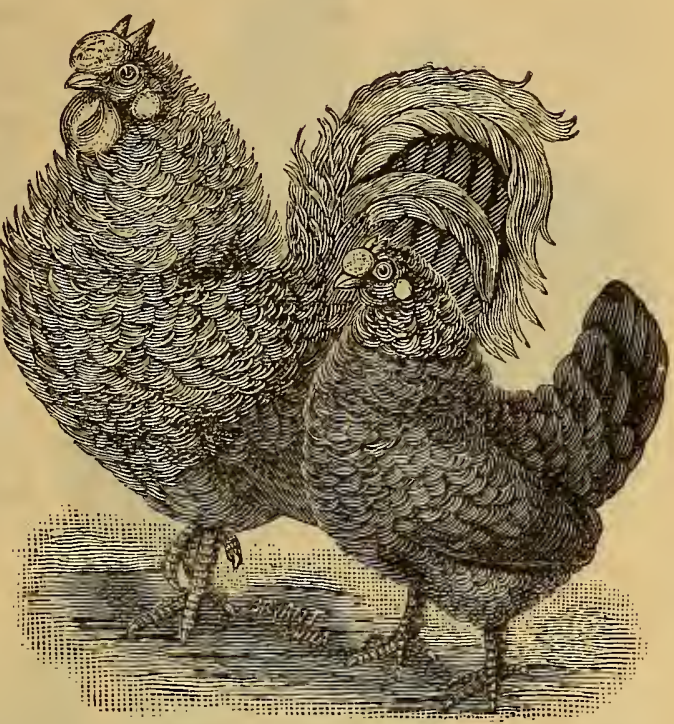

FRIZZLED FOWLS

Frizzled Fowls are worth from $\$ 10.00$ to $\$ 25.00$ per trio.

\section{RUMPLESS FOWLS.}

Rumpless fowls are of various colors, the only essential characteristic being the absolute want of a tail, or of any approach to one. It is, indeed, exceedingly difficult to breed any particular color, as few persons have interest in the breed sufficient to persevere long' enough for securing uniformity.

The handsomest are white; black also look well ; but speckled are the most common. The sizealso varies very much, ranging from three to seven pounds. Combs rather large and thin; legs usually lead color, but occasionally yellow.

As layers and sitters, they are identical with the barn. 


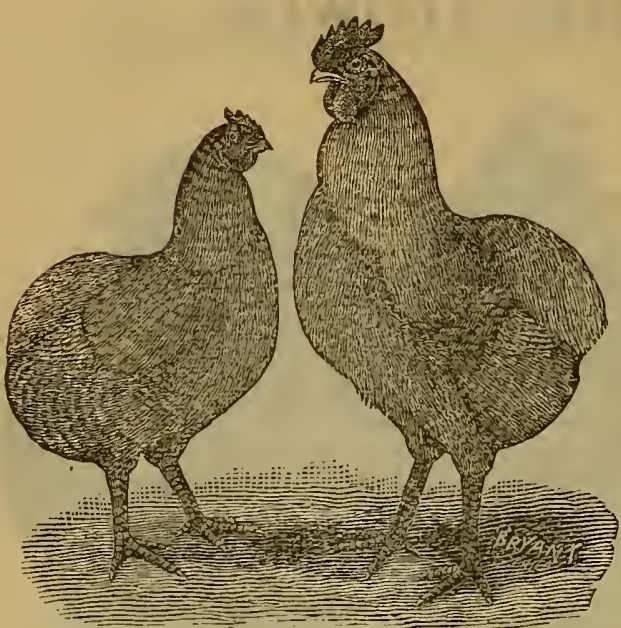

RUMPLESS FOWLS. yard fowls. Their shape commends them for a table fowl.

Some authorities say the eggs are very apt to prove sterile. 'T'ney dress more showy than any other fowl, the hind. el parts being more plump and round, without projection for tail, as in others.

Runipless Fowls are worth, per trio, from $\$ 8.00$ to $\$ 20.00$.

\section{SULTANS.}

These fowls, which rather resemble the Polish, were imported originally from Turkey, and are scarce even there. In general habits they are brisk and happy tempered, and fair layers of large white eggs. They are non-sitters, and small eaters. Their plumage is white, with full - sized compact tuft on the head, bearded as in the Polish; good flowing tail, and short well - feathered legs. They have the quaint little ways and habits of the

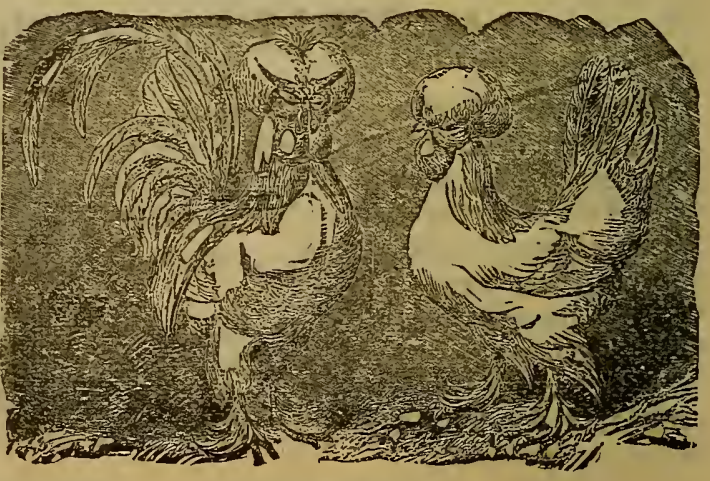

SULTANS. 
Bantams, and take petting with a confidence that makes them favorites with their owners.

Of course, this variety is not suitable for purposes of general utility, and can only be recommended to persons who want an ornamental fowl, not given to hatching, and that will do but little harm to any well kept barn.

The cock's spurs are peculiarly liable to grow very long when the fowl gets old; and so much curved that the point enters the leg and causes much pain. This should be guarded against and if necessary the spur shortened sufficiently to prevent such consequences.

Sultans are worth, per trio, from $\$ 10.00$ to $\$ 15.00$.

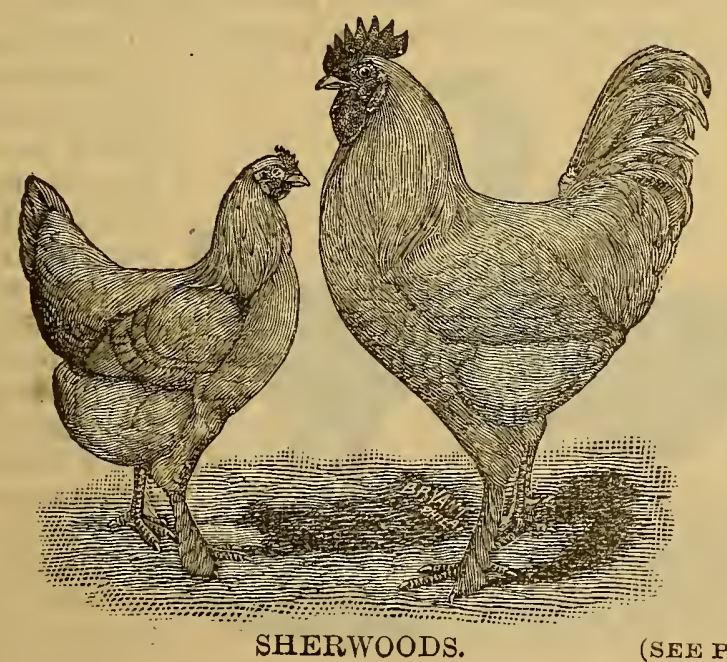

SHERWOODS.

(SEE PAGE 30.) 


\section{GAME BANTAMS.}

At all poultry exhibitions, the hens of these little beauties are continually surrounded by admiring visitors. Not only from the ladies, whose ey for the beautiful is not to be questioned, but, on all hands are heard exclamations of praise, which, were they not so truly deserved, would certainly not be so willingly given. 'Their graceful form, beautiful plumage, sprightly bearing, and dininutive size have alone made them such general favorites. Their contribution to the egg basket, in comparison to their demand on the grain-bin, is certainly a good one. Their fine-grained flesh is delicious. Their contented disposition and limited amount of room they require make them desirable, where more pretending, though perhaps less worthy varieties, could not be thought of.

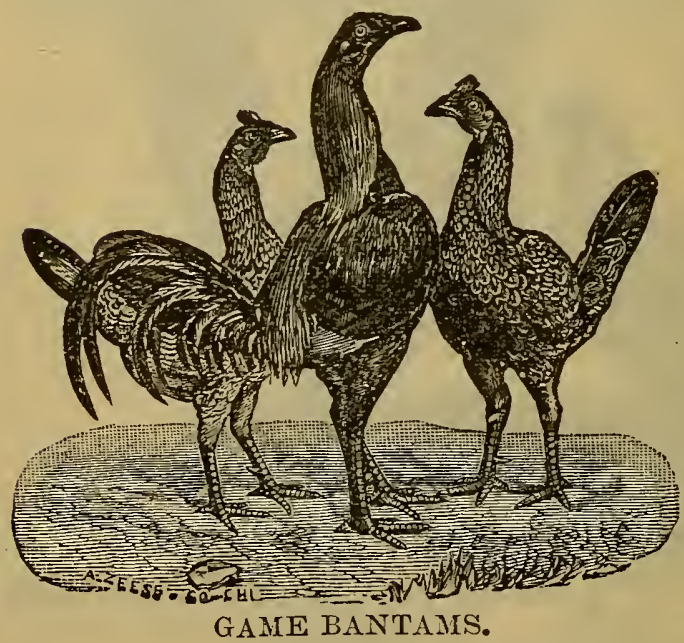

No fowls will afford more pleasure to their keeper than these little pets. The clear merry crow of the cock, his proud strut, and readiness to defend himself and his mates against all attacks are a continual source of amusement ; while the nimble little hell, ever on the lookout, and guardiug her brood with the most unremitting care, cannot but be admired by anyone who will watch the graceful movement of her stylish little form. Of the many varieties kept at different times, none will give more pleasure and satisfaction. On account of their diminutive size, many at once class them as a delicate variety. This is, however, an error, 
which a little time given to the rearing of them will soon expel. They mature rapidly, and being good foragers, the young soon say good-by to the old hen and look out for themselves.

Game Bantams come in the same varieties as the Jarge Games. The males should weigh under twenty-six ounces; females under twenty-four ounces.

They are worth, per trio, from $\$ 6.00$ to $\$ 25.00$.

\section{BANTAMS OTHER THAN GATIES.}

These dwarfs of the fowl family are amoug the most desirable pets that can be given to a child, aud even grown people cannot help admiring their great beauty as they run about a lawn. All the varieties of Bantams are bred nowadays for pets; and their diminutiveness and other qualifications of fine plumage, form, and carriage being retained, is quite a desideratum.

The Fall of the year is the best time to hatch this class of birds. They are generally a tender chick to rear, but with average good care these little birds will mature well after hatching in August or September. The cooler weather retards their growth, and they are thus kept from attaining the stout proportions of those of their race that are hatched at an earlier period in the season.

Those who aim to breed the smallest specimens of the respective varieties, who hatch their chickens in the Fall, will find their birds next Spring, on the average, one-fifth less in weight, and, with proper attention, quite as healthy, as well formed, and as perfect in general developement and feathering as their earlier hatched brothers and sisters of the same species. This fact is worth understanding by those who covet the smallest Bantams. 


\section{White=Booted Bantams.}

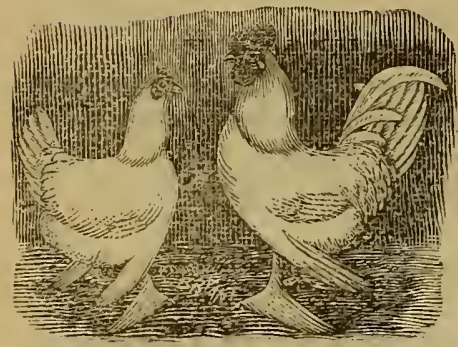

Very pretty feather-legged White Bantams are sometimes seen, which make exceedingly nice pets. These Bantams are worth from $\$ 8.00$ to $\$ 25.00$ per trio.

WHITL BOO'TED BANTAMS.

\section{Black Rose $=$ Comb Bantams.}

Black Rose Comb Bantams are of diminutive size, the hen weighing about two ounces less than the cock. The plumage is of a very rich blooning biack. The comb is of the rose order and the earlobe, a pure white. The carriage is very proud and stately, and the cocks are very courageous and will without hesitation attack any large fowl that encroaches on their territory.

They are hardy, and moderately good layers. The young chicks are not difficult to rear.

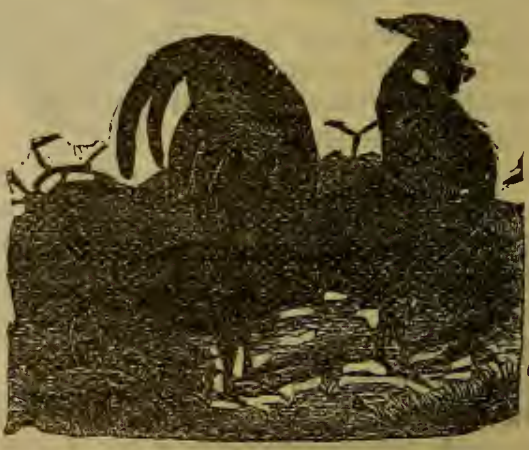

BLACK ROSE-COMB BANTAMS.

These Bantams are worth from $\$ 5.00$ to $\$ 20.00$ per trio. 


\section{White Rose $=$ Comb Bantams.}

Except that the legs are white, this variety of Bantam is identical with the Black Rose Comb Bantam, excepting of course, in color of plumage. They shuuld be as small as possible, and the earlobes must be white. The single comb, which will sometimes appear in the off-springs of the best strains, disqualifies them as show birds. They are very tame, and can readily be taught to fly up on their owner's shoulder; and in fact are one of the best and prettiest of the Bantam family. They are valued at from $\$ 5.00$ to $\$ 15.00$ per trio.

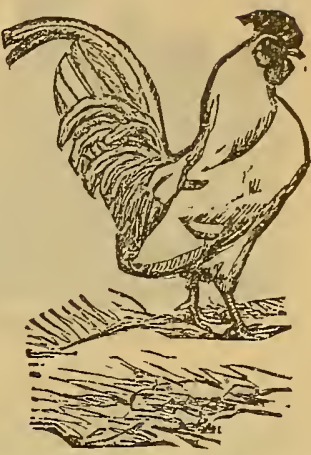

WHITE ROSE.COMB BANTAMS.

\section{Seabright Bantams.}

The Seabright Bantam is of two varieties, called respectively Gold and Silver, from the ground color of the plumage, which, in one case is a golden brown and in the other a clear white. In perfect specimens every feather is laced or margined all around as shown in the

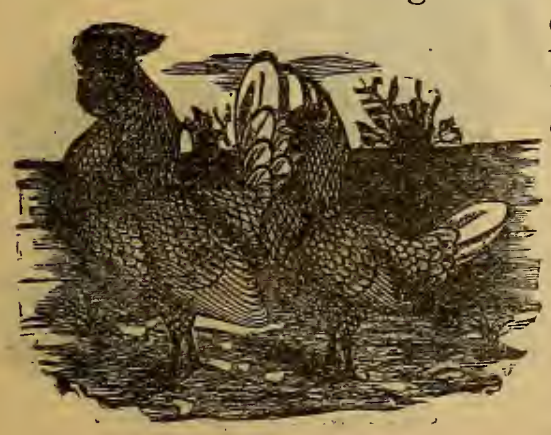

SEABRIGHT BA NTAMS. engraving. The tail of the cock has 110 sickle feathers, but is like that of the hen.

They are among the smallest and most beautiful of Bantams. The only objection to them is that their eggs are more prone than other varie. ties to be unfertile.

Seabright Bantams are worth $\$ 6$ to $\$ 25$ per trio. 


\section{Cochin Bantams:}

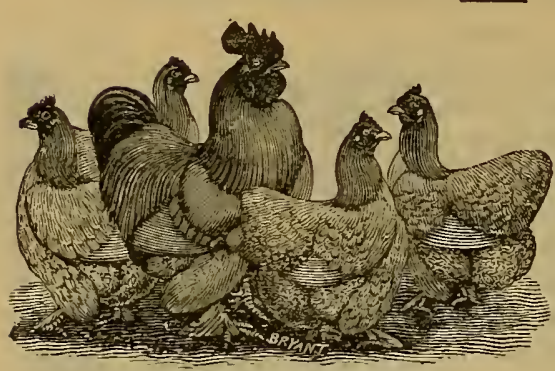

COCHIN BANTAMS.

This pretty little Bantam, as might be supposed, are of $\mathrm{Ch}$ in es e origin. It is a diminu tive Buff Cochin, but still shorter in the legs than the larger variety which it so much resem. bles. The chicks thrive and feather well and are generally full fledged when two months old, at which age they are very hardy. In disposition, they are quiet and gentle and much attached to each other.

They also come in White, Black and Partridge colored varieties. They are worth from $\$ 10.00$ to $\$ 25.00$ per trio.

\section{Japanese Bantams.}

This interesting variety, which is said to have been brought from Japan, makes most pleasing pets for children. Their quaint ways, upright carriage, and the long streaming sickle feathers of the cocks, all combine to make them one of the most attractive kinds of Bantains.

They are very hardy, the hens good layers and attentive mothers; while the chicks mature early and are easily reared. The only objection to them, is that they are apt to be too large if not hatched late in the season. The plumage is white, with black tail, but the hackle has often

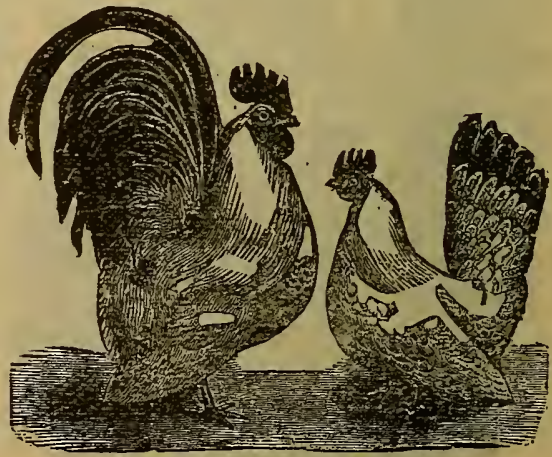

JAPANESE BANTAMS. 
a few black feathers in it. The comb is bright red, very large, and single, with deep serrations. The tail is very large, expanded, and carried so upright as in the best specimens to come in contact.with the head. The legs are free from feathers, and bright yellow in color.

There is no Bantam that can be recommended more highly than the Japanese.

There are also pure white, and pure black varieties.

They are valued at from $\$ 10.00$ to $\$ 25.00$, per trio.

\section{White Polish Bantams.}

The White Polish is a pretty little fowl, resembling in appearance the large variety by the same name, except, of course, in size, which is quite diminutive. They do no scratching to injure anything in a garden. They may be kept in the same yard with other fowls without any danger of crossing. In disposition they are quiet and gentle, and become with proper treatment, very tame. They are said to be good layers and excellent mothers.

This variety is quite rare, and the price of them is away up in the fancy figures, fowls selling for $\$ 15.00$ to $\$ 25.00$ per trio.

\section{Silkies.}

These are very pretty, interesting little creatures, but altogether fancy fowls, utterly useless for table or market. Their bones and flesh are coal-black, while, strange to say, their plumage is snowy white, soft and silky, resembling spun glass. Their eggs, though small, are said to be excellent; they are pinkish white in color something like those of the Bantam. The cock is a pattern of fidelity and gentleness; he assists his partner in the care of her family, and even acts as nurse. The hen is the best of foster mothers for Hamburgs and Polish, their soft, warm feathering tempting these delicate little 
fastidious beings to look to them for protection.

The points of a Silkie cock are: plumage, white; crest, small, low, and set far hack on the head; comb, darkreddish purple; earlobes, turquoise blue; wattles, purple; legs, eyes and beak, jet blick; tail, full, but not with

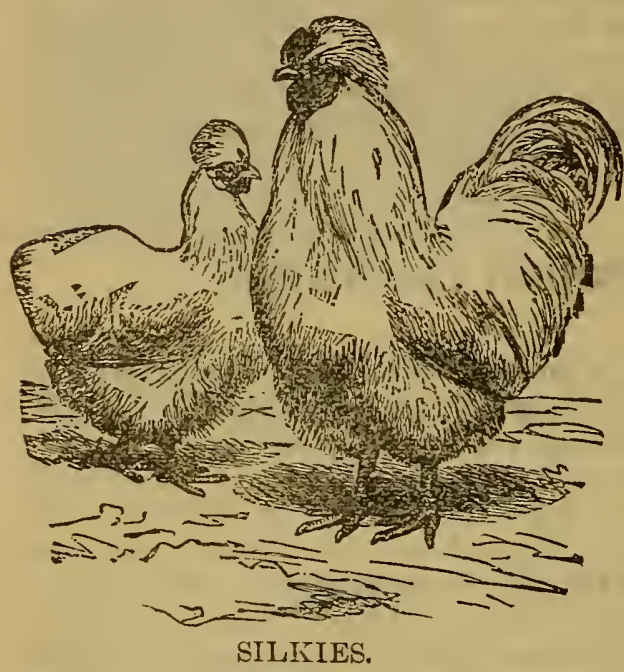
many sickle feathers; body, low-set but large, and broad in the breast. Hen precisely similar in points, except the tail, which in her consists of a small bunch of feathers like marabouts. Her comb also is smaller, and crest or tuft, larger.

Silkies are worth from $\$ 12.00$ to $\$ 25.00$ per trio.

The following varieties of other than Game Bantams have lately been introduced, namely: Rumpless, Frizzle, Bralnma, Minorca, and the different varieties of Leghorns, all of which are similar in every respect to their namesakes of the larger breeds of fowls. In weight they range from twenty-two to twenty-six ounces for males, and twenty to twenty-two ounces for females.

Any of these varieties are worth from $\$ 10.00$ to $\$ 25.00$ per trio. 


\section{GEESE.}

Geese kept for profit will thrive in a pasture without water of sufficient depth for swimming, but some people keep geese partly for pleasure; and it is better, where water-fowl may have a place, to keep them in such a manner that they will please the eye, for they may in due time please the palate just as much. They begin laying when about a year old, producing very large white eggs, having thick shells. The period of incubation is thirty days; and, owing to the thickness of the shell and toughness of the lining, it is very important in the last part of the sitting that the nest be dampened by sprinkling tepid water, if hens are used. Geese bring moisture to their nests in their feathers, by walking through the dewy grass in the early morning. Four eggs may be placed under a large hen; a goose will cover ten, and generally take good care of them, showing determined resentment at any intrusion. The gander also manifests a decided interest, guarding the nest and defending the sitter with bill and wing.

In some localities, breeding geese for their feathers will be found to be very profitable. Sevcral pickings can be made in a season. Geese are particularly self-supporting on a pasture, pond, or river. They come up regularly at night to their pen. They will thrive where other fowls would starve; and have no competitors except ducks. Their carcass is salable, the only objection to it being the dark color of the flesh; but it is juicy and most excellent eating. When the goslings are hatched they should be kept up until they are old enough to graze well; and after that they will take care of themselves. Always feed them in the evening in their pen, to accustom them to coming home at night. In the winter feed to the geese corn and boiled potatoes and meal mixed with warm water or skim milk.

\section{TOULOUSE GEESE.}

The Toulouse heads the list as the largest of all. The plumage on the colored parts is gray, lighter in shading on the neck and breast than on the wings; the back part of the body is pure white in plumage. They have reached the 
enormous weight of sixty-eight pounds per pair: They are very hardy, are not noisy, and are easily raised. Their heavy bodies admit of their being confined by a low fence.

The geese lay thirty to forty eggs each in a season, and seldom offer to sit. We find them good to hatch, easy to raise, and much stronger when young than common goslings. They grow so rapidly, that at four weeks they will. weigh from six to eight pounds each; and at three months, fifteen to eighteen pounds. They yield half a pound of feathèrs to a "picking." "They are small feeders for their size; and

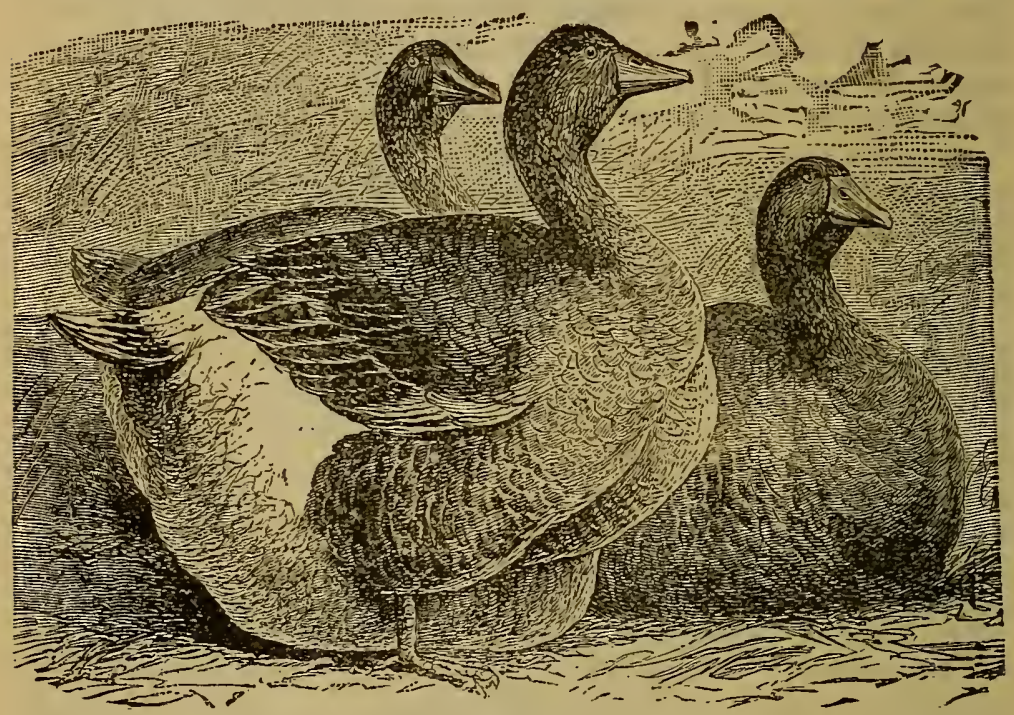

TOULOU $\$ E GEESE.

require no food but pasture, except in winter. In color, geese and ganders are exactly alike, viz.: a uniform, handsome gray, with breasts and under parts of body a shade lighter. They are gentle in disposition, not unruly, and can be fenced easier than sheep; breed at one year old; and in all respects are very profitable. The sexes can be distinguished by their forms and voices: ganders are taller, more upright, with larger necks; and gobble in higher, finer, and more rapid tones than the goose, the voice of which is low. deep bass, and slow. Price per pair, $\$$ ro to $\$ 20$. 


\section{EMBDEN GEESE.}

Embden Geese are uniformly pure white, have prominent blue eyes, flesh-colored beak, bright orange legs, remarkably strong in the neck, and their feathers tend to curl from the shoulders to the head. They are very hardy and well adapted to any climate. Their flesh is highly esteemed by epicures. It does not partake of that strong taste noticeable in common geese, it is as tender and juicy when properly cooked as that of any of our best wild and aquatic fowls, and is less liable to shrink in the process of cooking.

Embden Geese attain large size, in some instances a pair will weigh fifty pounds; some have reached up to sixty pounds, but the average weight when in good condition is about forty pounds per pair. They are very good layers,

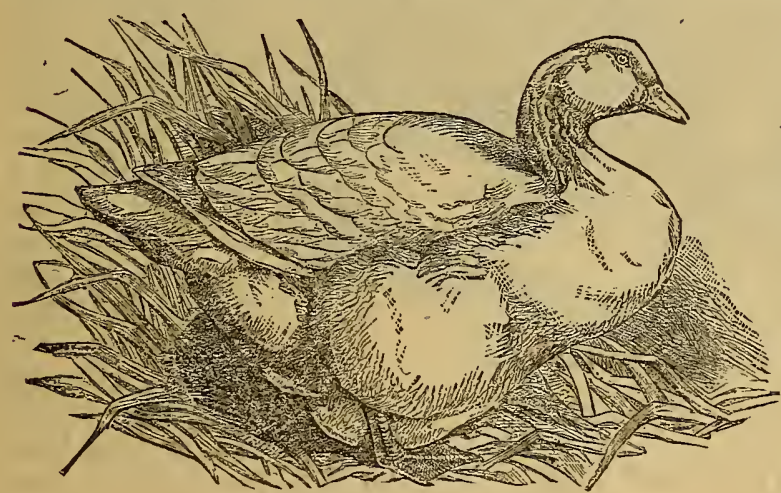

EMBDEN GOOSE

taking into consideration their size ; - but, like the Toulouse', are poor sitters, o w ing to their weight and cumbrous movements.

A large pond or extent of water is not abso-

lutely necessary for the Embden Geese, though a pond or stream near-by would be very advantageous toward improving their plumage and affording them agreeable exercise. Breeders most generally set their eggs under hens, and give them the same care and food as other valuable geese. The goslings, though strong and hardy when hatched, are somewhat clumsy, and should be kept within a low inclosure, where there are no weeds nor long grass to bother them until they are a few weeks old.

Embden Geese are worth $\$ 5.00$ to $\$$ ro.oo per pair. 


\section{EGYPTIAN GEESE:}

Among ornamental water fowl the Egyptian Geese take a high place. They are a part of the hieruglyphics of the

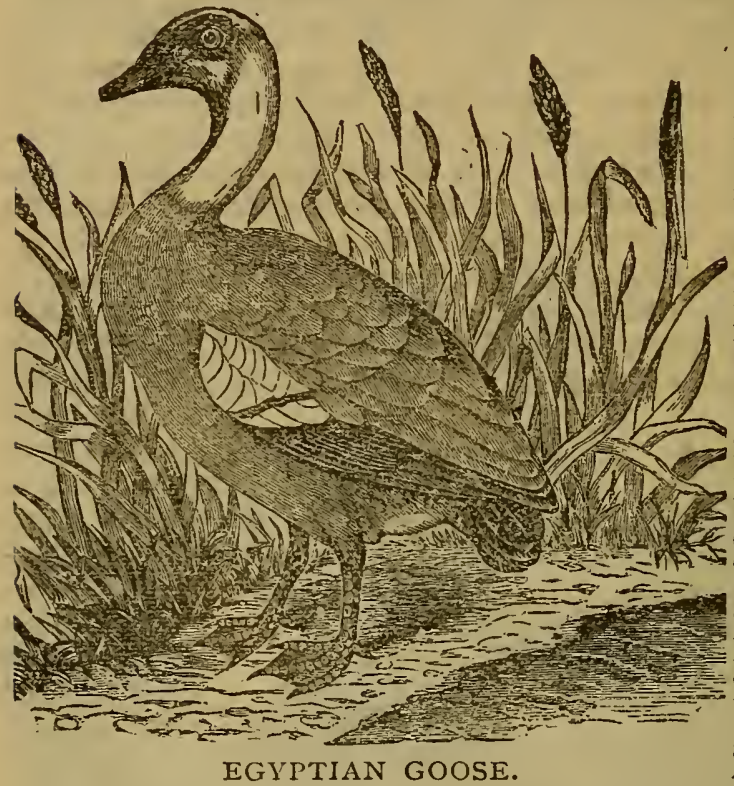

Egyptians, a favorite article of food for the priests, and their eggs àre considered of deli: cious flavor. As an ornamental water. fowl Egyptian Geese are very desirable. They are a rare bird, hard to be obtained, but" are easily kept. Their weight is about I 2 lbs. per pair. They are quite hardy, and by having a suitable pond for them, can be bred as well as any geese. They lay from five to seven eggs at a clutch; and by setting the first laying under a hen, they will lay a second time. They are very pugnacious over their nest and young, and woe to the-intruder.

\section{THE CANADA GOOSE.}

The plumage of this goose is very handsomely marked; the head a glossy black, as is also the neck, except a band of white across the throat; the upper part of the body is grayish brown; the wing coverts pale gray edged with brown; the lower parts of the body shading into grayish white; the abdomen pure white; and the tail black.

The movements of the Canada Goose upon the land are rather awkward, but upon the water they are extremely graceful, resembling the Gray Swan. The eggs are of a 
dull greenish tint, rather elliptical in form, and somewhat larger than a medium hen's egg. The period of incubation is four weeks. The male bird during this time never leaves the side of the female, except to procure food, and takes

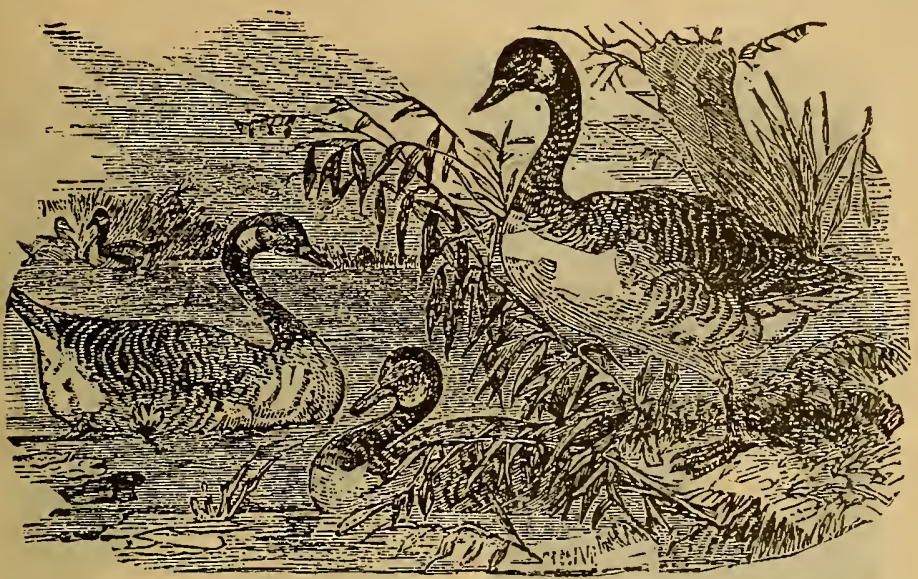

CANADA GEESE.

her place at intervais. The young brood follow cneir parents to the water at a very early age, and are watched over and taught by both until they are able to care for themselves; and the whole family remain together until the following spring.

We can generally procure the Canada "Goose, partially domesticated, at very moderate prices.

\section{African Geese.}

African Geese are described as follows: head large, with large black knot on top, heavy dulap under the the throat; bill, large, stout and black in color; eyes, hazel or brown; neck, long and curved; plumage, light-gray, with dark stripe reaching from top to body; back broad, and dark gray; breast and body, a lighter shade of gray; wings and tail, dark gray, shanks of medium length and in color a dark orange; toes, straight, and connected by the web, same colur as the shanks.

They are worth from $\$ 10.00$ to $\$ 20.00$ per pair. 


\section{Hong-Kong or Chinese Geese.}

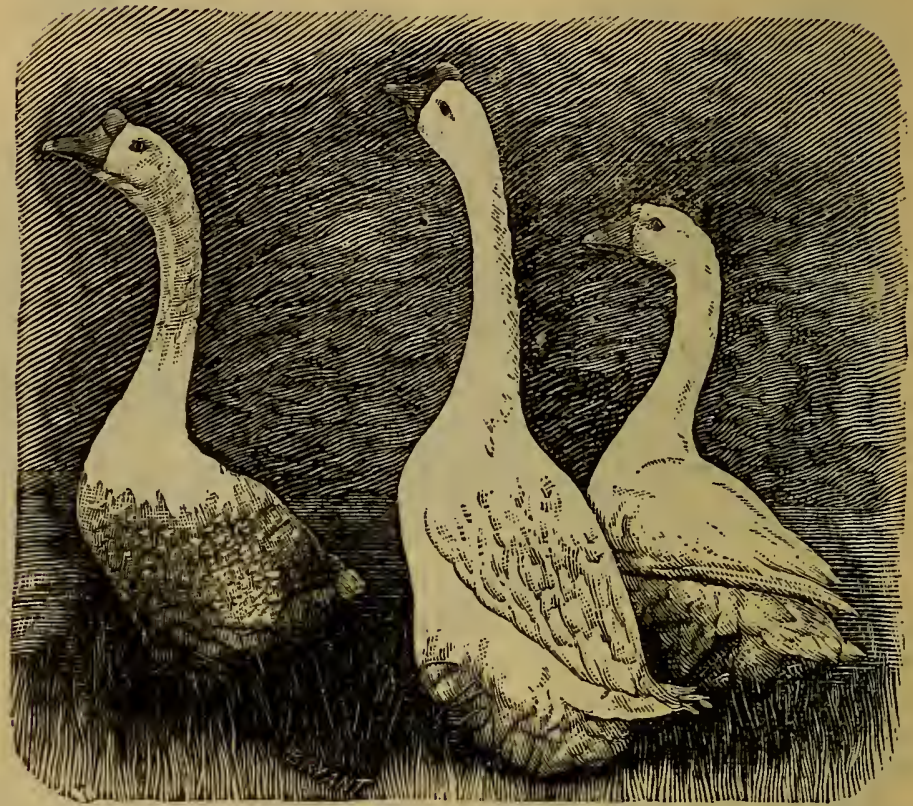

CHINESE GEESE.

Of the Hong-Kong, or Chinese Geese, there are two varieties; one pale white in plumage, the other an even shade of gray, like the Toulouse. They are a small breed, but excel in egg production. While their eggs are not so large as those of some other breeds, yet they lay twice as many. The peculiar knot at the base of the bill makes them at once odd and ornamental. They are more swan-like in shape and carriage than any other known variety.

They are worth from $\$ 10.00$ to $\$ 20.00$ per pair. 


\section{DUCKS.}

Ducks are easily hatched, and easily raised-much more so than chickens or turkeys. Probably the worst thing for ducklings is an unlimited range and water to swim in. The little things are, in a measure, nude, and should be kept in pens with dry soil floors or stone pavement that can be washed down daily. No kind of poultry will succeed on bare boards. All the water they need is best furnished by burying an old pot in the ground and laying a round piece of board. on top of the water with room for the ducks to stick their heads in and fish out the corn that is put in the water. This amuses them and does no harm, while, if allowed to go off to ponds or streams, they are very liable to fall a prey to vermin in some shape, or to get their bodies wet and chilled from remaining too long in the water.

After they are grown, however, many of the varieties must. have water which they can swim about in, and also have a reasonable amount of liberty. Those who live near running streams, or whe have a lake or pond in close proximity to them, have the matter settled favorably; though perhaps a little more may require to be done with a stream, if it be but a shallow one. Even a little stream can be made to do a great deal in this way by damming it up, and thus creating an artificial lake; or the bed of the stream for a short distance may be dug out, and extended a little on each side, which will then make a good place for the ducks to disport in.

Good results uniformly attend the hatching of duck eggs when they are from healthy ducks, not in-bred, which are given their liberty and have plenty of water to disport themselves in.

Ducks are excellent foragers. They are incessantly busy in any meadow or pond until their crops are filled. It is a beautiful sight to see them deploy in long lines, running their long bills through the grass in search of snails, crickets, and other insects. With a good range, and access to tide-water, they will require very little feed to keep them in good condition.

Before concluding our remarks on ducks, we ought, perhaps, to mention that good, and even necessary as is the custom of hatching some ducklings under hens, still it 
is generally allowed to be unwise to keep birds so hatched as stock birds.

It is also advisable to shut up drakes, or most of them, when ducks are sitting or have young, as about this time many of the drakes are very troublesome, both to mothers and young.

The sexes are soon to be distinguished by their cry, that of the duck being a more decided and quickly repeated "quack," whilst there is nothing like hoarsenesss from the throat of the drake. The curly tail is not an infallible and tructworthy sign, as we have known many old ducks with a most perfect curl.

The easiest and most common way of judging when good ducklings are fit to die, is to observe if they are "getting cross-winged." They will do well then, and not much before then.

\section{PEKIN DUCKS.}

Pekin Ducks are probably tre most valuable breed of ducks known to-day. They are very large, mature early and have snow - white plumage. The eggs hatch from two to three days sooner than other varieties, and the ducklings seem larger and stronger at birth. They can be raised in any place where ch i ckens

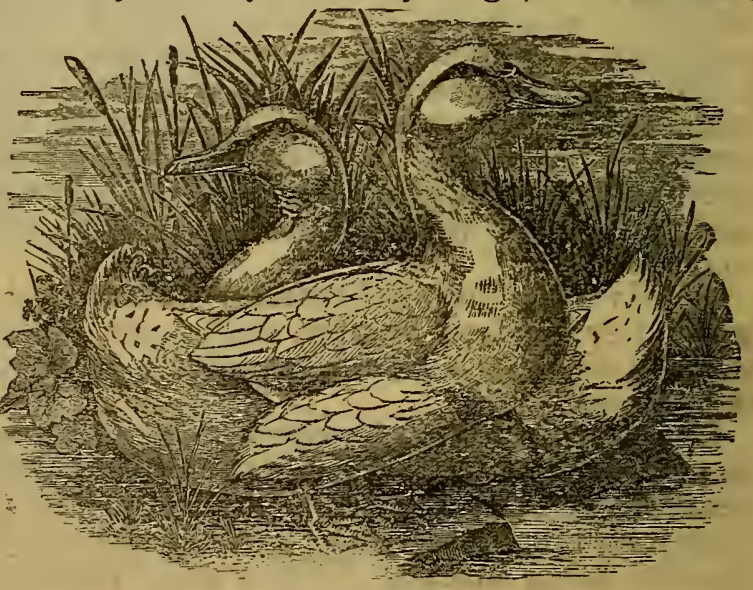

PEKIN DUCKS. can, and do not need any more water than land fowls until they are two or three months old. They are excellent foragers and excellent layers. With a good range they require 
very little feeding. The ducklings can be marketed in July and August, and at th s season command high prices. Fourteen to eighteen pounds per pair are not uncommon weights during the first year, without much fattening. As egg producers their record is remarkable; and they are as near perpetual layers as any of the gallinaceous breeds of fowls that can be named.

Price of Pekin Ducks per pair $\$ 5.00$ to $\$ \mathbf{r} 5.00$.

\section{AYLESBURY DUCKS.}

The Aylesbury Ducks are of English origin. They are among the native breeds what the Dorkings are among the common fowls-the best and most palatable for the table. Breeders of the Aylesbury Duck claim for it extreme hardiness, good laying qualities, and the very best quality for the table. It is closely feathered and does not look as heavy as it is, on land; but when swimming on the water it setties down deeper than any other kind, that is, "draws more

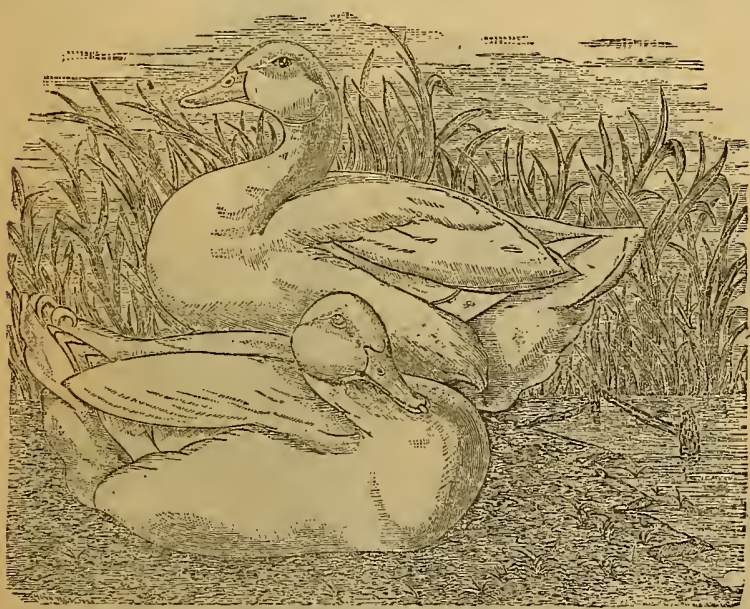

AYLESBURY DUCKS. water for its size." When well fattened, early in the winter they will weigh sometimes eighteen pounds per pair. There are more of them however, that will never weigh more than fourteen pounds per pair. They begin to lay early in the season, are not troublesome about sitting, and their eggs hatch well. The ducklings are strong and easy $\hat{\imath} \mathrm{c}$ raise. We have known them to 
weigh fourteen pounds per pair, at three months old. No duck is heavier at that age. For foraging and ranging fields and streams for insect food, the Aylesbury is "ahead." The young will turn out at 3 o'clock in the morning, in midsummer, and start for the fields to gorge themselves with grasshoppers that are not as active thus early; for the chill of the night and the dews, making them an easy prey to the ducklings. The leading market duck in England is the Aylesbury. Like other kinds of large ducks.it only needs water for drink, and a puddle or place to swim in is not necessary to its highest thrift and development.

Aylesbury Ducks are worth $\$ 5$ to $\$$ I5 per pair.

\section{ROUEN DUCKS.}

The history of the origin, not only of nearly all the various species of our domestic animals, but also of the varieties into which they are divided, is extremely obscure or wanting: altogether. The origin of the Rouen Duck is, however, quite certain. The French city, whose name the variety bears, and the district adjoining, had but little, comparatively, to do with its "makeup"; but the combined labors of breeders in France and ir. England

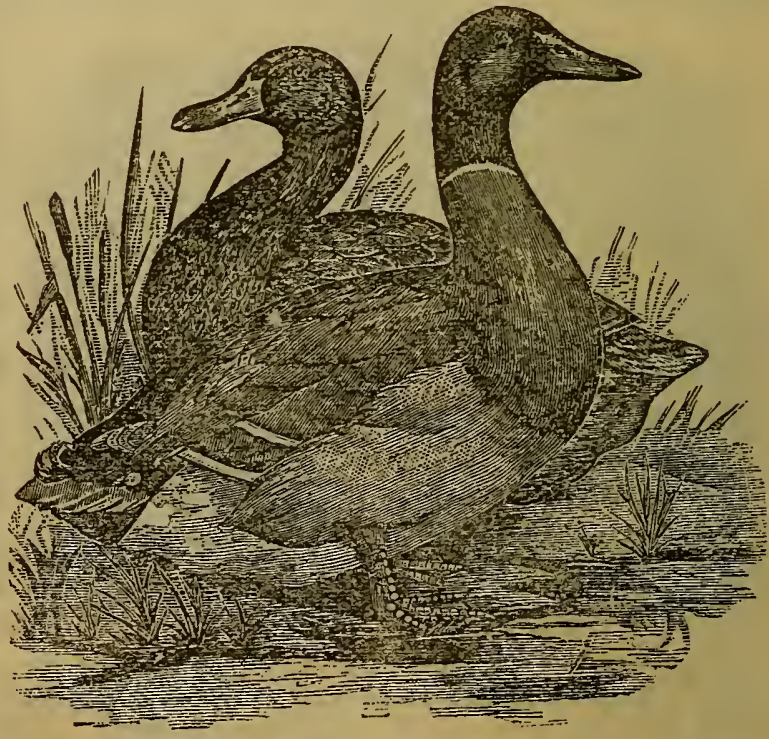

ROUEN DUCKS. 
evolved in the process of time, from the common domestic ducks, by selection on the basis of size; the plump, massive strain or variety, to which some chance incident gave the name of Rouen.

Rouen Ducks are very heavy anu handsome birds. How they acquired their name has not been satisfactorily explained. They have broad breasts, long slender necks, and long bills. The plumage of the drake is very fine, with his rich green head, wings chiefly of grayish-brown, but showing also green, blue, and white. The duck, of course, is less showy, though her wings display the same variety of color; but then, her head is brown, which color is relieved only by two stripes of a lighter shade. The legs are orange. These birds when fattened will come to surprising weight; and they will do better than any except Pekins, where water is scarce. The Rouen dralie puts on a summer dress like that of the duck. The chief distinction of sex, to a novice, is when the curl is in his tail.

These ducks are worth $\$ 5.00$ to $\$$ II per pair.

\section{CAYUGA DUCKS.}

This variety is of a solid metallic black plumage. They are of large size, and among the most prolific layers of the

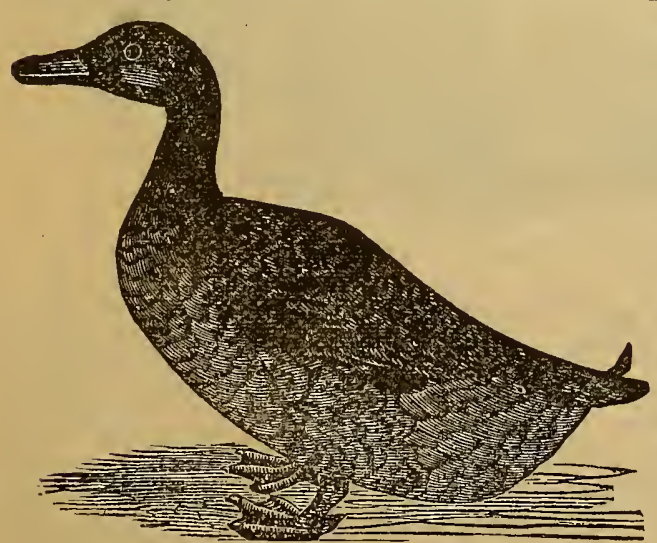

CAYUGA DUCKS. entire duck family. They are said to have originated in the American lake whose name they bear. No duck is hardier or more easily reared than they, and no one will give better satisfaction. Their fles'.1 has a slight gamey flavor, probably inherited from their wild ancestors. and by most per. sons it is highly eso 
teemed on this account. They fitten easily and quickly. A pond of water or "a rumning stream is necessary to secure the best results with this variety of duck; as, unlike the Pekin, they will not do well unless they have access to water.

Cayuga Ducks are worth from $\$ 5.00$ to $\$ 10.00$ per pair.

\section{Muscovy Ducks.}

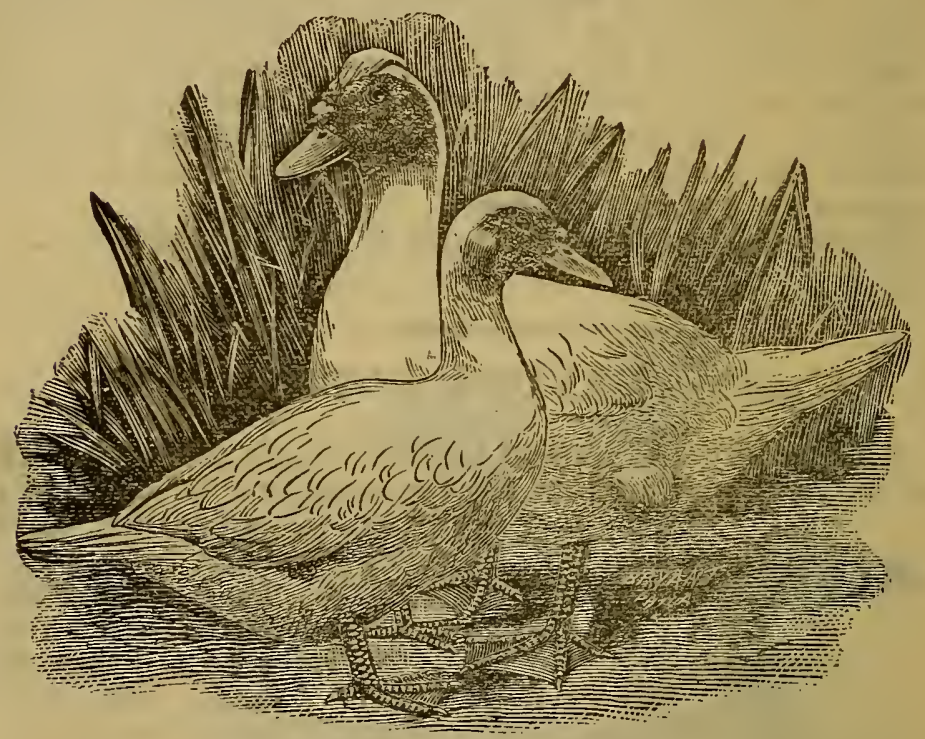

WHITE MUSCOVY DUCKS.

Muscovy Ducks are rather odd-looking to those who have never seen them before. Their long tails, their fierce-looking red heads and faces, their oddly blotched and patched bodies, (in the colored variety), the oddly ruffled feathers on the back of the clrake's neck, and their goose-like hissing, all go to make them objects of curiosity. They have a sort of musky scent, hence, the name Musk duck or Muscovy: They are all good eating 
at almost any age, if properly cooked, and the young are always a palatahle dish. Their management does not differ materially from that of other ducks, save that they require a great yuantity of fresh grass, which they should be allowed to pick for themselves, the same as geese; and that they breed only in pairs. An odd, or unmated duck, is useless, as far as breeding is concerned. The eggs of the Muscovy Duck are five weeks in hatching, instead of four, as is the case with the various other breerls common to poultry fanciers. They are useful as curinsities, and also as practical fowl, to a limited extent.

Muscovy Ducks are worth from $\$ 4$ to $\$ 10$ per pair.

\section{Black East Indian Ducks.}

The black East Indian is a great favorite as an ornameutal water fowl, and may almost be described as graceful, certainly as neat. The plumage is black, tinted with green, and the legs are dark, as well as the bill. The pure East Indian must nerer show the white feath$\mathrm{er}$. This is a small variety, about the size of the Call Jucks. As its name indicates, it is black in color. ${ }^{*}$ Its flesh is highly esteemed by epicures. They are excellent flyers, and will sometines be gone from their quarters for days at a time.

They are worth from $\$ 8.00$ to $\$ 20.00$ per pair.

\section{The Wood Duck.}

The Wond Duck can he domesticated by setting the eggs under a hen or tame duck, and approaching the young frequently until they become familiar; never allowing them to become unnecessarily frightened. As they become donesticated they increase in size; and if the birds are promerly moulted, by attention and proper food, their crests becoine more and more developed, and the plumage more brilliant. They will not breed in confinement until 
they become accustomed to their abode and contented therein.

Their great beauty renders thorough domestication so desirable that no prejudice in favor of small size should be allowed to interpose, as no poultry show is complete in their absence. The adult drake has a red bill, margined with black, and having a black spot between the nostrils, and a sort of hooked projection at the end. The irises of the eyes are orange-red. Crown of head and crest pendant of the rich glossy bronze-green, and beautifully marked with a line of pure white running over the eye, and another behind it, producing a very striking appearance. Chin, hroat, and color around the neck, pure white. Breast dark violet brown, marked with spots of white, increasing in size until they spread into the white of the belly. Sides under the wings thickly and beautifully marked with fine, undulating, parallel lines of black on a ground of yel-

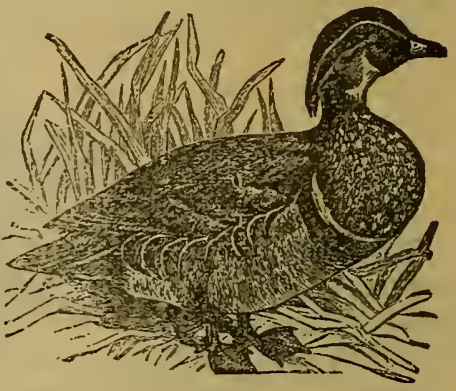

WOOD DUCK. lowish-drab. Tail coverts, long, of a hair-like texture at the sides, over which they droop, and are of a deep greenishblack. The back is dusty brown.

The female has a smaller crest on the head, with a crown of dark purple, a bar of white behind the eye, white chin and throat; neck, drab; breast, dusky brown, with gold and greenish reflections. Tail is shorter, and the hair-like coverts of the male are wanting. Altogether their plumage is splendid and attractive.

Prices are a matter of correspondence.

\section{MANDARIN DUCK.}

The Mandarin Duck, sometimes called the Chinese Teal, is the most gorgeous in appearance of all the ornamental duck tribes, and deserves greater attention from breeders and exhibitors than it has heretofore received. It nearly resembles the Carolina or Wood Duck in many respects. It is comparatively small in size. It is closely and neatly built, 
and the plumage of the drake in grandeur is almost beyond description. The long crest on the head points backward, and can be raised or lowered at will The top of the head

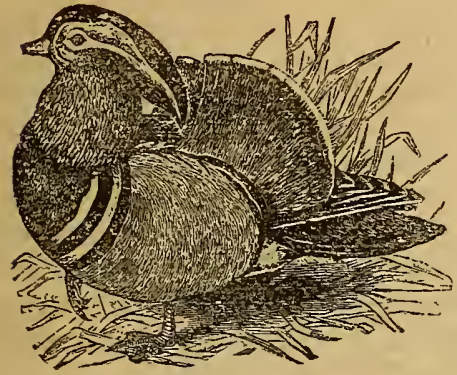

MANDARIN DUCK. is black, which color extends down to the nape of the neck, below which is a clearly-defined white line passing over the eye down to the base of the bill. The cheeks and the long pointed feathers of the neck, and two raised wing feathers, are of a bright orange-brown. The upper parts of the breast and back are of a glossy black; and the lower, white. The flight feathers are black and white. The tail black, but white underneath. The sides of the breast are greenish-orange, with a clear white marginal line. The legs are a deep pink. From the middle of June to the middle of September the drake assumes the color of a duck; which is a dull olive brown, mottled, and having grayish under parts. In China domestic specimens are highly prized, being considered as striking examples of conjugal fidelity when paired or mated; hence, in that country, it is customary to carry a pair in the wedding procession, which are afterwards presented to the married couple as objects worthy of imitation. Very high prices have been paid for importations of these birds from China.

\section{CHILIAN DUCKS.}

These ducks are most interesting and beautiful in appearance. The male is about two feet in length, but has a longer tail than other ducks. The male bird has head and throat brown, with purple hues. From the back of head downward extends a dark stripe, with a stripe of white on each side of it; also the back is white and black undulating in stripes or lines, and the upper part of breast is whis.. The wing bars are green, bordered on the front with buff, and on the back with white. The principal tail plumage is very dark gray, or nearly black; bill a lead color, being about two inches long; legs not always the same shade of color, 
but varying from a leac color to a dull brown. The sides, apart from the wings, are white and black penciled, with a distinctness that is truly remarkable. When young, the drakes are of dun or gray color till about February, when they take on their full feathering and distinctive markings. The female is smaller than the male, and does not have so long a body, or any remarkable elongation of tail; neither is her plumage so beautiful. They belong, as a breed, to the aristocracy of ducks, their forms being elegant, their long symmetrical bodies presenting an appearance of delicacy in their action ; slender, firm-cut necks, and general "make-up." The flesh is tender and excellent. This duck, like every other species of wild ducks may be domesticated with ease, and will prove a valuable addition to our yards.

\section{CRESTED WHITE DUCKS.}

These are quite large and are very beautiful, having large topknots. They are pure white in plumage, and lay well. They mature early, and are most excellent ducks for table use. They are prolific layers.

The crest is large and well-balanced on the top of the head; the eyes are large and bright; and the bill and feet are yellow in color. Some of their offspringare very likely to come plain-headed, as the breed has not been bred sufficiently long to reproduce its like to a certainty. These ducks have many

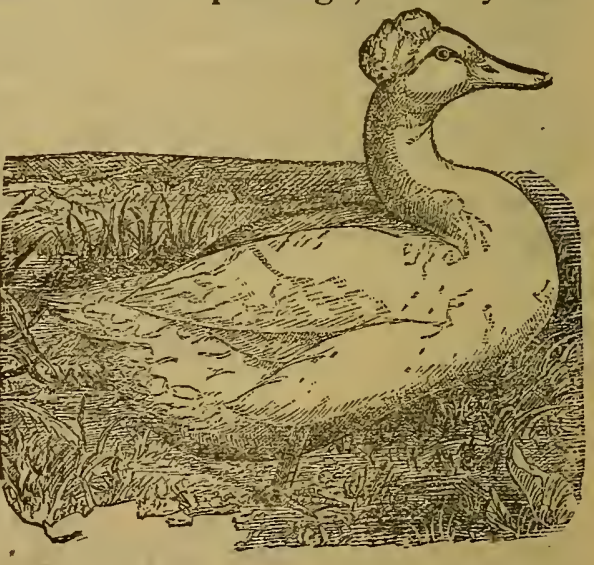
CRESTED WHITE DUCKS. qualities that recommend them to the fancier; but for the farmer, the other white breeds (the Pelzin and Aylesbury) have more real economic qualities.

Crested White Ducks are worth from $\$ 5.00$ to $\$ 25.00$ per pair, 


\section{Call Ducks.}

There are two kinds of this variety, the gray and the white. Both are quite small and are bred usually for ornamental purposes. The Call Ducks are very pretty, and first-class eating, too. A slice of one of the little fellows goes down very nicely, as we know by experience. We have for years past tried an occasional cross with a Rouen, and many a choice morsel has been the result; though we, for our regular stock, never allowed them to become mixed. The body is round, close, and the form very neat. As a rule the eggs are smaller than those of the Aylesbury, but of the same variable shades; yet the size of the eggs may not be compared to the size of the bird. The larger birds frequently lay the smaller eggs. For breeding pur-

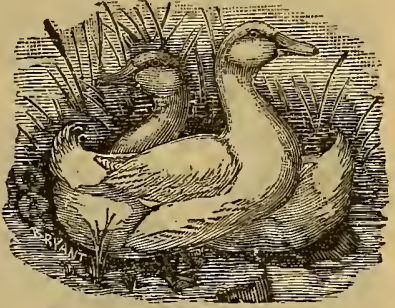

WHITE CALL DUCKS. poses look more to shape and perfection of markings than to weight; being especially careful to reject those having malformation of wing. : On a small pond they make very pretty and interesting ornaments. These ducks are sometimes used by sportsmen to decoy wild ducks.

Either variety is worth from $\$ 8.00$ to $\$ 20.00$ per pair. 


\section{TURKEYS.}

Turkeys are pre-eminently a wild fowl, and require plenty of liberty to become profitable. Where the range is limited; the breeding of Turkeys should not be attempted. It is on a grain or grass farm where they can roam around at will and gather in the scattered grains and grass-hoppers, that they prove so profitable when well cared for and regularly and liberally fed.

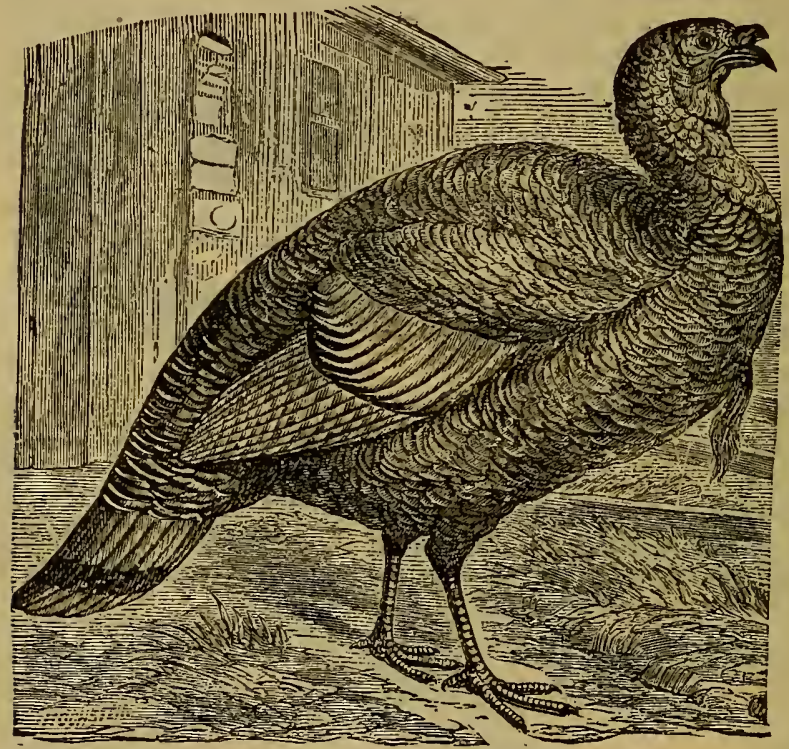

NARRAGANSETT TURKEY.

It is a great mistake to attempt to hatch too early. May is a good time to set the Turkey eggs. The first clutch of eggs the Turkey hen lays should be taken aw ay and set under a hen. The hen Turkey soon goes to laying again, and she can be left to hatch these out herself. By this means you get two broods from her, while if you leave her to hatch out the first laying she would raise but one, and perhaps but few of these, owing to trailing them through the high wet grass. When the second lot of Turkeys are out, the grass has been cut and the stubble is short. Until about two months old the young Turkeys must be well protected from dampness and dews, which are always fatal to them.

Turkeys will not bear close breeding like hens, for they 
carry a great deal of their wild nature in their blood, and even under domestication they are allowed to indulge in half-wild habits.

There is one thing which should be remembered by every turkey breeder when he sees the young poults clear from the shell, it is to make sure they are free from lice. And if they are, let him fix a place for them on a sunny knoll or a spot free from dampness. They can easily be confined by placing long boards edgewise and driving a few stakes on each side to support them firmly. Then make a large coop with a tight roof and put in three or four inches of chaff, cut straw, leaves, or dry sawdust on the bottom, to protect them from the cold, damp ground, for a month or more. There is nothing so fatal to young poults as cold rains, heavy dews, or sleeping in damp places. They require more care at first than chickens, but make rapid growth when young; and should, by care and food, be forced along as quickly as possible that their bodies may keep pace with the quick growing wing and tail feathers.

Those who grow tobacco should always keep a flock of turkeys, as they are very destructive to the large green worms that do so much damage to that crop. If allowed a range, and fed on grain at night, they can easily be taught to come up at regular hours.

Turkeys when full-grown are, perhaps, the hardiest variety of poultry we have; and it is a rather strange fact that this hardy variety is among the most tender when young. During the cold winter months the turkeys will generally be found perched up in some tree or on the ridge of the barn and seem to be contented and take it in preference to a lower and warmer perch. However, it would no doubt be better if they could be taught to roost in a certain fixed place, sheltered by some building, or that has at least a partial protection from the cold north winds; and thus during some of the zero weather of winter the turkeys will be saved from having frost-bitten feet. Yet, these same turkeys, that roost on the ridge of a barn in the winter time, can not endure even the least careless exposure when young. They are of American origin, and, although domesticated, their natural habits are but little changed, and it is yet their delight to wander off through the woods and be in a measure free from all signseof civilization. 


\section{BRONZE TURKEYS.}

These are the largest of 'Turkeys; and on account of their mammoth size, hardiness, and richness of plumage are by far the most profitable to breed. Nothing can exceed their brilliant plumage in the sunlight, forming as it does lustrous hues, most dazzling to the eye. Gobblers of this breed sometimes reach the enormous weight of $40 \mathrm{lbs}$., and young birds weighing from 15 to $20 \mathrm{lbs}$. are quite common.

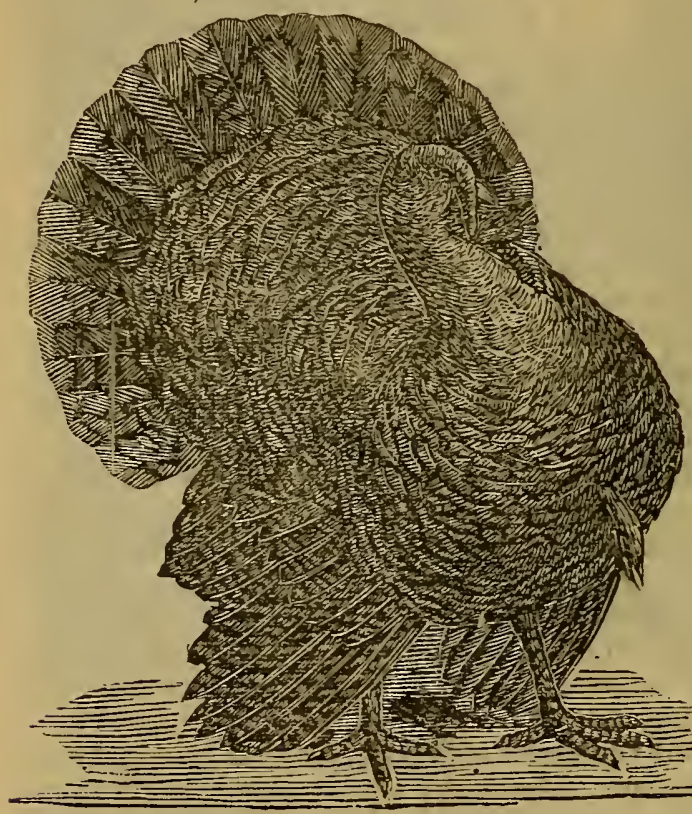

BRONZE TURKEY.

A merican breederscan justly be prouc of having ori. ginated such a fine breed as the Bronze is every. where acknowledged to be. The large size, as well as the brilliant plurnage, is due to the wild tur key, with which they have been crossed to maintain the size and markings.

Many flocks having been? closely bred for several y e ars, d im in is h ill size; while the color's so highly prized get paler erery succeeding year. Some of our prominent breeder have recourse to the wild stock for breeding males, every two or three years, and thus keep up a high standard for their flocks of Bronze Turkeys.

Bronze Turkeys are worth from $\$ 10$ to $\$ 30$ per pair 


\section{WHITE HOLLAND TURKEYS.}

White Holland Turkeys are one of the most beautiful of all the Turkey family. When two years old, and in full

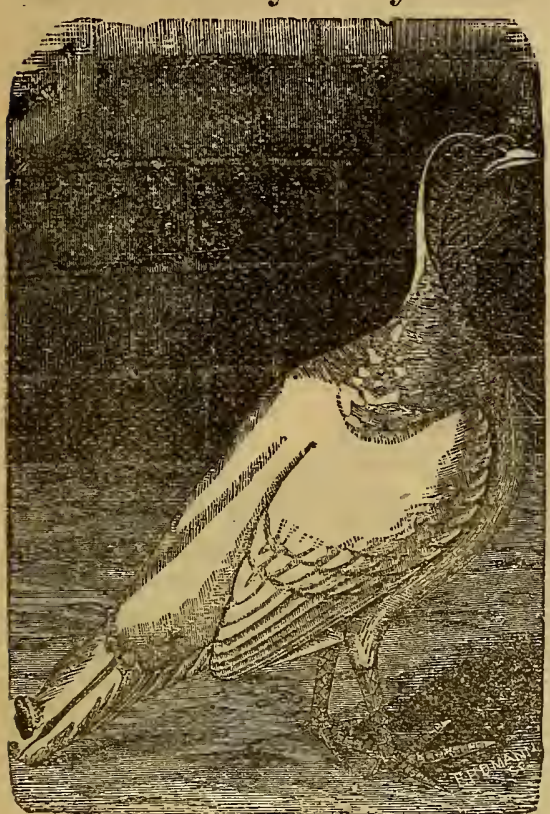

WHITE HOLLAND TURKEY. plumage, they are grand looking birds. The cocks are very proud and inde. pendent in look and ac. tion. They are not as large as the Bronze, Narragan. sett, or Black; they are fine sized when well fed. They are said to be somewhat delicate, but this is perhaps a popular prejudice, founded on nothing more substantial than the undoubtedly erroneous idea that white in it elf denotes delicacy or weakness. At any rate, where one has a fine, light gravely soil there is not the slightest doubt but that they will do well. All turkeys are rather shy, and have to be petted a little in order to have them tame enough to do well; for all should know that the feeling of security that the tame fowl has, goes a long way toward making it a profitable investment for its owner.

White Holland Turkeys are worth $\$ 10$ to $\$ 25$ per pair.

\section{Black Turkeys.}

This breed, which is considered by some, to be equal to any in economic qualities, is of a metallic black plumage, with salmon colored legs. They are quite hardy. nature early, and in size closely resemble the Bronze variety.

The price is the same as that of the Bronze Turkey. 


\section{Narragansett 'Turkeys.}

This breed has a light horn-colored beak; dark hazel eyes. Plumage of body, a metallic black, with each feather ending in a broad light steel gray barred-edged with black; tail, long and black, each feather irregularly penciled with bars of brown, and ending with a broad black band, edged with light gray; shanks, long and strong, in color, a deep salmon; or brown.

Narragagsetts are worth from $\$ 10.00$ to $\$ 20.00$ per pair.

\section{Buff Turkeys.}

This variety has a bluish white beak; eyes, dark hazel; shanks and toes, large and strong, and in color bluishwhite or flesh color. The plumage is a pure buff throughout, except the wings, which are of a lighter shade than the body. 'They are valued at from $\$ 10$ to $\$ 25$ per pair.

\section{Slate Turkeys.}

This breed has a light blue, dark blue, or horn colored beak; eyes, bright and in color dark hazel; shanks and toes, large and strong, in color light or dark blue. Plumage, slate or ashy blue, throughout, sometimes dotted with small black spots, but the more free from dots the better.

Slate Turkeys are worth from $\$ 10.00$ to $\$ 25.00$ per pair. 


\section{GUINEA-FOWLS.}

The rearing of Guinea-towls does not offer more difficulty than that of the most hardy chickens They do not require that particular care so necessary for the successful rearing of young Turkeys. In a state of liberty, free to roam about a large farm, from which they will never attempt to escape, they hatch out their young and provide for them without the help of man. If confined in a run or poultry-yard with other fowls, they never sit, but, on the other hand, they lay an abundance of eggs, which can be given to a broody hen, or put into an incubator. For the first days the young are fed exactly like young chickens. As with the rearing of all the inhabitants of the poultry-yard, they require from time

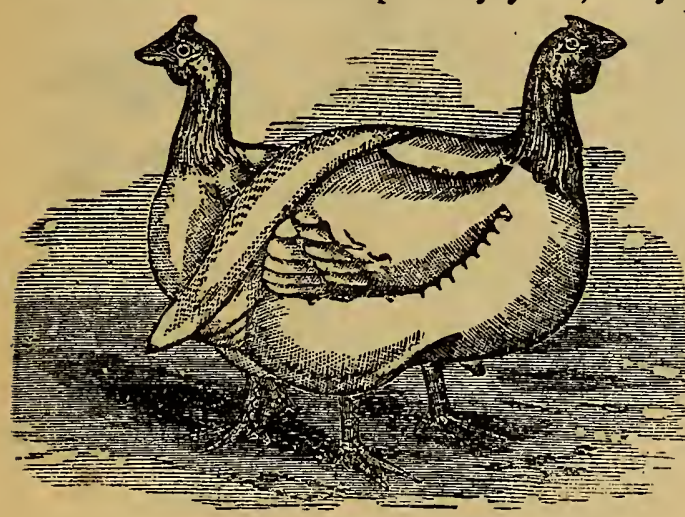

WHITE GUINEA-FOWL. to time a small quantity of finelyminced meat, which gives vigor to the young, and a most robust constitution.

The Guineahen is a continuous layer in her season, but does not commence until the grass and weeds get up a little in the spring, as she has a disposition to hide her nest. A little care in observing her habits will soon overcome this inconvenience, as the male bird is always found near the nest, and by his noisy demonstration calls the attention. The eggs of the Guinea fowl are preferred to any other, and the flesh of the bird is considered by many persons superior in flavor to any other domestic fowls, though a little dark-colored. A few hours in salt water will render the flesh quite fair, and as good as pheasant, which it resembles in taste. We consider the Guineafowl as a bird that might be raised with profit, besides being ornamental.

Young Guinea-fowls reach the adult period earlier than 
chickens, and consequently give less trouble in rearing. At a nonth old they can do without the natural or artificial mother, and can manage for themselves.

In their natural state Guineafow ls mate in pairs, but under domestication one cock will serve two or even three hens. The hen can be dis ting $\mathrm{u}$ ished from the male by her peculiar cry. A pair of the fowls should be kept in every poultry farm. They are ever on the look-out

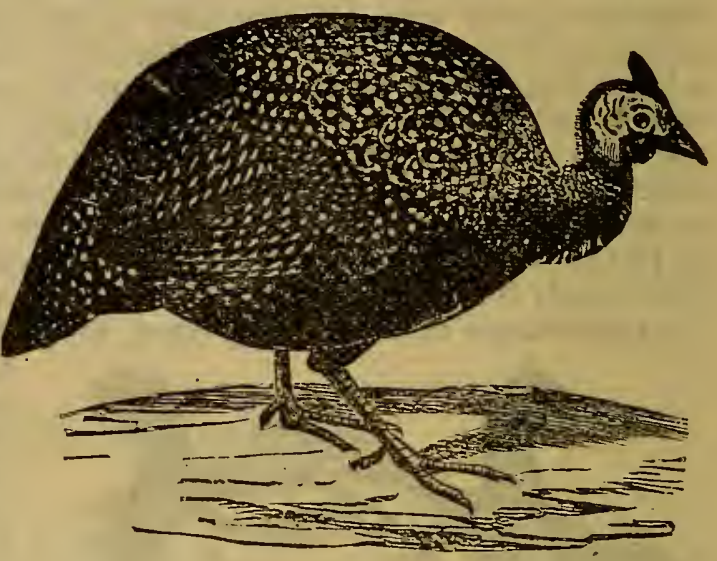

PEARL GUINEA. for hawks or other marauders, and will give notice of their approach by the alarm cry, which can be heard for a mile, and which they will keep up until aid arrives.

There is also a Lavender colored variety.

Pearl and Lavender Guineas are worth $\$ 3.50$ per pair. White Guineas, \$5.00.

\section{PHEASANTS.}

These beautiful and very ornamental birds can be successfully reared in a wire enclosure. The hens lay from six to ten eggs, which can be left for them to hatch or be placed under a hen. The old birds will thrive well enough on a mixed grain diet, but the young birds require in addition insect food. If allowed their liberty, of course they will procure this for themselves; but if kept in confinement, they should be given meal-worms or else insects. An inexpensive and ingenious way of securing this kind of food in summer-time, is as follows: Hang a beef's liver in a barrel, the bottom of which is covered to a depth of six inches with moist sand. The liver soon gets fly-blown, and the mag. gots drop into the sand, and in a few days are fit food for the young Pheasants. 


\section{SILVER PHEASANTS.}

The male Silver Pheasant, without possessing the gorgeous colorations of many species of the group, is a very beautiful bird. The foce is entirely covered with a bright vermilion skin, which during the spring becomes exces-

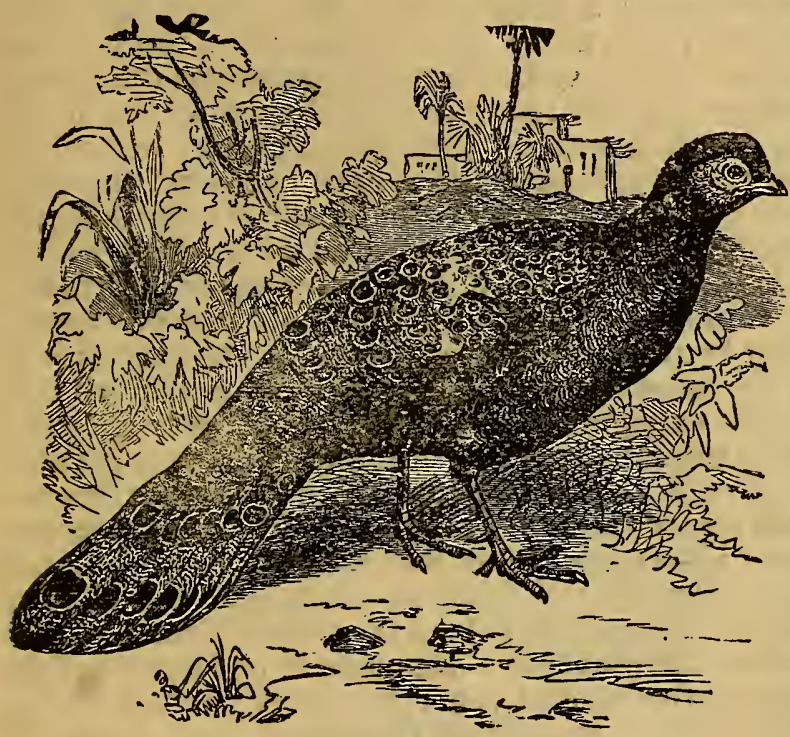

PHEASAN'T. sively brilliant, and is greatly in. creased in size, soas to almost resemble the $\mathrm{comb}$ and wattles of a cock; the flowing c rest is blue-black, the billight green. The upper part of the body is white, penciled with the most delicate tracery of black.

The whole under parts are bluish-black; the legs and feet, red; the spurs well developed and usually very sharp. The female is smaller than the male; her general color is brown, mottled with a darker tint; the crest and tail are much less ample than those of the cock; the outer tail feathers are light, marked with blark on the outer webs. The female in confinement usually lays from eight to fourteen eggs, and the young are easily teared under a common fowl. 


\section{THE GOLDEN PHEASANT.}

In its mature plumage the male Golden Pheasant is one of the most gorgeous of the whole tribe. The head is ornamented with a long crest of silky, orange-colored feathers. This extends backwards over a tippet formed of broad, flat feathers, which are of a deep orange color, with dark blue bars across the tips; these latter form, when the feathers are in position, a series of horizontal lines across the tippet. Below this tippet, on the lower part of the neck, the feathers are deep reen, margined with velvet black; below this again are the scapular feathers of a dark crimson; the back and rump are golden-yellow; the tail itself is very long, the two longest central feathers are covered with small irregular circles of light brown on a dark ground, giving them a mottled appearance. The other feathers are barred diagonally with dark brown on a lighter ground. On each side of the base of the tail extend the long, narrow upper tail coverts, of a bright orange-crimson, The wings, when closed, show the deep blue tertiaries covering the chestnut secondary quills. The upper part of the throat is light brown, the breast and under parts orange-scarlet. Taken altogether, its appearance is so remarkable that it looks more like one of the bizarre creatures of Chinese fancy than a real bird. The birds of this genus differ from the true Pheasants in the fact that the mature masculine plumage is not assumed until the autumn of the second year; the young cocks looking, during the first twelve months of their lives, very much like the hens; from which, however, they can be readily distinguished by pulling one or two feathers from the neck, which are reproduced in the distinctive masculine character. The hens are very plain and unobtrusive, being barred with alternate shades of light and dark brown. When barren, they, like the other birds of the whole family assume the gorgecus apparel of the male.

\section{PEA-FOWLS.}

Pea-fowls are the most beautiful of all domesticated fowls, and on a large lawn they are very ornamental. They will 


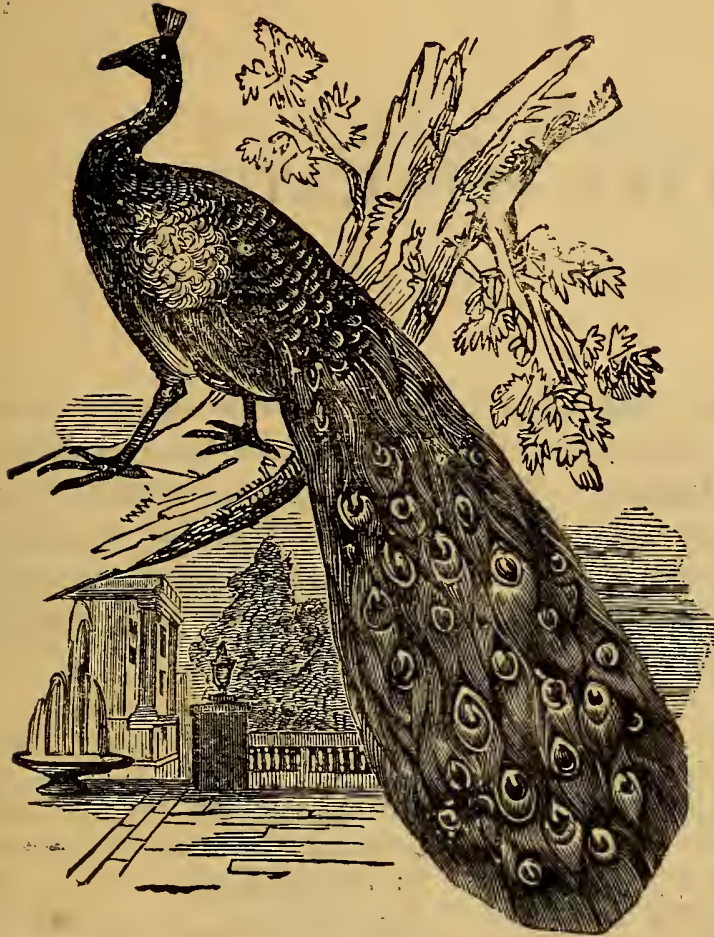

PEA-FOWL.

not bear confinement, and thrive only when allowed full liberty. The hens lay two litters a season, of ten or twelve e ggs each lit. ter. The eggs should be set under a large motherly hen or Turkey. The chicks are very pretty, and quite hardy. much more so than young Turkeys. They will live to a great age, and are very free from the diseases that all other kind of fowlsaresubject to. As an edible fowl, the Pea fowl is considered quite equal to the Turkey, the meat having a very gamey flavor.

Pea-fowls are worth from $\$ 10.00$ to $\$ 20.00$ per pair; the white variety from $\$ 25.00$ to $\$ 50.00$ per pair. 


\section{POULTRY PUBLICATIONS.}

In compiling this hand-book we have drawn very largely on the various poultry journals, for both information and illustration. We advise all our readers who intend breeding fancy fowls, to subscribe for at least one good poultry publication. Below will be found about all there are. We will have any one sent to your address for one year, on receipt of price.

American Poultry Journal, Chicago, Ill., • • \$.50 American Fancier, (weekly), Johnstown, N. Y., 1.00 Ainerican Stock Keeper, "Topeka, Kausas, $\quad .50$ California Poultry Tribune, San Diego, Cal., • $\quad .50$ Carradian Poultry Review, Toronto, Can., . 1.00 Consolidated Fanciers' Journal, Nashville, Tenn., $\quad .50$ Farm Poultry, Boston, Mass., . . . . 1.00 Fanciers' Monthly, San Jose, Cal., . . . $1: 00$ Feathers, Washington, D. C., . $\quad . \quad .50$ Michigan Poultry Breeder, Battle Creek, Mich., $\quad .50$ National Fancier, Indianapolis, Ind., . . . $\quad .50$ Nebraska Poultry Journal, Auburn, Neb., . $\quad . \quad .50$ Ohio Poultry Journal, Dayton, Ohio., · • . .65 Pacific Poultryman, Tacoma, Wash., . . . . $\quad .50$ Poultry Keeper, Parkersburg, Pa., . . . . $\quad .50$ Poultry Herald, St. Paul, Minn., . $\quad . \quad . \quad .50$ Poultry Monthly, Albany, N. Y., . $\quad$. $\quad$ • 1.00 Southern Funcier, Atlanta, Ga, . . . . . $\quad .50$ Westeri Poultry Journal, Cedar Rapids, lowa, . $\quad .50$ Western Garden and Poultry Journal, DesMoines, Ia. .50 


\section{FANCIERS' BOOKS.}

WILL BE SENT, POST PAID, ON RECEIPT OF PRICE.

Beal's Profitable Poultry Keeping, Illustrated, $\$ \$ 1.50$ Burnham's New Poultry Book, . . . . 1.50 Cooper's Game Fowls, . . . . . . 5.00 Felche's Poultry Culture, . . . . . . 1.50 Poultry Doctor, by John E. Diehl, . . . . .25 Profits in Poultry and Their Profitable Management; most complete work extant, . . . 1.00 Renwick's Thermostatic Incubator,

Paper 36 cents, Boards, $\quad .56$

Standard of Excellence in Poultry, . . . 1.00 Stoddard's on an Egg Farm $\quad$ • $\quad$ • $\quad .50$ Wright's Illustrated Book on Poultry,

Colored, $\$ 10.00 ;$ plain, $\quad 5.00$

Wright's Practical Pigeon Keeper, • • • 1.50 Wright's Practical Poultry Keeper, • • • $\quad 2.00$ Rabbits for Exhibition, Pleasure and Market, · 1.25 Domestic Cat, by John E. Diehl, . • • • $\quad .25$ Associated Fanciers' Bonk on the Dog, . . $\quad . \quad .15$ Bird Food Co's Book on Cage Birds, . . . . $\quad .15$ Toy Dogs, by John E. Diehl, . . . . $\quad .25$ 


\section{POULTRY SUPPLIES.}

Stone Drinking Fountains.-Half gallon, 25 cents each, weight 3 lbs.; one gallon, 35 cents, weight 6 lbs.; two gallons, 50 cents, weight 12 lb.s. Sent by freight or express.

Galvanized Wire Netting, for poultry fencing. Makes. the cheapest and best. 2 inch mesh, No. 19 wire, at $1 \frac{1}{4}$ cts. per square foot, in rolls containing 150 feet. Widths, $24,30,36,48,50$ and 72 inches. Also smaller mesh for Pigeons and Bantams.

Egg Testers, for distinguishing unfertile eggs, by mail, 30 cents.

Punches, for marking fowls, by mail, 30 cents.

Caponizing Instruments, per set, $\$ 3.00$.

Insect Powder, per pound by mail, 50 cents.

Poultry Powder, for curing diseases and making hens: lay, by mail 40 cents, otherwise 25 cents per box.

Roup and Cholera Pills, by mail, 25 cents.

Egg Baskets (to hold one setting), per dozen, \$1.25; to hold two settings, $\$ 1.50$ per dozeu.

Wilson's Bone Mill, for grinding bones and oyster shells, $\$ 5.00$.

Beef and Pork Cracklings, per hundred pounds, $\$ 2.50$.

Bone Meal for Poultry, per 30 lbs. $\$ 1.40 ; 60$ lbs. $\$ 2.25$; $100 \mathrm{lbs}, \$ 3.00 ; 200 \mathrm{lbs}$., $\$ 5.00$.

Granulated Bone, per 30 lbs., $\$ 1.25 ; 60$ lbs., $\$ 2.00 ; 100$ lbs., $\$ 2.75 ;-200 \mathrm{lbs}, \$ 5.00$.

Crushed or Fine Ground Oyster Shells, 50 lbs., 75 cts.; 00 lbs. , $\$ 1.40 ; 200$ lbs., $\$ 2.00 ; 350$ lbs. $\$ 3.25$. 

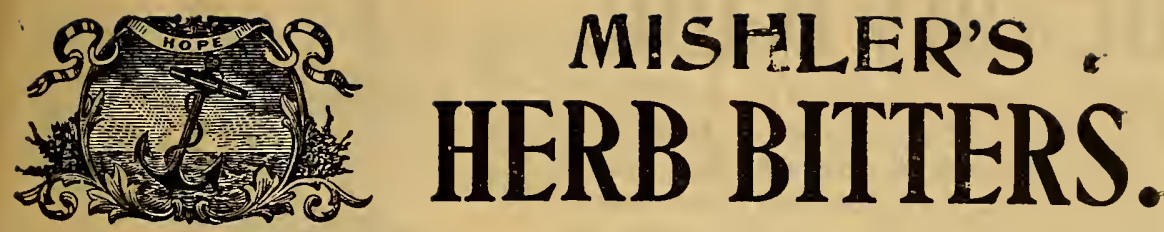

Whether we will or not, we all have our doses of "BITTERS" to take in this life. We swallow them with a wry face or without one, but-swallow them we must, and in any case they are often among the most beneficial of life's experiences. More than honey-dew and rose-water are needed te produce strong men and women.

The MISHLER'S HERB BITTERS have long been a favorite "stand-by" in the Lancaster Co., $\mathrm{Pa}$., and many other prominent Hospitals. This of itself speaks for their worth.

They will purify the blood, they will improve the appetite, they will strengthen. the digestion, they will regulate the bowels, they will regulate the kidneys, in short they will renovate the whole system. Sold by druggists at $\$ 1.00$ per bottle or six bottles for $\$ 5.00$.

MISHLER'S HERB BITTERS are for everybody who needs them.

"MISHLER'S RED LABEL BITTERS are "for ladies only." The two must never be confounded, however.

Only a woman knows how much all women at times need the purifying, strengthening, vivifying influence of some safe, certain, trustworthy remedy for the weaknesses andills peculiar to her sex. By the judicious use of MISHLER'S RED. LABEL B1TTERS the system may be cleansed and strengthened, irregularities. corrected auu tú ourden of womanhood may be lightened as much as it can be done by the functions of sex being rendered as easy and natural as possible.

This medicine must not be used recklessly. Follow directions. Use it occasionally, and only when you really need something.

'MISHLER'S RED LABEL BITTERS are sold by druggists at $\$ 1.50$ per bottle. If your druggist does not keep it send direct to the manu facturers.

MISHLER'S GREEN LABEL BITTERS. The Herb Bitters are so modified by the addition of alteratives and restoratives, that the result is a specific for Blood. Diseases, Scrofula, White Swelling, etc.

Remember that the GREEN LABEL BITTERS like the RED LABEL BITTERS. are intended for specified diseases only. It is sold by druggists at the same price as the Red Label Bitters.

, None genuine unless $x$ it up in square glass bottles, with a closely graduatedi weasure of doses thereon, and authenticated by our private proprietary Internal Revenue Stamp with engraved likeness of B. MISHLER over the cork, and a facsimile of our signature on bottom of the iabel.

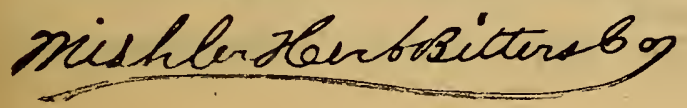

400 Nortl, 'Third Street, Philanelphia, PA. 
Beauty Balm.

THIS is, indeed, a "magical beautifier," for

its effect is instantaneous! It at once imparts to the skin that clearness, color, brilliancy and girlish glow which is so beautiful in healthy youth. It is invisible in itself-no one can detect its presence upon the face, and yet its effect is charmingly apparent.

This invisibility is owing to the fact that it excites all the life and brings into play all the beautifying forces of the natural skin itself. It is in truth the nearest approach to nature ever invented.

The inventor of Beauty Balm has made an exhaustive investigation in order to make a harmless preparation for the female face, that would beautify it without injury to the skin. And the result was more than a beautifier; it has a double purpose ! It also eradicates the cause of complexion blemishes! Its effects are permanent ! It is a true friend to the skin.

Beauty Balm is an absolutely pure preparation. It acts directly upon facial blemishes and eradicates them without the use of internal remedies.

It effectually removes all discolorations, it gradually eradicates all blotches, pimples, chaps, blackheads, etc. It acts upon the pores of the skin, annihilating all obstructions which check the perspiration. When this is confined under the skin the complexion is made to suffer. It will also cure skin "redness," remove sunburn and freck. les, and alleviate any itching and burning sensation.

Beauty Balm is an enemy to wrinkles; it makes war upon them at once. When a few minutes each day are devoted to wrinkle massage with the finger tips, and with Beauty Balm, the most obtrusively apparent wrinkles will gradually take their departure. Carefully follow directions on each bottle.

Price \$1.00. if your dritggist does not keep it, serid direct to the manu facturers. Sample mailed free on application.

THE FRIZZINE TOILET CO., 400 N. 3rd St., Philadelphia, Pa. 

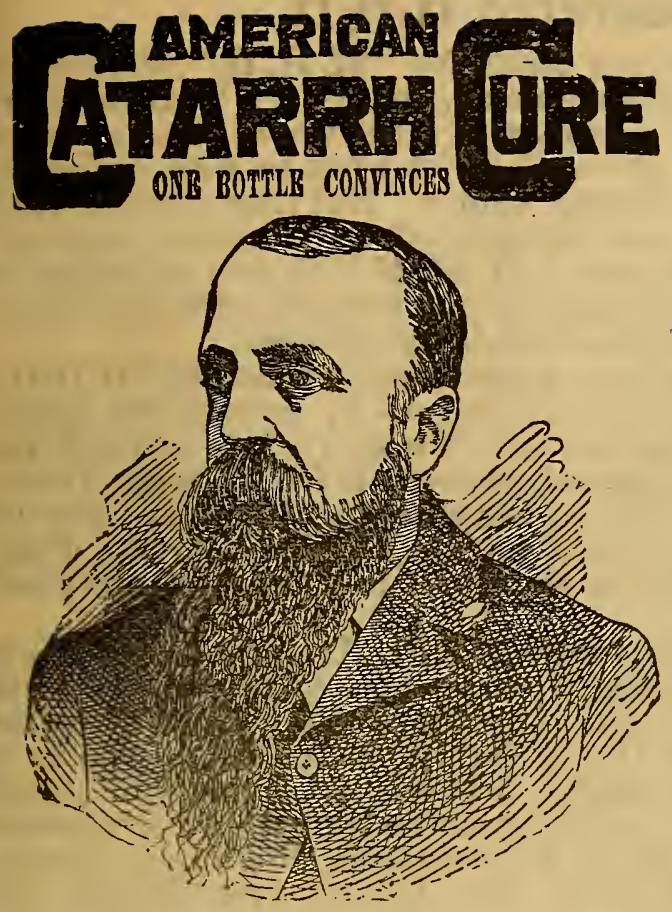

CATARRH of the Nose and 'Throat is one of the most unpleasant and annoying affections. Often it begins with an ordinary cold, which may continue until the mucous lining of the nose becomes so thickened as to impede the breathing. After thirty years of study, Dr. Jones has invented the most potent and successful remedy ever compounded for this distressing complaint. It quickly relieves the catarrh as well as the headache and hawking, cough which occasionally accompany it. It stops the ringing in the ears and restores the sense of taste and hearing. Neither douche, inhaler nor atomizer are necessary for its use.

American Catarrh Cure is the only remedy known to cure this offensive and dangerous disease. It immediately restores the voice of public singer's and speakers, and by curing their Catarh it prevents any future loss of their vocal powers.

It quickly cures children-one bottle curing two or three cases. Their Catarrh not having reached the chronic stage, soon yields to treatment. It cures the dropping in the throat in one week, thus. preventing the disagreeable hawking and spitting.

One bottle cures cases of ten years' standing. It is the wonder of. the age. It produces a vigorous appetite and a healthy complexion. Sold by Druggists or delivered by mail to any P. O. in the U. S. on receipt of juire $\$ 1.00$ per bottle, by DR. W. B. JC:IES, 400 North Third St., Philadeiphia, Pa. 


\section{No Family Medicine Chest complete without the Celebrated H.H.H.}

We want you to weigh well our claim for "H. H. H.", that worldfamous liniment. Seems a strange name, doesn't it? Well you know what's said about a name-a rose by any other would smell as sweet. Just so with "H. H. H." It would do its work as well under any one of ten thousand other possible names. But then none of these - others might be as unusual, and therefore effective because "catchy."

And so "H. H. H." it is, and "H. H. H." it will be to the end of the chapter, at least as long as men and women suffer from aches and pains for which they want an infallible liniment.

Now we admit that it does seem a good deal to claim for "H.H.H." that it is "the very best of all." Yet we do it, because we believe in the stuff. "Dinna let your modesty wrang ye," is a Scotch proverb we also believe in. Misplaced modesty is foolishness. There's a time for everything, and for modesty among the rest. But not when you've got the best thing of its kind under heaven. That's the time to talk out as loudly as you know how, and let everybody know about your treasure.

And so we sound a trumpet before "H. H. H." and praise it us an unrivalled embrocation for bruised places, swollen places, sore joints, and everything else of the kind. It is the result of years of patient research and experiment by Dr. $D$. DoDGE TomLInson and is no "fake" nostrum, but a thoroughly first-class combination. Thousands of people have tried it, and its genuine worth has been demonstrated in many a severe case of Rheumatism, Neuralgia, Swelled Joints, Backache, Lame Muscles, Sore Throat, Cramps, etc., ete. Careful attention to directions and the exercise of your own Common Sense will soon teach you how and when to use it to the very best advantage.

\section{AS A HORSE MEDICINE.}

It is not often you can get a liniment that is strong enough for use on horses without being too strong for human beings.

Here is a strong point in favor of "H.H.H." It can be used on both man and beast. As a horse liniment.it has no equal. Its effects are simply wonderful. It is a SURE CURE for all the diseases of "man's best friend" among the lower animals for which it is recommended, Callous Lumps, Soft Spavins, Windgalls, Sweeny, Fistula, Thrush, Contracted Hoofs, Ringbone,Splint, Curb, Distemper, Swollen Tendons, Lumps and Enlargements arising from any cause whatever-all these have been found, in actual practice, to yield to the remarkable virtues of this justly celebrated remedy:

ct.i. put up in three sizes which sell at $25 \mathrm{c}$., $50 \mathrm{c}$., and $\$ 1.00$ respectively, and is your druggist does not have it, you can send direct to the manufacturer.

OR. D. DODGE TOMLINŚON, 400 N. 3d St., Philadelphla, Pao 


\section{INDEX:}

PAGE.

American Dominiques 27 "Wonders, 28 Anconas, . . . 61 Andalusians, . 60 Asiatic Breeds, : 31-38 Bantams-Game, . . 74

Other than Game, . 75 Booted, . . . 76 Cochin, . . . 78 Japanese, • . . 78 Polish, . . . 79 Rose Comb, : . 76 Rumpless, . . 71 Seabrights, . . 77 Silkies, : 79-80 Book on Cage Birds, . 112 " " Dogs, . . 111 Brahmas, . . . 31

Dark, . . . 32

Light, . . . 31

White, . . . 33

Campines, . . . 60 Capons and Caponizing; 16 Cochins, . . . 34

Black, . . . 36

Buff, . . . 34

Partridge, . . . 35

White, . . 37

Crevecours, : : 41-42

Diseases of Poultry, . 17

Dominiques, · . 27

Dorkings, . . . 42

Colored, : : 4243

Silver Gray, 43-44

White,
Ducks, . . . . 87

Aylesbury, . . 89

Black East Indian, . 93

Call, • . . 97

Cayuga, . . . 91

Chilian, . . . 95

Crested, . . . 96

Mandarin, . . 94

Muscovy, . . . 92

Pekin, . . . 88

Rouen, . . . 90

Wood, . . . 93

English Breeds, · $\quad 42-44$

Erminettes, . . . 29

Fanciers' Books, etc., . 109

French Breeds, . 3942

Frizzles, • . • 71

Games, . . . 63

Black Breasted Red, 64

Birchen, • . . C6

Duckwing, . . 65

Indian, . . . 67

Malays, .. . . 67

Pyle, . . . 65

Sumatras . . . 69

White Georgian, . 66

Geese, · • . . 81

Africall, . . . 85

Canada, . . . 84

Chin ese or HongKong, 86

Egyptian, . • 84

Emibden, • • . 83

Toulouse, . . 81.82

Guinea Fowls, . . 103

Pearl, . . . 104 
PAGE.

Guinea Fowls, IVhite, .103 Hamburgs, . . . 48

Black, . . . 53

Golden Penciled, . 51

"Spangled, . 51

Silver Penciled, . 50

" Spangled, . 51

White, . . 52 Hatching and Caring

for Young Chicks, 14-16

Houdans, . . 39-40

Incubators, . . 20-21

Javas, • . . : 26

Black, . . . 26

Mottled, . . 27

White and Spangled, 27

Jersey Blues, . . 29

La Fleche, · $\quad 40-41$

Langshans Black, 38-39

Blue, • • . 39

White, . . 39

Leghorns, . . . 55

Black, . . . 58

Browll, . . . 56

Buffi, . : . 58

Duckwing, . . 58

White, . . . 56

Management of .

Poultry, • 9-14

Minorcas, Black,

$\begin{array}{lll}\text { " Single Comb, } & 59 \\ \text { " Rose } & \text { White, . . } & 59 \\ & 59\end{array}$

Miscellaneous Breeds, 70-73

Pea Fowls, . 106-107 Pheasants, . . . 104

Golden, . . . 106

Silver,. . . 105
Plymouth Rocks,

Barred,

Buffi, .

White,

Polish,

Bearded Golden,

$$
\begin{array}{lll}
\text { " Silver, : } 48 \\
\text { White, : } 47
\end{array}
$$

Plain Buff;

48

"Golden, . $\quad 47-48$

"Silver, . 47-48

"White, . 47

White Crested Blach, 46

White Crested White, 47

Poultry Doctor, . . 111

Poultry Manure, . . 14

Poultry Supplies, . 110

Prices of Fowls, . . . 22

Red Caps, . . . 54

Rumpless, . . . 71

Russian Black, . . 70

Scotch Creeper's, . . 30

Sherwoods, . . . 30

Sicilians, . . . 52

Spanish, . . 5463

Black, . . 54-55

Sultans, . . .

Turkeys, . . 9?-102

Black, . . . 101

Bliff; . . .. . 102

Bronze, . . 100

Narragansette, . 102

Slate,. . . 102

White Holland, . 101

Wyandottes, $\quad 24$

Black, Buff, Golden,

Yartidge, Sisiver and

ivhite, 

No. - - CAGB BrikDS- Containing over 150 ongravings and all liographic plateshowing allihedifferent kinds of Paney Canaries in thelenatural colors. full inforination in regard to Song and Fancy Canariesand how to breed them for profit. Fint on the treat. mentand breeding of all kinds of cage birds, with description of their diseases and the remedies needed to eure them. All about Parrots-and how to teach them to talk. In structions for building and stocking an aviary Mailed toany addiress on receipt of price-15eents:

No. 2. -THE DOG BUYKRAs GUIDE. A complete hand book for both the profession. al and amatems faneler contains-a finely executed celored frontispiece: Illustrated by over 100 well arawn engravings of nearly ailbreeds of dogs, also gives all the points of a typical specimen of the different varieties. Instructions for treating diseases: A chapter on ferrets. Also all kinas of dog furnishing yoods. It is-worth a great deal more than the price asked for it -15 cents.

No. 3-FANCY POULTRY:-A complete guide for breeding tand-and water fowls of all kinds, Contains 120 pages, a beauriful lithographicplate of a group of different fowls in their natural colors, engravings of
ํㅣ를 abes brex reet

$\mathbf{N}$

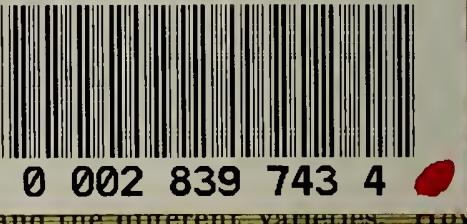

Ifry A 11 rent son

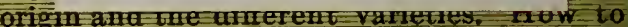
sefeet, breed and manage them, Their diseases, and symptoms, with remedies for the same by homoeopathic and allopathic treatments. By the late John F: Diehl. Mailed on receipt of 25 cents.

No. 5.-THE DOMESTIC CAT, $A$ valuable little book, describing the different breeds and varieties of cats, how to keepand rear them, Their diseases, with symptoms and remedies. This book is invaluable to the owners of cats. Written by Join E. Diehl. Mailed on receipt of 25 cents.

No. 6. - THE POULTRY DOCTOR, - A valuable little volume for the fancier and breed er of poultry. Showing how to rear and keep poultry. Giving symptoms $n f$ their different ailments with treatment by allopathic and homoeopathlc remedies. The rac: and best book of John E. Diehl, American Poultry Association Judge. Mailed on the receiptof 25 cents, in stamps or Post Office Money order.

A complete set of the above six books will be malled on receipt of $\$ 1,00$.

Remil foxall the above books to

\section{The Associated Fanciers, 400 North Third Street,} PHILADELPHIA, PA. 